\title{
ANÁLISE DAS OPERAÇÕES DE CROSS HEDGE DO BEZERRO E DO HEDGE DO BOI GORDO NO MERCADO FUTURO DA BM\&F
}

\author{
RODRIGO LANNA FRANCO DA SILVEIRA
}

\author{
Dissertação apresentada à Escola Superior de \\ Agricultura “Luiz de Queiroz”, da Universidade de São \\ Paulo, para obtenção do título de Mestre em Ciências, \\ Área de Concentração: Economia Aplicada
}

P I R A C I C A B A

Estado de São Paulo - Brasil

Agosto - 2002 


\title{
ANÁLISE DAS OPERAÇÕES DE CROSS HEDGE DO BEZERRO E DO HEDGE DO BOI GORDO NO MERCADO FUTURO DA BM\&F
}

\author{
RODRIGO LANNA FRANCO DA SILVEIRA \\ Bacharel em Ciências Econômicas
}

Orientador: Prof. Dr. JOAQUIM BENTO DE SOUZA FERREIRA FILHO

\begin{abstract}
Dissertação apresentada à Escola Superior de
Agricultura “Luiz de Queiroz", da Universidade de São

Paulo, para obtenção do título de Mestre em Ciências,

Área de Concentração: Economia Aplicada
\end{abstract}

P I R A C I C A B A

Estado de São Paulo - Brasil

Agosto - 2002 


\section{Dados Internacionais de Catalogação na Publicação (CIP) \\ DIVISÃO DE BIBLIOTECA E DOCUMENTAÇÃO - ESALQ/USP}

Silveira, Rodrigo Lanna Franco da

Análise das operações de Cross Hedge do bezerro e do Hedge do boi gordo no mercado futuro da BM\&F/ Rodrigo Lanna Franco da Silveira. - Piracicaba, 2002.

$106 \mathrm{p}$.

Dissertação (mestrado) - - Escola Superior de Agricultura Luiz de Queiroz, 2002.

Bibliografia

1. Bezerros 2. Bolsa de valores 3. Bolsa de mercadorias 4. Bovinocultura de corte 5. Economia a grícola 6. Mercado futuro 7. Operação financeira 8. Preços agríc olas I. Título

CDD 332.645

"Permitida a cópia total ou parcial deste documento, desde que citada a fonte - $O$ autor" 


\section{AGRADECIMENTOS}

Ao Deus da minha vida, pelo Seu amor e Sua fidelidade. Realmente, posso declarar: "O teu amor Senhor alcança os céus e a tua fidelidade chega até as nuvens" (S1 36:5).

Ao Professor Doutor Joaquim Bento de Souza Ferreira Filho pela orientação e incentivo ao longo da elaboração deste trabalho.

Aos professores Geraldo Sant'ana de Camargo Barros, Pedro Valentim Marques, Mirian Rumenos Piedade Bacchi e Sérgio De Zen pelas valiosas sugestões e contribuições. Em especial, gostaria de agradecer à Profa. Mirian pela ampla colaboração e disposição em vários momentos desta dissertação.

Ao Centro de Estudos Avançados em Economia Aplicada da Fundação de Estudos Agrários "Luiz de Queiroz" (CEPEA/FEALQ) e à Bolsa de Mercadorias \& Futuros $(\mathrm{BM} \& \mathrm{~F})$, na pessoa da pesquisadora Fabiana Perobelli, pelo fornecimento dos dados utilizados neste estudo.

Aos funcionários do DEAS, em especial à Maielli, pela atenção e esclarecimentos em todo o período do curso.

Ao Dr. Oscar Frick pelo incentivo e constantes esclarecimentos sobre os mecanismos e os fundamentos dos mercados futuros. 
A Profa. Sylvia Saes pela amizade, pelas sugestões e pelo grande estímulo à feitura e conclusão deste trabalho.

Aos colegas e amigos do Curso de Mestrado, Humberto, Mauro, Cléa, Roberta, Maria do Carmo e Ary, pelas contribuições diretas ou indiretas à esta dissertação.

Ao pessoal do CED, Márcia, Cibele, Sylvia, Marcos e Bruno, pelo incentivo e amizade na fase final desta dissertação.

À CAPES e ao CNPq pelo apoio financeiro durante o curso de mestrado.

À minha mãe, Maria Ingracia, pelo incansável incentivo ao estudo, o qual propiciou esta grande conquista. Ao meu pai, Plinio, pelo enorme apoio e amizade durante todo este período. À minha irmã, Anne, pelos constantes estímulos, os quais me ajudaram a seguir em frente neste trabalho.

À minha esposa, Flávia, pelo amor, atenção, carinho e intensa compreensão durante todo o período que envolveu este trabalho. 


\section{SUMÁRIO}

Página

LISTA DE FIGURAS.................................................................. vii

LISTA DE TABELAS .................................................................... viii

RESUMO ......................................................................................

SUMMARY .............................................................................. Xiv

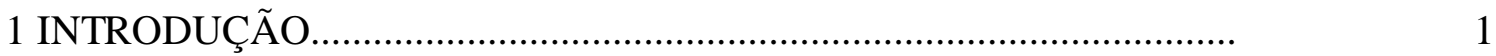

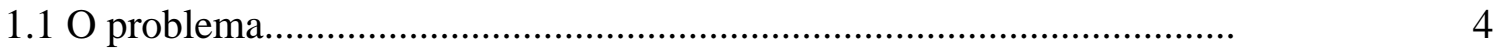

1.2 Objetivos..................................................................................

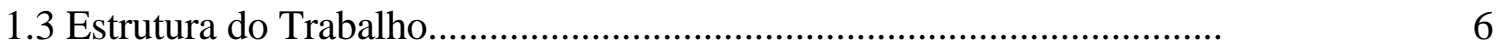

2 CARACTERÍSTICAS GERAIS DA PECUÁRIA BOVINA DE

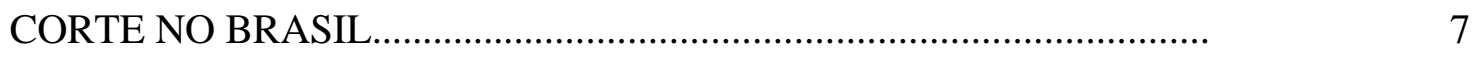

2.1 A importância da pecuária bovina de corte na economia

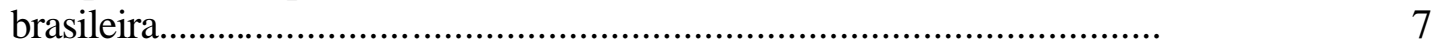

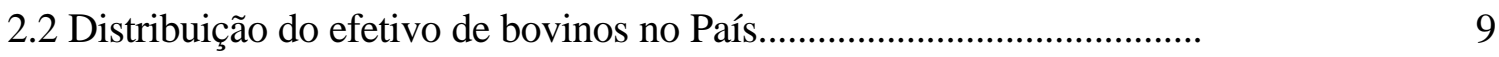

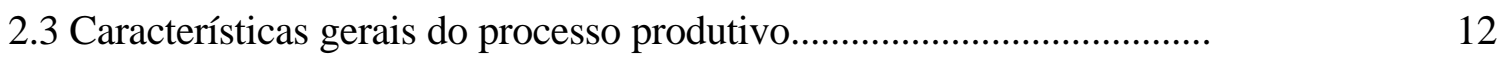

2.3.1 As etapas de produção da pecuária bovina de corte............................ 12

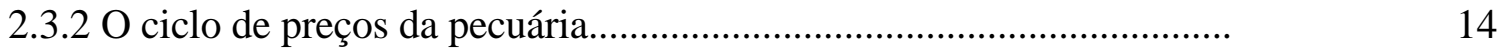

3 OS CONTRATOS FUTUROS AGROPECUÁRIOS DA BM\&F............. 17

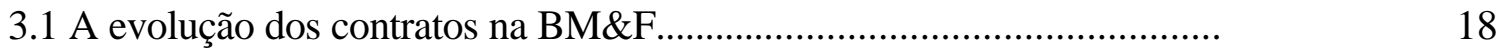

3.2 Os contratos futuros agropecuários................................................... 22

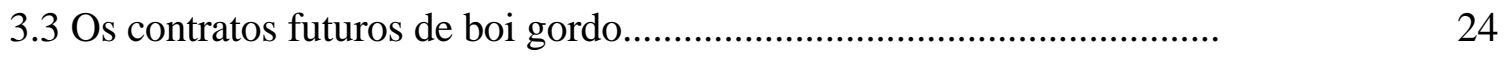


4 CONCEITOS FUNDAMENTAIS NO MERCADO DE FUTUROS....... 27

$4.1 \mathrm{O}$ conceito de hedge e cross hedge no mercado de futuros..................... 27

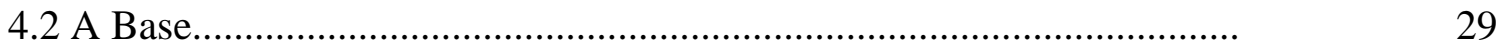

4.3 O Risco de Base.......................................................................

4.4 Razão de hedge de mínima variância..................................................... 33

5 REVISÃO DE LITERATURA..........................................................

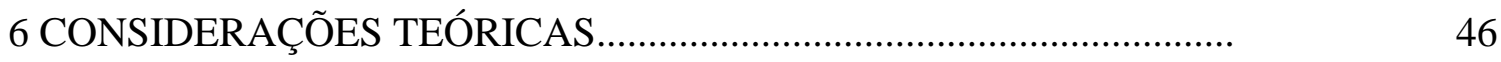

7 METODOLOGIA.......................................................................

7.1 Cálculo do Risco de Base.................................................................

7.2 Operações de hedge: razão ótima e efetividade...................................... 52

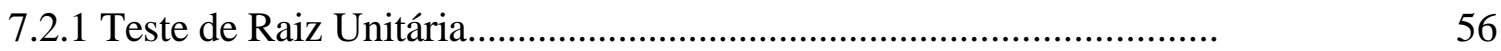

7.2.2 Metodologia para análise da eficiência do mercado futuro do boi

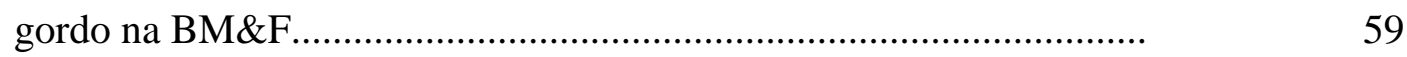

7.3 Dados Utilizados......................................................................

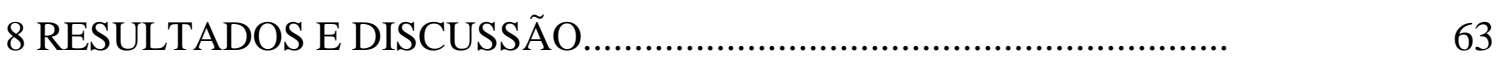

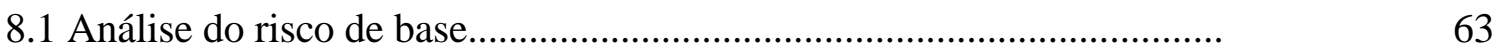

8.2 Estimação das razões ótimas das operações de hedge e sua

efetividade................................................................................

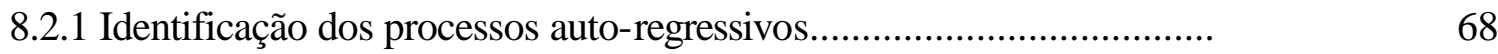

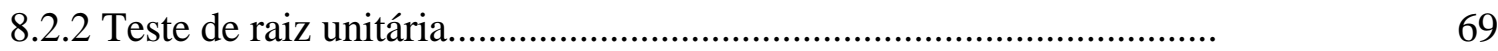

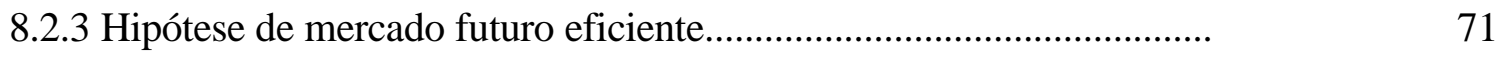

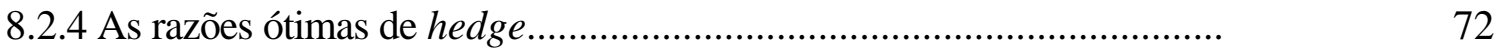

8.2.5 Efetividade das operações de hedge e cross hedge ............................

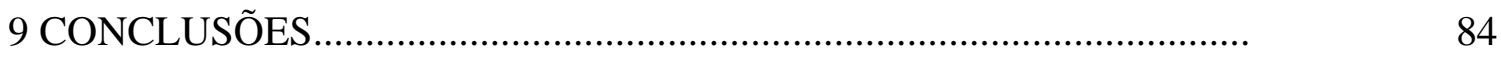

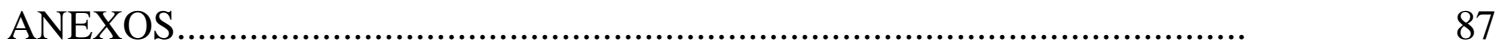

REFERÊNCIAS BIBLIOGRÁFICAS................................................... 


\section{LISTA DE FIGURAS}

Página

1 Valor das exportações brasileiras (em US\$ milhões) de carne

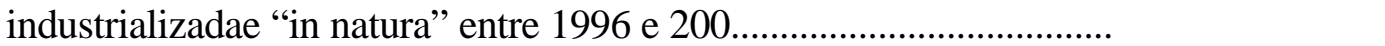

2 Volume geral anual de contratos futuros e de opções (em milhões) negociados na BM\&F entre 1994 e 2001 .........................................

3 Número de contratos futuros agropecuários negociados(em mil) na

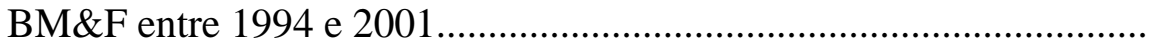

4 Médias semanais dos preços à vista do bezerro (em US\$) nas regiões de Araçatuba, Noroeste do Paraná, São José do Rio Preto, Três Lagoas, Bauru/Marília, Campo Grande, Presidente Prudente e Triângulo Mineiro.

5 Médias semanais dos preços futuros do boi gordo na BM\&F (1 ${ }^{\circ}$ vencimento) e dos preços à vista (em US\$) nas regiões de Araçatuba, Noroeste do Paraná, São José do Rio Preto, Três Lagoas, Bauru/Marília, Campo Grande, Presidente Prudente e Triângulo Mineiro. 


\section{LISTA DE TABELAS}

Página

1 Efetivo de bovinos nas regiões brasileiras em 1980, 1985 e 1996, suas respectivas participações em relação ao total obtido no Brasil e sua evolução no período............................................................................

2 Efetivo de bovinos nas unidades federativas de maior relevância para a pecuária de corte, suas respectivas participações no Brasil em 1980, 1985 e 1996 e sua evolução no período

3 Efetivo da pecuária bovina de acordo com a finalidade do rebanho no Brasil em 1980, 1985 e 1996 e sua evolução nestes anos..................

4 As maiores Bolsas de derivativos do mundo por volume de contratos negociados em 2001

5 Participação média de cada ativo no volume geral anual de contratos futuros e de opções negociados na BM\&F entre 1994 e 2001..............

6 Valor médio e variância da base (risco de base) na semana de vencimento do contrato para boi gordo e bezerro no período entre setembro de 1995 e fevereiro de 2001 
7 Resultados da regressão do logaritmo neperiano do desvio padrão da base na semana de vencimento do contrato em função de variáveis binárias para tipo do animal e localização.

8 Resultados dos testes "F" sobre a igualdade da variância da base do boi e do bezerro nas semanas de vencimento do contrato futuro de boi gordo da BM\&F no período entre setembro de 1995 e fevereiro de 2001

9 Ordem dos processos auto-regressivos das séries de preços à vista de bezerro e boi gordo e do preço futuro de boi gordo da $B M \& F$ indicada pelo AIC e SC

10 Resultados da identificação dos elementos deterministas e teste de raiz unitária para as séries de preços semanais à vista e futuro de boi gordo no período entre setembro de 1995 e fevereiro de 2001

11 Resultados da identificação dos elementos deterministas e teste de raiz unitária para as séries semanais de preços à vista de bezerro no período entre setembro de 1995 e fevereiro de 2001 ............................

12 Resultados da identificação dos elementos deterministas e teste de raiz unitária para as séries de preços semanais à vista e futuro de boi gordo na primeira diferença no período entre setembro de 1995 e fevereiro de 2001

13 Resultados da identificação dos elementos deterministas e teste de raiz unitária para as séries de preços à vista semanais de bezerro na primeira diferença no período entre setembro de 1995 e fevereiro de 2001 
14 Resultados das estimativas das razões de hedge dos preços semanais do boi gordo em Três Lagoas, Araçatuba, Bauru/Marília e Campo Grande no mercado futuro de boi gordo da BM\&F no período entre setembro de 1995 e fevereiro de 2001

15 Resultados das estimativas das razões de hedge dos preços semanais do boi gordo no Noroeste do Paraná, Presidente Prudente, São José do Rio Preto e Triângulo Mineiro no mercado futuro de boi gordo da BM\&F no período entre setembro de 1995 e fevereiro de 2001...........

16 Resultados das estimativas das razões de cross hedge dos preços semanais do bezerro em Três Lagoas, Araçatuba, Bauru/Marília e Campo Grande no mercado futuro de boi gordo da BM\&F no período entre setembro de 1995 e fevereiro de 2001

17 Resultados das estimativas das razões de cross hedge dos preços semanais do bezerro no Noroeste do Paraná, Presidente Prudente, São José do Rio Preto e Triângulo Mineiro no mercado futuro de boi gordo da BM\&F no período entre setembro de 1995 e fevereiro de 2001

18 Resultados das estimativas das razões de hedge dos preços semanais do boi gordo em Três Lagoas, Araçatuba, Bauru/Marília e Campo Grande com a inclusão da variável dummy no período entre setembro de 1995 e fevereiro de 2001

19 Resultados das estimativas das razões de hedge dos preços semanais do boi gordo no Noroeste do Paraná, Presidente Prudente, São José do Rio Preto e Triângulo Mineiro com inclusão da variável dummy no período entre setembro de 1995 e fevereiro de 2001 
20 Resultados das estimativas das razões de cross hedge dos preços semanais do bezerro em Três Lagoas, Araçatuba, Bauru/Marília e Campo Grande com a inclusão da variável dummy no período entre setembro de 1995 e fevereiro de 2001

21 Resultados das estimativas das razões de cross hedge dos preços semanais do bezerro no Noroeste do Paraná, Presidente Prudente, São José do Rio Preto e Triângulo Mineiro com a inclusão da variável dummy no período entre setembro de 1995 e fevereiro de 2001

22 Efetividade e razão de hedge dos preços do boi gordo no período entre setembro de 1995 e fevereiro de 2001

23 Efetividade e razão do cross hedge dos preços do bezerro no período entre setembro de 1995 e fevereiro de 2001 


\title{
ANÁLISE DAS OPERAÇÕES DE HEDGE DO BOI GORDO E CROSS HEDGE DO BEZERRO NO MERCADO FUTURO DA BM\&F
}

\author{
Autor: Rodrigo Lanna Franco da Silveira \\ Orientador: Prof. Dr. Joaquim Bento de Souza Ferreira Filho
}

\section{RESUMO}

O presente estudo visa analisar as operações de cross hedge dos preços do bezerro na Bolsa de Mercadorias \& Futuros (BM\&F). Para tanto, foram calculados o risco de base destas operações nas semanas de vencimento do contrato futuro de boi gordo, as razões de hedge ótimas e as respectivas efetividades, entre setembro de 1995 e fevereiro de 2001, nas principais praças de comercialização de gado bovino do País Araçatuba (SP), Bauru/Marília (SP), São José do Rio Preto (SP), Presidente Prudente (SP), Três Lagoas (MG), Triângulo Mineiro (MG), Campo Grande (MS) e Noroeste do Paraná. Como forma de comparação, as mesmas análises foram realizadas para o hedge do boi gordo. O valor médio da base e o risco de base do hedge do boi gordo e do cross hedge do bezerro foram calculados nas semanas de vencimento dos 58 contratos futuros de boi gordo e análises econométricas foram realizadas. Nesta primeira etapa, foi possível observar os seguintes resultados: i) valor médio e variância da base do bezerro foram superiores à do boi gordo em todas as regiões; ii) o desvio padrão da base do boi gordo foi $80,67 \%$ inferior ao desvio padrão do bezerro; iii) o risco de base do boi gordo foi estatisticamente inferior nas regiões que compõem o Indicador de Preço Disponível 
do Boi Gordo - IBG, calculado pelo CEPEA/FEALQ; iv) o risco de base do bezerro não apresentou diferenças estatisticamente significativas entre as regiões. Em uma segunda etapa, o estudo buscou analisar as razões ótimas e a efetividade do hedge do boi gordo e do cross hedge do bezerro, conforme a metodologia de Myers \& Thompson (1989). Tanto no cross hedge, como também no own hedge, as razões se mostraram elevadas no primeiro caso esteve entre $37 \%$ e $49 \%$, já no segundo variou entre $58 \%$ a $63 \%$. Com relação à efetividade, constatou-se que no caso do own hedge, o risco de preço pode ser reduzido em cerca de $50 \%$ com a tomada de posição em contratos futuros de boi gordo na proporção de hedge ótima. No entanto, para o cross hedge, a efetividade foi bastante baixa para todas as regiões, de aproximadamente 1,5\%. Se por um lado, a proteção contra os riscos de preço do boi gordo ocorre de forma eficiente, por outro lado a proteção contra movimentos adversos nos preços do bezerro possui baixa efetividade. Conclui-se, portanto, que os pecuaristas, os quais utilizam o preço do bezerro e a relação de troca entre boi gordo e bezerro para a decisão de venda do gado, não possuem um instrumento eficiente, nos mercados futuros, de proteção dos preços de sua atividade. 


\title{
ANALISYS OF CALF CROSS HEDGE AND FED CATTLE HEDGE AT BM\&F FUTURES MARKET
}

\author{
Author: Rodrigo Lanna Franco da Silveira \\ Adviser: Joaquim Bento de Souza Ferreira Filho
}

\section{SUMMARY}

The aim of the present study is to analyze the cross hedge operation for calves in the $\mathrm{BM} \& \mathrm{~F}$ future markets. The basis risk of these operations during the contract maturity weeks were calculated, as well as the optimal hedge ratios and the respective effectiveness. The period considered was September, 1995 to February, 2001, and the regions were chosen according to their importance in commercialization of bovine cattle: Araçatuba (SP), Bauru/Marília (SP), São José do Rio Preto (SP), Presidente Prudente (SP), Três Lagoas (MG), Triângulo Mineiro (MG), Campo Grande (MS) and Noroeste do Paraná.. For the sake of comparisons, the same analyses were carried for the fed cattle hedge operations, in the same regions. The average value of the basis and the basis risk of fed cattle hedge and calf cross hedge was calculated for 58 future contracts, in the last week of contract life, and econometric analyses were performed. The main results arising from the preceding analyses can be pointed out: i) average basis value and basis risk of calf were higher than the values of fed cattle in all regions; ii) the basis standard deviation for fed cattle was 80,67\% lower than for calf; iii) the regions comprised by IBG, calculated by the CEPEA/FEALQ, showed lower fed cattle basis risk compared to the other regions under study; iv) the calf basis risk in the regions studied did not present statistically significant differences. In a second stage, the study analyzed 
the optimal hedge ratio and the related effectiveness of own and cross hedge, according to the methodology proposed by Myers \& Thompson (1989). The estimated hedge ratio was high in both cases, between $37 \%$ and $49 \%$ for the optimal hedge ratio and 58\% to $63 \%$ for the cross hedge. The own hedge figures mean a 50\% reduction in price risk when hedging at the optimal ratio, a value that drops consistently to about $1,5 \%$ for all regions when the cross hedge is considered. The main conclusion of the study is that the BM\&F fed cattle future markets are quite effective as a price risk reduction strategy for the own hedge operations, but lack effectiveness in this sense for the calves cross hedge. Market agents trying to use the calf price and the exchange relation between fed cattle and calf prices for cattle selling decisions should not rely on this mechanism for price risk reductions. 


\section{INTRODUÇÃO}

Os contratos de derivativos agropecuários são negociados, no Brasil, na Bolsa de Mercadorias \& Futuros (BM\&F). As commodities que participam destas negociações são: café arábica, boi gordo, soja, milho, algodão, açúcar cristal e álcool anidro carburante.

O potencial deste mercado ainda está longe de ser explorado, já que o volume transacionado é considerado muito baixo. A participação média destes contratos, em relação ao total negociado na BM\&F, entre 1996 e 2001, foi praticamente insignificante, alcançando apenas 0,58\%. Segundo Fileni (1999), dois aspectos principais explicam tal quadro. $\mathrm{O}$ primeiro deles está relacionado à falta de conhecimento operacional dos agentes envolvidos no processo produtivo. Neste ponto, enormes esforços, relacionados à implementação de programas de treinamento e divulgação, vêm sendo realizados pela $\mathrm{BM} \& \mathrm{~F}$ nestes últimos anos. $\mathrm{O}$ segundo aspecto se baseia na incerteza quanto ao comportamento da relação entre preços futuros e preços à vista. Tal incerteza é causada principalmente pela baixa liquidez deste mercado.

Conforme Barros et al. (2000), a falta de liquidez se constitui no motivo determinante para explicar os baixos números de negócios realizados com os derivativos agropecuários. Neste quadro, o risco destas operações se torna mais elevado, o que acaba inibindo as negociações e assim contribuindo para a continuidade deste processo. 
Rochelle (1997) argumenta que a liquidez do mercado futuro afeta diretamente a diferença entre os preços à vista e futuro. Esta diferença é definida como base. Em mercados com baixa liquidez, existe uma maior volatilidade no preço futuro, existindo uma maior dificuldade para avaliá-lo em um período futuro. Assim, as perações estarão sujeitas a um maior risco de base (risco associado aos movimentos imprevisíveis da base), afetando, portanto, o grau de efetividade do hedge. Neste sentido, a eficiência dos contratos futuros na transferência de risco fica prejudicada, levando a uma menor utilização (Pennings \& Meulenberg, 1997).

Apesar de ter as características acima descritas, o mercado de derivativos agropecuários no Brasil possui um vasto espaço a conquistar. Tal fato fica evidente ao analisar as medidas que foram adotadas pela $B M \& F$ a fim de permitir investimentos estrangeiros neste mercado e ao observar as fortes mudanças que o País vem passando nestes últimos anos, tais como: i) a abertura financeira e comercial da economia aos fluxos de capitais e mercadorias internacionais, que vem expondo o País a uma maior concorrência internacional, obrigando à reestruturação de vários setores com o objetivo de obter ganhos de eficiência e competitividade; ii) a estabilização monetária obtida com o Plano Real; e iii) a queda do intervencionismo estatal na economia.

Neste último ponto, é de especial importância destacar o menor intervencionismo do governo no setor agrícola, principalmente no que diz respeito à política de preços mínimos. Com esta prática, o governo acabava prejudicando a evolução do mercado de futuros, já que ao estabelecer preços mínimos, o risco associado ao preço do produto era eliminado. Além disso, verifica-se uma gradual saída do governo como agente financiador do processo produtivo, transferindo, aos poucos, tal responsabilidade ao setor privado. Pode-se concluir que além dos riscos de produção ligados a fatores bioclimáticos e dos riscos de mercado, os quais envolvem as oscilações dos preços do produto, a atividade agropecuária vem se deparando nos últimos anos com o risco da falta de recursos para o desenvolvimento de sua atividade. 
Tanto os riscos de variações de preços, quanto a problemática que envolve a captação de recursos podem ser amenizados com o uso do mercado de derivativos. A redução dos riscos de preços pode ser obtida com estratégias desenvolvidas no mercado de futuros e de opções. Já os riscos, que envolvem a falta de recursos, podem ser atenuados com o uso combinado de CPR (Cédula do Produtor Rural) e o mercado de futuros e de opções (Schouchana e Perobelli, 2000). Dessa forma, é perceptível a importância do papel que o mercado de derivativos vem oferecendo ao setor agropecuário brasileiro.

De forma geral, de acordo com Martits (1998), a globalização dos mercados e a necessidade do governo em se centrar em questões sociais, vem levando o setor privado a utilizar de forma mais intensa instrumentos privados de proteção de risco.

Os resultados do quadro, acima exposto, já são possíveis de se sentir ao observar a evolução do número de contratos agropecuários negociados na BM\&F entre 1996 e 2001. Enquanto, 315.885 contratos foram negociados em 1996, em 2001 somaram-se 748.688 contratos, representando um aumento de aproximadamente 137\%. O maior número de negociações, neste período, ocorreu com os contratos de café arábica. Em 2001, a participação deste contrato, em relação ao total de agropecuários negociados, foi de $65,31 \%$.

Diante deste enorme potencial a ser explorado e das grandes vantagens que os agentes podem obter com seu uso, tornam-se de extrema importância estudos que abordam análises relacionadas à eficiência de certas operações de hedge em mercados futuros específicos. 


\subsection{O problema}

A pecuária bovina de corte do País se constitui em uma atividade na qual a maior parte de seus agentes está exposta a um alto risco de preço. Isso se deve principalmente ao fato da maior parte do sistema de produção, o qual é constituído pelas etapas de cria, recria e engorda, ser horizontalizada (sistema em que existe uma especialização em uma ou duas fases do processo produtivo). De acordo com dados do Censo Agropecuário (1996), elaborado pelo IBGE (Instituto Brasileiro de Geografia e Estatística), aproximadamente $86,75 \%$ do rebanho pecuário de corte nacional, o que corresponde a 98,9 milhões de cabeças de gado, não provêm de produção verticalizada (sistema em que as três etapas são realizadas de forma conjunta). Em conjunto aos fatores culturais e questões ligadas à localização e preço da terra, aspectos econômicos levam os produtores à especialização do processo produtivo. No sistema horizontal, além do investimento em capital e da área para desenvolvimento da atividade serem menores que no sistema verticalizado, a circulação do produto é mais intensa (Oliveira,1991).

O preço do bezerro se constitui em uma variável chave tanto para os pecuaristas especializados na cria dos animais, como também para os agentes envolvidos na cria/engorda, recria/engorda e engorda. Para estes últimos, o preço do boi gordo não é

analisado isoladamente para a decisão de se realizar ou não sua venda. É essencial que se avalie o preço do bezerro devido ao fato da reposição do rebanho ser fator fundamental para a continuidade da atividade. Assim, o risco de preço, para estes pecuaristas, envolve a relação de troca entre boi gordo e bezerro (Schouchana \& Caffagni, 2001). Vale ainda observar que, no sistema de produção verticalizado, os pecuaristas também levam em consideração o preço do bezerro no gerenciamento da atividade, já que existe um custo de oportunidade associado à manutenção do animal na propriedade.

De forma a se protegerem dos riscos dos preços do bezerro, os pecuaristas brasileiros podem realizar operações conhecidas como cross hedge no mercado futuro de 
boi gordo da BM\&F. O risco do cross hedge está relacionado tanto aos movimentos imprevisíveis que ocorrem na diferença entre os preços à vista e futuro do produto mencionado no contrato, como também aos movimentos imprevisíveis na diferença entre os preços à vista do ativo hedgeado e do ativo especificado no contrato. Ou seja, a base associada ao cross hedge possui dois componentes (Hull, 1996). As estratégias que envolvem este tipo de operação devem ser analisadas com extremo cuidado, pois deve ser levado em consideração o risco adicional de preço associado às diferenças na qualidade do produto (Rochelle, 2000).

\subsection{Objetivos}

O objetivo deste trabalho é analisar as operações de cross hedge do bezerro no mercado futuro do boi gordo da BM\&F para as seguintes regiões: Araçatuba (SP), Bauru/Marília (SP), São José do Rio Preto (SP), Presidente Prudente (SP), Três Lagoas (MG), Triângulo Mineiro (MG), Campo Grande (MS) e Noroeste do Paraná.

Dessa forma, os objetivos específicos consistem em:

1) calcular, para cada região, o risco de base nas operações de cross hedge dos preços do bezerro na semana de vencimento do contrato futuro de boi gordo da BM\&F;

2) analisar, em cada região, a razão ótima do cross hedge e a efetividade desta operação, considerando o período da safra e entressafra.

Adicionalmente, serão atualizadas as análises do risco de base do hedge dos preços do boi gordo na BM\&F e calculadas a razão ótima desta operação e a respectiva efetividade. Com isso, o estudo irá verificar as diferenças da variância da base entre boi gordo e bezerro e entre as regiões consideradas, mediante um modelo de regressão e testes de hipóteses. 
Neste sentido, será possível observar se os agentes envolvidos na atividade pecuária bovina de corte do País possuem instrumentos eficientes de gerenciamento dos preços tanto do boi gordo, como também do bezerro.

\subsection{Estrutura do Trabalho}

A fim de alcançar os objetivos propostos, o trabalho percorrerá alguns tópicos, os quais serão descritos de forma bastante sucinta a seguir.

Inicialmente, serão analisadas as características gerais da pecuária de corte no Brasil. Para tanto, serão dimensionadas sua importância na economia nacional e suas etapas de produção. Finalizando esta seção, alguns pontos relacionados aos ciclos de preços desta atividade serão mencionados.

A próxima etapa consistirá na avaliação da evolução dos contratos futuros agropecuários da $\mathrm{BM} \& \mathrm{~F}$, em especial os contratos de boi gordo. Feito isso, serão desenvolvidos conceitos relativos às operações de hedge e cross hedge, base, risco de base, razão de hedge de mínima variância e efetividade do hedge; conceitos estes que serão utilizados nos capítulos posteriores. O passo seguinte consiste em uma revisão de literatura e a realização de algumas considerações teóricas sobre os métodos já utilizados em outros trabalhos para avaliar a eficiência das operações de hedge. Em seguida, será descrita a metodologia utilizada para estudar o problema em questão. Posteriormente, será feita uma discussão dos resultados obtidos, e por fim, serão mencionadas as conclusões observadas. 


\section{CARACTERÍSTICAS GERAIS DA PECUÁRIA BOVINA DE CORTE NO BRASIL}

Este capítulo está dividido em dois tópicos. O primeiro deles tem o objetivo de dimensionar a importância da pecuária bovina de corte para a economia brasileira. Em seguida, serão analisadas as características gerais do processo produtivo e do ciclo de preços.

\subsection{A importância da pecuária bovina de corte na economia brasileira}

A pecuária é uma das atividades mais importantes do setor agropecuário brasileiro. Ao considerar os negócios realizados dentro da porteira, o Produto Interno Bruto (PIB) da agropecuária, em 2001, segundo o Centro de Estudos Avançados em Economia Aplicada - CEPEA/FEALQ/USP $(2001)^{1}$, foi de aproximadamente R $\$ 99,4$ bilhões. Deste total, $47,1 \%$ corresponde às atividades da pecuária ( $R$ \$ 44,9 bilhões).

O País, além de possuir o segundo maior rebanho comercial do mundo, foi considerado, em 2001, o segundo maior produtor mundial de carne bovina com 7 milhões de toneladas, aproximadamente $14 \%$ do total produzido. Neste mesmo ano, apresentou 34,1 milhões de abates, garantindo o terceiro melhor resultado em termos mundiais (FNP, 2001). Além disso, dados do USDA (Departamento de Agricultura dos Estados Unidos da América) apontam que o setor é responsável por aproximadamente 50\% da produção de carnes no País (Bliska \& Gonçalves, 1999).

1 CENTRO DE ESTUDOS AVANÇADOS EM ECONOMIA APLICADA; CONFEDERAÇÃO NACIONAL DA AGRICULTURA. Agricultura apresenta crescimento de 8,65\% em 2001. 5p. (Relatório PIB do Agronegócio CNA/CEPEA-USP de janeiro a dezembro de 2001) 
É importante destacar que carne bovina tem apresentado resultados positivos na balança comercial brasileira, já que países da Europa vêm importando grandes quantidades deste produto por causa de consecutivos problemas de fbre aftosa em seus rebanhos. A Figura 1 mostra o crescimento do valor das exportações entre 1996 e 2001, principalmente quando se trata da carne "in natura", que obteve um incremento, no período, de aproximadamente 68,85\%. Em 2001, foram exportados aproximadamente 502,99 mil toneladas de carne bovina, indicando um aumento de 48,29\% em relação a 2000. A receita obtida chegou a US\$ 1,01 bilhões, o que representou $35,32 \%$ do valor total das exportações de carnes e 1,74\% do valor total exportado pelo País neste ano.

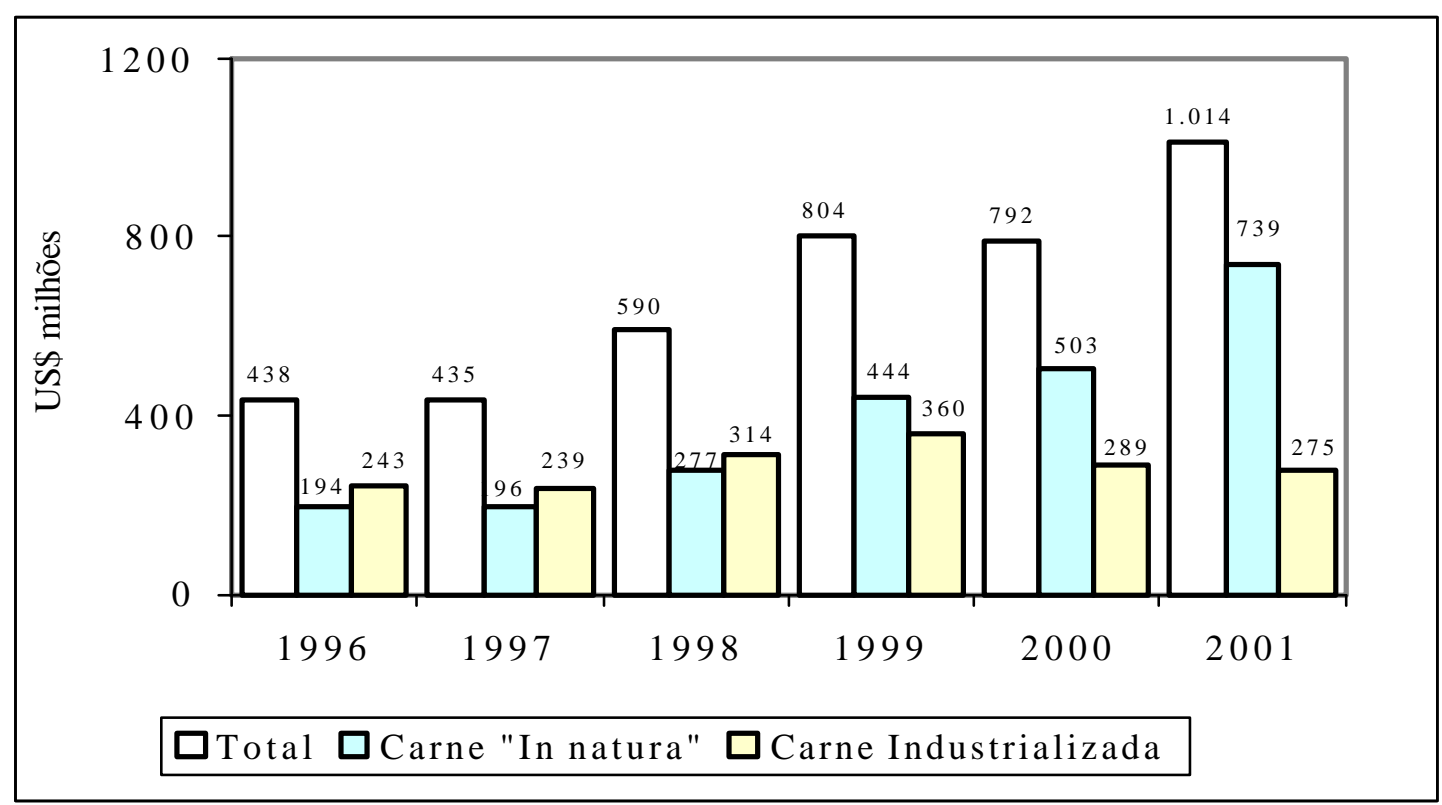

Figura 1 - Valor das exportações brasileiras (em US\$ milhões) de carne industrializada e “in natura" entre 1996 e 2001.

Fonte: SECEX (2001)

Os números apresentados refletem a intensa mudança estrutural que a atividade vem passando nestes últimos anos. A bovinocultura de corte vem deixando de ser uma atividade extrativista e extensiva, ao permitir o uso intensivo de tecnologia e ao adotar modelos de gerenciamento mais eficazes, visando obter maior eficiência e assim garantir 
seu espaço no quadro competitivo mundial. Dessa forma, a busca por ganhos de produtividade, qualidade, redução de custos e agregação de valores tem sido exaustivamente perseguida. Estes fatores estão sendo essenciais para se enfrentar o forte aumento da competitividade nos mercados externo e interno, tanto de produtos substitutos, caso das aves e suínos, como também de produtos de origem externa (Santos, 1999).

\subsection{Distribuição do efetivo de bovinos no País}

O Brasil vem obtendo fortes incrementos na produção bovina. De acordo com o Censo Agropecuário de 1996, elaborado pelo IBGE, o efetivo de bovinos apresentou um total de 153,1 milhões de unidades, um crescimento de 29,62\% em relação aos números de 1980. Estes dados confirmam o segundo maior rebanho de gado bovino do mundo, ficando atrás somente da Índia, porém o rebanho deste país não é considerado comercial.

O Centro-Oeste vem se constituindo no principal centro produtor de bovinos do País. A região foi responsável, em 1996, por aproximadamente 33,17\% do efetivo total. Observa-se pela Tabela 1, que a atividade, na região, obteve um crescimento de 52,63\% entre 1980 e 1996. Apesar das regiões Sudeste, Sul e Nordeste também apresentarem aumento neste período $(3,21 \%, 7,04 \%$ e $6,21 \%$ respectivamente), suas participações sofreram significativas quedas. Em especial, nota-se que o Sudeste era considerado a região mais importante na produção bovina em 1980, respondendo por 29,50\% do efetivo de bovinos do País. Em 1985, a região é superada pelo Centro-Oeste, passando a ter uma participação de 27,91\%. Em 1996, esta porcentagem caiu ainda mais, chegando a $23,49 \%$. 
Tabela 1. Efetivo de bovinos nas regiões brasileiras em 1980, 1985 e 1996, suas respectivas participações em relação ao total obtido no Brasil e sua evolução no período.

\begin{tabular}{|c|c|c|c|c|c|c|c|}
\hline \multirow[t]{2}{*}{ Regiões } & \multicolumn{2}{|l|}{1980} & \multicolumn{2}{|l|}{1985} & \multicolumn{2}{|l|}{1996} & \multirow{2}{*}{$\begin{array}{c}\text { Evolução } \\
(\mathrm{A} / \mathrm{C})\end{array}$} \\
\hline & Unidades (A) & $\%$ & Unidades (B) & $\%$ & Unidades $(\mathrm{C})$ & $\%$ & \\
\hline Centro-Oeste & 33.261 .006 & 28,17 & 36.116 .293 & 28,21 & 50.766 .496 & 33,17 & $\overline{52,63}$ \\
\hline Sudeste & 34.834 .792 & 29,50 & 35.741 .876 & 27,91 & 35.953 .897 & 23,49 & 3,21 \\
\hline Sul & 24.494 .853 & 20,74 & 24.826 .784 & 19,39 & 26.219 .533 & 17,13 & 7,04 \\
\hline Nordeste & 21.506 .108 & 18,21 & 22.391 .193 & 17,49 & 22.841 .728 & 14,92 & 6,21 \\
\hline Norte & 3.989 .113 & 3,38 & $8.965 .609,00$ & 7,00 & 17.276 .621 & 11,29 & 333,09 \\
\hline Brasil & 118.085 .872 & 100,00 & 128.041 .755 & 100,00 & 153.058 .275 & 100,00 & 29,62 \\
\hline
\end{tabular}

Souza (1996) analisa que a transferência da produção para a região Centro-Oeste vem causando uma série de modificações no sistema produtivo. $\mathrm{O}$ ritmo de instalações de frigoríficos, os quais ficavam mais próximos dos centros consumidores, tem sido bastante forte nesta região. Segundo o autor, a explicação para esta tendência consiste no objetivo de diminuir problemas relacionados ao transporte do animal até o matadouro. Geralmente, ao percorrer longas distâncias, o gado sofre contusões, as quais levam à queda da qualidade do produto final. Adicionalmente, De Zen (1997) observa que os principais motivos que estão por trás deste deslocamento estão associados ao ganho competitivo dos frigoríficos situados póximos aos locais de produção. Além do custo de transporte dos animais vivos ser mais elevado se comparado ao da carne desossada, a oferta de animais, nestas regiões, é maior, levando a menores preços do boi gordo.

Santos (1999) confirma esta tendência, citando estudos que mostram uma elevação de aproximadamente 50\% no número de abates no Centro-Oeste nos últimos dez anos, valor bastante superior à média do País (25\%). O autor ainda observa que este crescimento não está ligado somente ao deslocamento dos frigoríficos para a região. Deve-se considerar também a evolução que o Centro-Oeste vem obtendo no processo de produção (aperfeiçoamento zootécnico) e no melhoramento da infra-estrutura de produção. Destaca-se a crescente adesão à produção de novilho precoce. Com isso, é possível ofertar a carne em um menor espaço de tempo, com uma qualidade superior. 
Cabe ainda comentar o forte avanço que a região Norte obteve no período assinalado pela Tabela 1, chegando a ter, em 1996, aproximadamente 17,3 milhões de bovinos. Entretanto, este crescimento percentual é fortemente influenciado pelo baixo número de bovinos que a região possuía em 1980.

Ao analisar os estados produtores, percebe-se que Minas Gerais, no período que compreende os anos de 1980 até 1996, sempre assumiu a liderança no número de bovinos. Entretanto, de acordo com a Tabela 2, o crescimento de seu rebanho, no período em questão, foi muito pequeno, cerca de 2,48\%. Já o estado do Mato Grosso do Sul, passou de quarto maior estado produtor em 1980, para segundo em 1985, mantendo tal posto em 1996, porém com um rebanho em forte crescimento, chegando próximo das unidades apresentadas por Minas Gerais. Entre 1980 e 1996, a evolução no número de efetivos de bovinos foi de $66,52 \%$. Outro estado que merece um destaque especial é o Mato Grosso. Enquanto em 1980, era considerado o oitavo maior estado produtor, atingiu, em 1996, a quarta posição, com um crescimento de 175,38\%, chegando a possuir 9,43\% das unidades de bovinos do País.

Tabela 2. Efetivo de bovinos nas unidades federativas de maior relevância para a pecuária de corte, suas respectivas participações no Brasil em 1980, 1985 e 1996 e sua evolução no período.

\begin{tabular}{|c|c|c|c|c|c|c|c|}
\hline \multirow[t]{2}{*}{ Unidades Federativas } & \multicolumn{2}{|l|}{1980} & \multicolumn{2}{|l|}{1985} & \multicolumn{2}{|l|}{1996} & \multirow{2}{*}{$\begin{array}{c}\text { Evolução } \\
\text { (A/C) }\end{array}$} \\
\hline & Unidades (A) & $\%$ & Unidades (B) & $\%$ & Unidades (C) & $\%$ & \\
\hline Minas Gerais & 19.560 .399 & 16,56 & 19.983 .506 & 15,61 & 20.044 .616 & 13,10 & 2,48 \\
\hline Mato Grosso do Sul & 11.862 .907 & 10,05 & 15.017 .906 & 11,73 & 19.754 .356 & 12,91 & 66,52 \\
\hline Goiás & 16.089.510 & 13,63 & 14.476 .565 & 11,31 & 16.488 .390 & 10,77 & 2,48 \\
\hline Rio Grande do Sul & 13.985.911 & 11,84 & 13.509 .324 & 10,55 & 13.221.297 & 8,64 & $-5,47$ \\
\hline São Paulo & 11.685 .216 & 9,90 & 12.210 .369 & 9,54 & 12.306 .790 & 8,04 & 5,32 \\
\hline Bahia & 8.942 .727 & 7,57 & 9.315 .074 & 7,28 & 8.729 .953 & 5,70 & $-2,38$ \\
\hline Paraná & 7.893 .313 & 6,68 & 8.574 .564 & 6,70 & 9.900 .885 & 6,47 & 25,43 \\
\hline Mato Grosso & 5.243 .044 & 4,44 & 6.545 .956 & 5,11 & 14.438 .135 & 9,43 & 175,38 \\
\hline Outros Estados & 22.822 .845 & 19,33 & 28.408 .493 & 22,19 & 38.173 .853 & 24,94 & 67,26 \\
\hline Total & 118.085 .872 & 100,00 & 128.041 .493 & 100,00 & 153.058 .275 & 100,00 & 29,62 \\
\hline
\end{tabular}




\subsection{Características gerais do processo produtivo}

Para se entender o mercado de reposição da pecuária bovina de corte, é necessário uma análise das características de seu processo produtivo. A seguir serão apresentadas as peculiaridades que envolvem as etapas de produção. Feito isso, o estudo se voltará para uma breve descrição do ciclo de preços da pecuária.

\subsubsection{As etapas de produção da pecuária bovina de corte}

De acordo com Bliska \& Gonçalves (1999), no Brasil, a pecuária bovina de corte é realizada, em geral, de forma extensiva, em regime de pasto natural ou cultivado. Como já descrito anteriormente, existem, basicamente, três etapas de produção: cria, recria e engorda.

A cria envolve essencialmente a produção de bezerros. De Zen (1993) define que o animal para ser considerado bezerro, no que diz respeito à comercialização, deve possuir idade de até dezoito meses, com um peso que varia entre quatro a oito arrobas. Esta fase de produção é de relevante importância ao se verificar que: i) é o período mais importante em termos de crescimento do animal. Peixoto (1999) descreve que na fase que compreende o crescimento até a desmama, o animal chega a obter cerca de $25 \%$ a $30 \%$ do peso final para o abate; ii) será responsável pela taxa de crescimento do rebanho; iii) irá determinar a quantidade de animais a ser ofertada para reposição (Hasegawa, 1995).

Em relação à recria, é possível estabelecer que esta fase compreende desde a desmama até o ponto em que a fêmea inicia seu período reprodutivo (dois a três anos) e em que o macho inicia a fase da engorda (Zimmer, 1999; Bliska \& Gonçalves, 1999). No final deste processo, o animal será chamado de novilho ou garrote. De acordo com De Zen (1993), o garrote apresenta as seguintes características: idade de dezoito a vinte 
e quatro meses e peso de oito a onze arrobas. A principal função desta etapa do processo produtivo está relacionada à manutenção do bezerro até se tornar um novilho.

Como já explicitado, a última etapa do processo de produção da pecuária bovina é a engorda. Como o próprio nome indica, esta fase tem por objetivo aumentar o peso do animal a fim de que se tenha um maior lucro no abate. Segundo Zimmer (1999), os animais que participam da engorda são os novilhos, bois adultos e fêmeas de descarte. $\mathrm{O}$ peso médio ideal para o animal é de 16,5 arrobas, o que equiivale a um animal vivo com peso entre 450 a $500 \mathrm{~kg}$. Conforme Schouchana \& Caffagni (2001), em geral, caso o regime de engorda seja de pasto, o período desta fase varia entre doze a dezoito meses, já no regime de confinamento, a engorda possui uma duração média de seis meses.

É perceptível que produção de carne bovina está diretamente condicionada à eficiência reprodutiva e à velocidade de crescimento dos animais. Uma maior aceleração no ritmo de crescimento traz impactos mais importantes que a queda da taxa de mortalidade ou uma melhora dos índices reprodutivos. Neste sentido, aspectos relacionados à nutrição e à precocidade são essenciais nesta questão (Souza, 1996; Faria, 1999).

Poucos produtores realizam as três fases mencionadas acima. Ou seja, a verticalização é muito pouco utilizada. Pela Tabela 3, constata-se que, nos três períodos analisados, a especialização em uma ou duas das etapas é mais comum. Além disso, percebe-se uma gradual queda na verticalização entre 1980 e 1996. Fatores culturais, questões ligadas à localização e preço da terra e aspectos econômicos levam os produtores à especialização do processo produtivo. $\mathrm{O}$ investimento em capital e a área para desenvolvimento da atividade, em geral, são menores e a circulação do produto é mais intensa que no sistema verticalizado (Oliveira,1991). 
Tabela 3. Efetivo da pecuária bovina de acordo com a finalidade do rebanho no Brasil em 1980, 1985 e 1996 e sua evolução nestes anos.

\begin{tabular}{|c|c|c|c|c|c|c|c|}
\hline \multirow[t]{2}{*}{ Finalidade } & \multicolumn{2}{|l|}{1980} & \multicolumn{2}{|l|}{1985} & \multicolumn{2}{|l|}{1996} & \multirow{2}{*}{$\begin{array}{l}\text { Evolução } \\
(\mathrm{A} / \mathrm{C})\end{array}$} \\
\hline & Unidades (A) & $\%$ & Unidades (B) & $\%$ & Unidades $(\mathrm{C})$ & $\%$ & \\
\hline Corte & 87.305 .677 & 73,93 & 94.689 .528 & 73,95 & 114.001 .898 & 74,48 & 30,58 \\
\hline Cria & 20.524 .263 & 17,38 & 22.375 .255 & 17,47 & 25.434 .682 & 16,62 & 23,92 \\
\hline Recria & 10.109 .983 & 8,56 & 9.916 .425 & 7,74 & 12.796 .500 & 8,36 & 26,57 \\
\hline Engorda & 11.513 .298 & 9,75 & 16.278 .161 & 12,71 & 8.572 .177 & 5,60 & $-25,55$ \\
\hline Cria e recria & 21.018 .056 & 17,80 & 19.949 .609 & 15,58 & 33.350 .559 & 21,79 & 58,68 \\
\hline Cria e engorda & 3.314 .786 & 2,81 & 4.284 .154 & 3,35 & 7.869.291 & 5,14 & 137,40 \\
\hline Recria e engorda & 4.183 .924 & 3,54 & 5.041 .467 & 3,94 & 10.879 .967 & 7,11 & 160,04 \\
\hline Cria, recria e engorda & 16.641 .367 & 14,09 & 16.844 .457 & 13,16 & 15.098 .722 & 9,86 & $-9,27$ \\
\hline Leite & 23.754 .484 & 20,12 & 25.972 .763 & 20,28 & 32.884 .077 & 21,48 & 38,43 \\
\hline Cote e Leite & 6.660 .984 & 5,64 & 6.929 .885 & 5,41 & 5.911 .253 & 3,86 & $-11,26$ \\
\hline $\begin{array}{l}\text { Animais de trabalho e } \\
\text { ignorada }\end{array}$ & 364.727 & 0,31 & 449.581 & 0,35 & 261.047 & 0,17 & $-28,43$ \\
\hline Total & 118.085 .872 & 100,00 & 128.041 .757 & 100,00 & 153.058 .275 & 100,00 & 29,62 \\
\hline
\end{tabular}

Cabe ainda analisar a distribuição geográfica destas etapas de produção. Hasegawa (1995) argumenta que, em geral, as fases de cria e recria são realizadas em áreas que possuem terras com valores mais baixos, cujas localizações são distantes dos principais centros consumidores. Já as atividades de engorda, são realizadas em áreas próximas destes centros. Ou seja, as primeiras fases do processo produtivo se localizam no Centro-Oeste e a engorda é realizada, geralmente, em São Paulo. Porém, como mencionado no item 2.2, a distribuição, acima descrita, vem sofrendo amplas modificações.

\subsubsection{O ciclo de preços da pecuária}

O ciclo de preços da pecuária bovina de corte possui características bastante peculiares. É possível observar dois tipos de ciclos nesta atividade. De acordo com Igreja (1987), o primeiro está relacionado às variações estacionais que ocorrem durante o ano agrícola. Já o segundo, refere-se a um ciclo plurianual. 
As variações estacionais ocorrem devido aos períodos "das águas" e da "seca", ou seja, estão diretamente relacionadas à sazonalidade da produção forrageira. Em geral, na região Centro-Sul, existe uma maior quantidade e qualidade das pastagens no primeiro semestre do ano. Nestes meses, os proprietários retêm o gado para um aumento de peso e ao atingir o ponto ideal para abate, ocorre a venda. Dessa forma, existe uma maior oferta de animais para abate neste período, o que leva à queda das cotações. Já no segundo semestre do ano, com a queda na qualidade e na quantidade das pastagens devido ao período da "seca", a oferta do boi para o abate se reduz, o que acaba provocando aumento em sua cotação. Pode-se concluir, portanto, que enquanto o primeiro semestre marca o período da safra do boi gordo, o segundo semestre indica a entressafra (Neves \& Couto, 1999; Kassouf, 1988).

Quanto ao ciclo plurianual, sua origem está relacionada às expectativas dos agentes do sistema produtivo em relação ao preço do boi gordo no futuro. Sua duração oscila entre cinco e seis anos, sendo que possui duas fases. A primeira delas se inicia quando existe uma tendência de queda nos preços do boi gordo. A partir deste fato, todas as etapas de produção formam expectativas pessimistas em relação aos preços em um momento futuro. Os produtores, responsáveis pela etapa de cria, ao possuir uma expectativa de queda nos preços, acabam abatendo as matrizes, com o objetivo de minimizar o prejuízo futuro e cobrir seus custos de produção. Duas conseqüências drásticas são criadas. No curto-prazo, há aumento da oferta de animais para o abate, o que contribui ainda mais para o declínio dos preços. No longo-prazo, a oferta de animais para reposição fica comprometida, já que as matrizes dariam origem aos bezerros (Neves \& Couto, 1999; Igreja, 1987; Kassouf, 1988).

Esta diminuição na oferta de bezerros levará, em períodos futuros, a uma queda na oferta de boi gordo. Neste sentido, o movimento de declínio dos preços sofre reversão, já que a expectativa de preços formada pelos agentes deste mercado se altera completamente. Este é o início da segunda fase do ciclo pecuário, a fase ascendente. $\mathrm{O}$ produtor diminuirá a oferta de matrizes para abate, visando aumentar a oferta de animais 
para reposição. Segundo Neves \& Couto (1999), os preços irão se elevar após dois ou três anos do início desta fase. Dois impactos, novamente, serão sentidos: i) os preços do boi gordo sofrerão um aumento ainda maior devido à queda da oferta de animais para abate; ii) haverá aumento de animais de reposição para o abate, o que acarretará, futuramente, na fase descendente dos preços (Igreja, 1987).

Dois pontos valem ser ressaltados. O primeiro deles se baseia no fato da vaca ser considerada um bem de capital e de consumo, já que tanto gera bezerros, como também serve para o abate (Hasegawa, 1995). Além disso, verifica-se que enquanto, no longo prazo, o setor pecuário acaba dependendo da evolução cíclica do rebanho, no curtoprazo, o pecuarista tem a opção, dependendo dos preços praticados no período, pelo abate ou pela manutenção do gado no pasto (Souza, 1996).

No entanto, com a inovação tecnológica que a pecuária bovina de corte vem passando nestes últimos anos, a precocidade dos animais tem sido cada vez maior, levando a uma menor duração deste ciclo. 


\section{OS CONTRATOS FUTUROS AGROPECUÁRIOS DA BM\&F}

A Bolsa de Mercadorias \& Futuros (BM\&F) é a única Bolsa brasileira que atua no mercado de derivativos agropecuários. Sua origem está ligada à fusão, em 1991, entre a Bolsa de Mercadorias de São Paulo (BMSP) e a Bolsa Mercantil \& de Futuros, fundadas em 1917 e 1985, respectivamente. Em 1997, a Bolsa Brasileira de Futuros, localizada no Rio de Janeiro, aderiu à esta união. Dessa forma, a BM\&F acabou se tornando o principal mercado de negociação de derivativos no Mercosul (Marques \& Mello, 1999).

Nos anos de 1997 e 1998, a BM\&F foi considerada a quarta maior Bolsa de derivativos do mundo, ficando atrás somente da Chicago Board of Trade (CBTO), da Chicago Mercantile Exchange (CME) e da London Intl. Finl. Futures \& Options Exchange (LIFFE). Em 1999, sua posição caiu para o décimo lugar. Em 2000, sua classificação sofreu uma melhora, subindo para a oitava colocação, mantendo tal posto em 2001, com um total de 97,8 milhões de contratos negociados (Tabela 4). 
Tabela 4. As maiores Bolsas de derivativos do mundo por volume de contratos negociados em 2001.

\begin{tabular}{clr}
\hline Posição & \multicolumn{1}{c}{ Bolsas } & Volume de Contratos* \\
\hline $1^{\circ}$ & Korea Stock Exchange (KSE) & 854.791 .792 \\
$2^{\text {o }}$ & Eurex Deutschland (EUREX) & 541.614 .348 \\
$3^{\text {o }}$ & Chicago Mercantile Exchange (CME) & 411.712 .208 \\
$4^{\text {o }}$ & Chicago Board of Trade (CBOT) & 260.333 .070 \\
$5^{\circ}$ & London Intl. Finl. Futures \& Options Exchange (LIFFE) & 202.697 .100 \\
$6^{\circ}$ & Euronext Paris** & 149.304 .585 \\
$7^{\text {o }}$ & New York Mercantile Exchange (NYMEX) & 103.025 .093 \\
$8^{\circ}$ & Bolsa de Mercadorias \& Futuros (BM\&F) & 97.827 .714 \\
$9^{\circ}$ & Chicago Board Options Exchange (CBOE) & 74.058 .028 \\
$1^{\circ}$ & London Metal Exchange (LME) & 59.413 .250 \\
\hline
\end{tabular}

Fonte: Resenha BM\&F (2002)

* Exclui contratos de opções sobre ações, spot e fracionários. No caso da LIFFE, os futuros de ações também não são considerados.

** Corresponde à fusão das Bolsas de Paris, Bruxelas e Amsterdã.

\subsection{A evolução dos contratos na BM\&F}

Como boa parte dos investimentos realizados em Bolsas possuem perspectivas de longo-prazo, o desenvolvimento de regras estáveis é um dos requisitos essenciais para o desenvolvimento destes mercados (Rochelle, 1997). A primeira metade da década de 90 foi marcada pela forte intervenção estatal no mercado financeiro brasileiro, causando um impacto significativo sobre as Bolsas brasileiras. Neste período, dois planos econômicos afetaram de maneira bastante negativa o mercado de derivativos. $\mathrm{O}$ primeiro deles foi $\mathrm{o}$ Plano Collor I, o qual teve como medida principal o bloqueio de $70 \%$ dos recursos financeiros do setor privado. No ano seguinte, implantou-se o Plano Collor II, no qual houve a liquidação compulsória de todos os contratos negociados na Bolsa Mercantil \& de Futuros. Após um mês desta determinação, o mercado voltou ao seu funcionamento.

Ao longo da segunda metade da década de 90, algumas ações, envolvendo abertura comercial e financeira do País ao exterior, fim das altas taxas inflacionarias e a queda do intervencionismo estatal, foram importantes para o desenvolvimento do mercado de derivativos no Brasil. De acordo com Souza (1998), após a implantação do Plano Real, houve um crescimento imediato no volume financeiro e no número de 
contratos negociados, já que com estabilidade econômica, o desempenho do mercado de derivativos se torna maior.

Entretanto, observou-se uma tendência de queda no número de negócios na BM\&F a partir de 1995. Isso se explica pelas fortes crises financeiras que abalaram os mercados mundiais (Crise Asiática e da Rússia) e pela desvalorização do câmbio brasileiro em janeiro de 1999. De acordo com a Figura 2, enquanto em 1995, 148,8 milhões de contratos foram negociados, em 1999, este número caiu para 55,9 milhões. Já no ano de 2000, houve uma melhora significativa, chegando a um volume de 82,9 milhões de contratos, com um posterior crescimento de $18 \%$ em 2001, quando o volume de transações atingiu 97,8 milhões de contratos. 


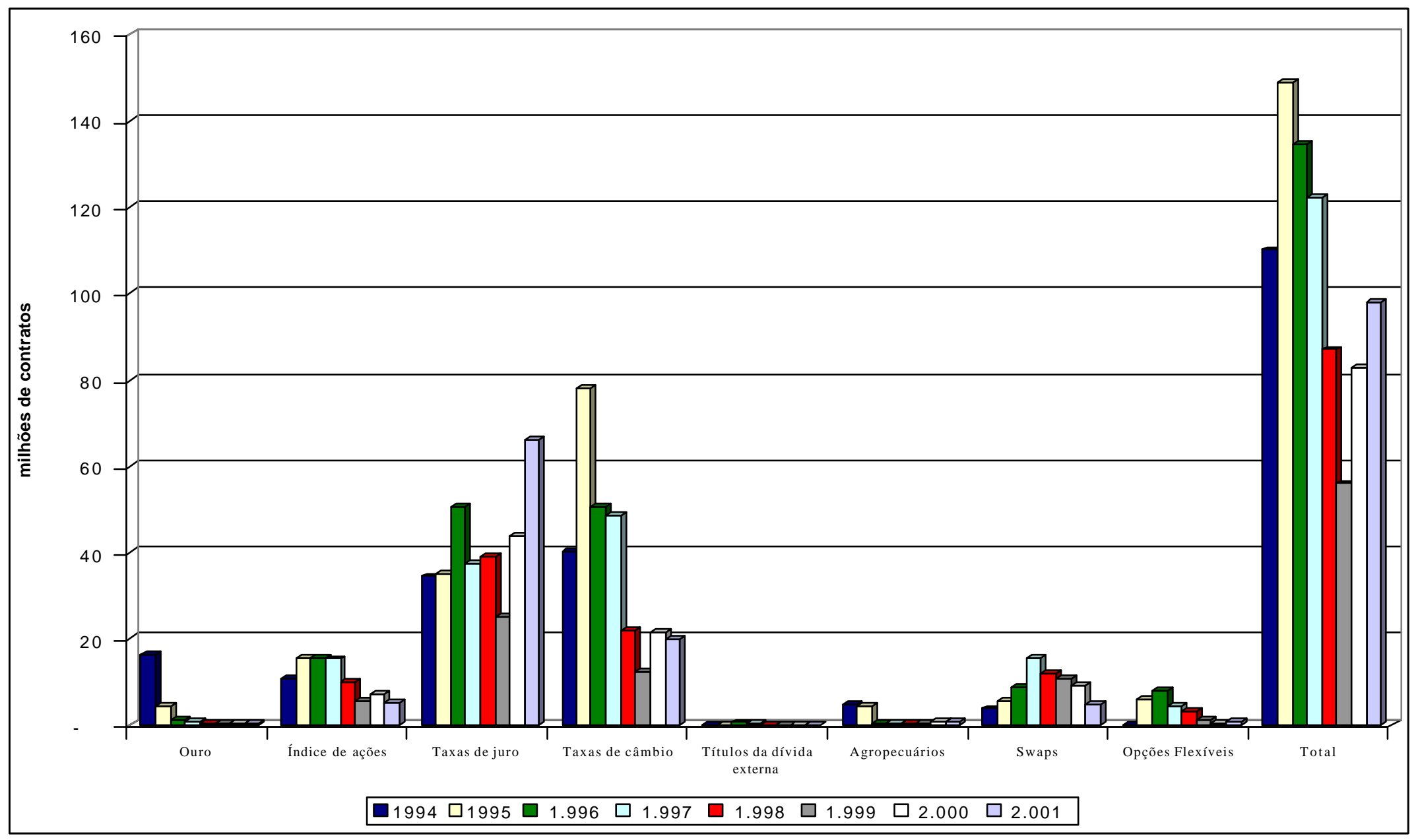

Figura 2 - Volume geral anual de contratos futuros e de opções (em milhões) negociados na BM\&F entre 1994 e 2001.

Fonte: Resenha BM\&F (1996-2001) 
Constata-se, pela Tabela 5, que os derivativos referentes às taxas de juro, taxas de câmbio, índice de ações e swaps foram os mais negociados entre 1994 e 2001, na BM\&F, apresentando uma participação média de 41,7\%, 32,5\%, 9,9\% e 9,3\% respectivamente.

Tabela 5. Participação média de cada ativo no volume geral anual de contratos futuros e de opções negociados na BM\&F entre 1994 e 2001.

\begin{tabular}{ccccccccc}
\hline & $\begin{array}{c}\text { Ouro } \\
\end{array}$ & $\begin{array}{c}\text { Índice de } \\
\text { Ações } \\
(\%)\end{array}$ & $\begin{array}{c}\text { Taxas de } \\
\text { Juro } \\
(\%)\end{array}$ & $\begin{array}{c}\text { Taxas de } \\
\text { Câmbio } \\
(\%)\end{array}$ & $\begin{array}{c}\text { Títulos da } \\
\text { Dívida } \\
\text { Externa(\%) }\end{array}$ & $\begin{array}{c}\text { Agrope- } \\
\text { cuários } \\
(\%)\end{array}$ & $\begin{array}{c}\text { Swaps } \\
(\%)\end{array}$ & $\begin{array}{c}\text { Opções } \\
\text { Flexíveis } \\
(\%)\end{array}$ \\
\hline 1994 & 14,72 & 9,63 & 31,33 & 36,42 & 0,00 & 4,38 & 3,44 & 0,00 \\
1995 & 2,94 & 10,34 & 23,65 & 52,40 & 0,00 & 2,94 & 3,63 & 4,10 \\
1996 & 0,75 & 11,40 & 37,47 & 37,48 & 0,45 & 0,23 & 6,40 & 5,82 \\
1997 & 0,62 & 12,51 & 30,49 & 39,70 & 0,25 & 0,23 & 12,58 & 3,62 \\
1998 & 0,43 & 11,53 & 44,93 & 25,36 & 0,01 & 0,44 & 13,68 & 3,62 \\
1999 & 0,85 & 9,97 & 45,22 & 21,75 & 0,00 & 0,99 & 19,31 & 1,90 \\
2000 & 0,30 & 8,45 & 52,87 & 26,06 & 0,00 & 0,81 & 10,82 & 0,69 \\
2001 & 0,26 & 5,43 & 67,40 & 20,43 & 0,00 & 0,76 & 4,84 & 0,86 \\
Média & 2,61 & 9,91 & 41,67 & 32,45 & 0,09 & 1,35 & 9,34 & 2,58 \\
\hline
\end{tabular}

Fonte: Resenha BM\&F (1996-2001)

Cabe observar que nos anos de 1994 e 1995 houve um alto volume de negociações com os derivativos agropecuários. Isso pode ser explicado pelo extinto fundo de commodities, o qual foi criado em setembro 1992 e administrado, em geral, por bancos mediante captação de recursos dos clientes. O valor destes fundos, em março de 1994, era de aproximadamente US\$ 11 bilhões. O Banco Central determinou uma aplicação de no mínimo $10 \%$ do valor deste fundo nos mercados de futuros e de opções agropecuários, em especial no mercado de opções de café arábica, que chegou a negociar 4,6 milhões de contratos em 1994, representando 96\% do total transacionado no mercado de derivativos agropecuários. Esta ação do governo teve a finalidade de estimular este mercado. As operações realizadas ficaram conhecidas como box fechado ${ }^{2}$. O fim desta ação governamental ocorreu em 1995 (Souza, 1998). Com isso, o volume de negociações com derivativos agropecuários se reduziu bruscamente, levando a uma

\footnotetext{
${ }^{2}$ A operação de box fechado consiste em uma combinação entre posições comprada e vendida, no mercado de opções, com vencimentos simultâneos e diferentes preços de exercício.
} 
participação, em relação ao volume total de contratos negociados, não significativa. Entretanto, esta participação vem crescendo - de 0,23\% em 1996 para 0,76\% em 2001.

\subsection{Os contratos futuros agropecuários}

Como mencionado na introdução deste trabalho, a Bolsa de Mercadorias \& Futuros $(\mathrm{BM} \& \mathrm{~F})$ contempla contratos futuros dos seguintes produtos agropecuários: café arábica, boi gordo, soja, milho, açúcar cristal, algodão e álcool anidro carburante.

Ao realizar uma análise específica no mercado futuro agropecuário da BM\&F, desconsiderando o mercado de opções, é possível observar uma evolução significativa no número de negociações entre 1994 e 2001 - de 84,9 mil para 733,5 mil contratos futuros. Neste período, verifica-se um aumento anual médio de aproximadamente 33\%. Os motivos para tal crescimento foram já mencionados: estabilização monetária, abertura comercial e queda da intervenção do governo na economia.

Verifica-se pela Figura 3 que os contratos futuros mais negociados e com maiores crescimentos, entre 1994 e 2001, foram café arábica e boi gordo. Enquanto, em 1994, os mercados futuros de café arábica e de boi gordo apresentaram volumes de 79,2 mil e 5,7 mil contratos respectivamente, em 2001, estes números passaram para 475,1 e 92,4 mil contratos. Além disso, constata-se, neste período, uma participação média de cerca de $60 \%$ e $26 \%$, respectivamente.

Cabe observar que os contratos de soja, algodão e milho possuíram uma pequena participação ao longo destes anos. Já com relação ao mercado futuro de açúcar cristal, nota-se uma evolução positiva em sua liquidez, atingindo em 2001 um volume de 93,9 mil contratos - $13 \%$ do volume negociado nos mercados futuros agropecuários da BM\&F. Quanto ao contrato futuro de álcool anidro, as negociações em 2000 (ano que marca a introdução do contrato) e 2001 envolveram, respectivamente, 53,9 mil e 67,5 mil contratos, garantindo uma participação, nestes dois anos, de aproximadamente $9 \%$. 


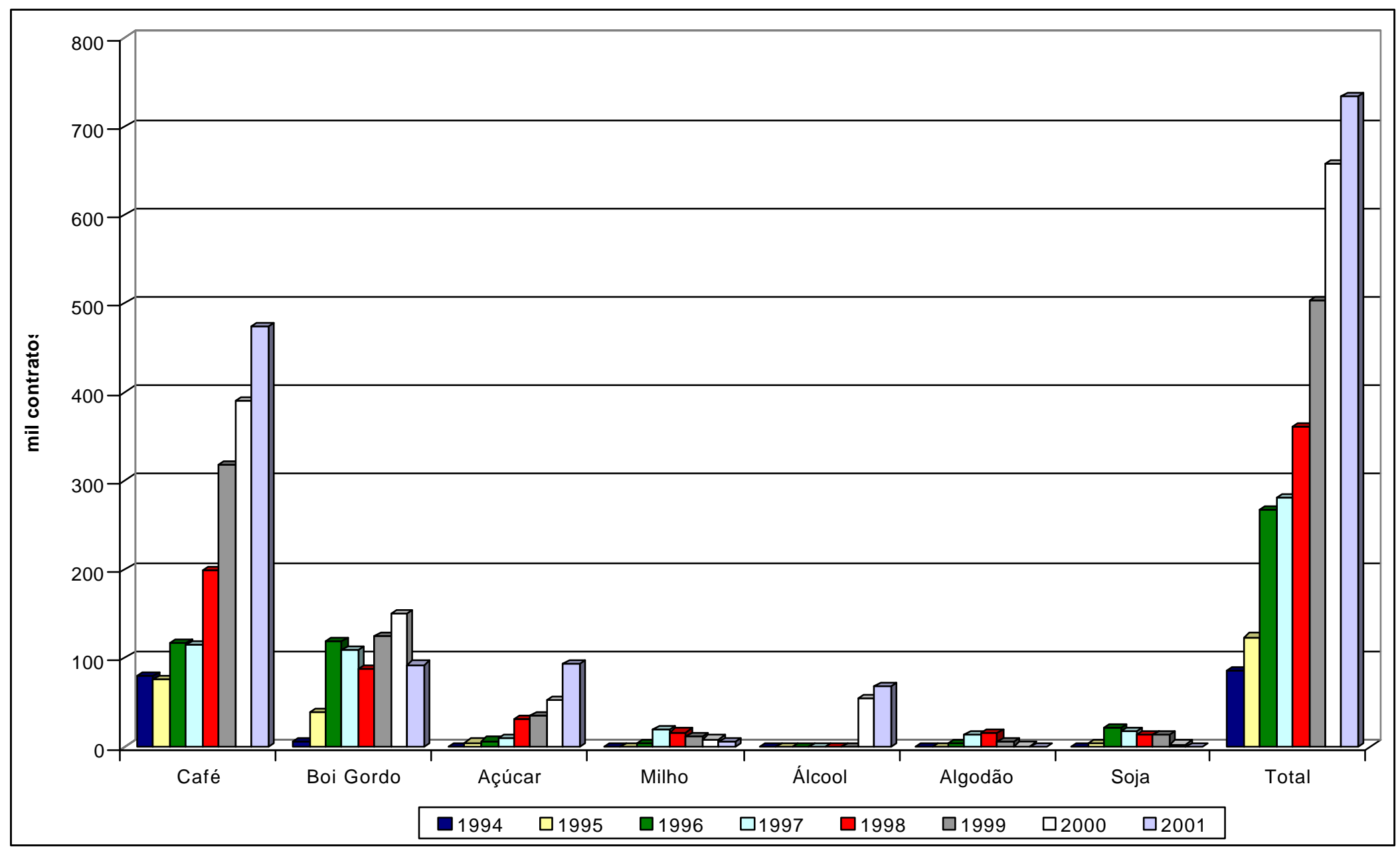

Figura 3- Número de contratos futuros agropecuários negociados (em mil) na BM\&F entre 1994 e 2001.

Fonte: Resenha BM\&F (1994-2001) 


\subsection{Os contratos futuros de boi gordo ${ }^{3}$}

A negociação dos contratos futuros de boi gordo, no Brasil, teve início em 1980, na Bolsa de Mercadorias de São Paulo (BMSP). Em outubro de 1986, durante o Plano Cruzado, o Banco Central determinou a liquidação compulsória do contrato. Em novembro deste mesmo ano, as negociações voltaram a ocorrer, porém foram poucos os negócios realizados.

Em 1987, a Bolsa Mercantil \& de Futuros realizou o lançamento dos contratos futuros de boi gordo. Dessa forma, duas Bolsas brasileiras, BMSP e a Bolsa Mercantil \& de Futuros, negociavam, a partir deste ano, os contratos em questão. Entretanto, as negociações, na BMSP, encerraram-se em 1991. Isso ocorreu devido à instabilidade econômica e política que o País passou na década de 80, levando à não evolução significativa do mercado de futuros agropecuário. Nesse período, os agentes de mercado preferiam investir em ativos reais, como aquisições em boi gordo, ao invés de aplicar seus investimentos no mercado financeiro. Neste sentido, os preços do boi gordo sofreram forte distorção no mercado à vista, o que acabou prejudicando o progresso do mercado futuro deste ativo, comprometendo bruscamente sua liquidez.

Em 1991, a recém criada Bolsa de Mercadorias \& de Futuros (BM\&F) lançou o contrato futuro cambial de boi gordo. A versão do contrato tinha como objeto de negociação o boi gordo, castrado, bem acabado, com peso entre $450 \mathrm{~kg}$ a $550 \mathrm{~kg}$ e de idade máxima de 60 meses. Cada contrato envolvia uma negociação de 330 arrobas líquidas. Foram definidos 8 meses de negociação: fevereiro, abril, junho, agosto, setembro, outubro, novembro e dezembro. No caso de liquidação física do contrato, estabeleceu-se quatro cidades para entrega dos animais: Araçatuba (SP), Barretos (SP), Presidente Prudente (SP) e São Paulo (SP).

\footnotetext{
${ }^{3}$ Esta seção tem como base Rochelle (1997) e Frick (1995).
} 
A liquidação física do contrato estava sujeita a uma série de problemas relacionados à grande dificuldade na formação de lotes que obedeciam totalmente às especificações do contrato. Era comum se observar disputas entre vendedores, que procuravam entregar o produto com padrões mínimos de qualidade, e compradores, que reivindicavam animais de qualidades mais apuradas.

Em maio de 1994, com o objetivo de superar este entrave, a BM\&F deu o primeiro passo para possibilitar a liquidação financeira do contrato. Estabeleceu um convênio com o Centro de Estudos Avançados em Economia Aplicada (CEPEA), da Escola Superior de Agricultura "Luiz de Queiroz" - ESALQ/USP, para a formulação de um índice de preços no mercado físico, o Indicador de Preço Disponível do Boi Gordo ESALQ/BM\&F (IBG). Além disso, foi estabelecido que no caso de liquidação física, haveria somente um único local de entrega (Araçatuba - SP), reduzindo, dessa forma, os custos e problemas operacionais advindos da existência de vários locais. A manutenção da possibilidade de ocorrer liquidação física se deve ao fato dela garantir a convergência dos preços à vista e futuro à medida que se aproxima da data de vencimento do contrato. Outras quatro mudanças foram realizadas no desenho do contrato: i) a pesagem dos animais passou a ser feita em balança da BM\&F e em curral credenciado pela Bolsa; ii) o rendimento de carcaça para o cálculo do peso líquido passou a ser realizado em função do peso bruto do animal; iii) os meses de negociação caíram de oito para cinco (março, maio, agosto, outubro e dezembro) e; iv) determinou-se que a data de vencimento do contrato, assim como o último dia de negociação, seria no décimo quinto dia útil do mês de vencimento.

Em dezembro de 1994, a BM\&F determinou que novas especificações seriam adotadas a partir do contrato com vencimento em agosto de 1995, sendo este aberto à negociação em dezembro de 1994. A partir deste contrato, além de ser criada a possibilidade da liquidação financeira com base na média aritmética dos últimos cinco dias úteis do IBG ESALQ/USP, a entrega física somente poderia ocorrer com a manifestação da intenção das duas partes, compradores e vendedores. Em 1996, a 
negociação dos contratos futuros de boi gordo passou a ocorrer em todos os meses do ano.

Os impactos destas medidas, aliado à estabilização monetária obtida com o Plano Real, fizeram-se sentir com o aumento no volume de contratos negociados entre 1994 e 2000 - de 5,7 mil para 150,4 mil contratos futuros.

No entanto, em 2001, o mercado futuro de boi gordo na BM\&F sofreu uma diminuição na liquidez, apresentando 92,4 mil contratos futuros negociados - queda de aproximadamente $38 \%$ em relação a 2000. Este resultado pode ser explicado pela alteração, a partir do vencimento de março de 2001, na cotação futura do boi gordo, que passou a ser realizada de dólares para reais por arroba. É importante mencionar que o ritmo de negociações teve diminuição somente no início do ano, já que os agentes buscavam se adaptar à nova metodologia de precificação. Ao considerar que os preços do boi são formados no mercado interno, esta modificação visou garantir, aos participantes deste sistema agroindustrial, uma maior visibilidade dos preços em um momento futuro. Com a cotação em dólar por arroba líquida, era necessário levar em consideração uma variável adicional, a taxa de câmbio, o que aumentava o risco no processo de descoberta de preços e na realização de operações de hedge (Perobelli, 2001). 


\section{CONCEITOS FUNDAMENTAIS NO MERCADO DE FUTUROS}

O objetivo principal desta seção consiste em fornecer os principais conceitos que serão utilizados nos próximos capítulos.

\subsection{O conceito de hedge e cross hedge no mercado de futuros}

O conceito de hedge está associado a uma operação que possui a finalidade de reduzir o risco de uma posição dadas as variações de preço, que possam vir a ocorrer, do ativo negociado (Silva Neto, 1999). Marques \& Mello (1999) definem o ato de hedge como uma forma de administração do risco, em que se busca a defesa contra variações indesejadas dos preços.

Working (1962) amplia o conceito de hedge ao mencionar que esta operação não só tem o propósito de evitar o risco, como também de assegurar lucros. Neste sentido, o autor define cinco modalidades de hedge: i) de carregamento - a decisão da empresa em adquirir contratos futuros ocorre em conjunto com a função de carregamento, sendo que o sucesso desta operação estará associado às mudanças na base; ii) operacional - o objetivo da utilização da operação é facilitar o processo de negociação da empresa, já que o índice de preços utilizado nos mercados futuros fornece uma sinalização da evolução dos preços; iii) seletivo - o hedge é realizado em função da expectativa de preço; iv) de antecipação - a finalidade é de antecipar as negociações à vista; com o aparecimento de uma oportunidade favorável, o agente antecipa o hedge; v) para se evitar o risco de movimentos adversos nos preços. 
É possível estabelecer duas categorias de hedge: de venda e de compra. A primeira delas é apropriada para o agente que possui o ativo no presente ou terá sua posse no futuro. Como exemplo, suponha um pecuarista, que possui o objetivo de se proteger da queda de preços do boi gordo. Para tanto, entrará no mercado vendendo contratos futuros ${ }^{4}$. Ou seja, realizará um hedge de venda, assumindo uma posição vendida no mercado (short), garantindo, assim, o preço desejado para seu ativo.

Já o hedge de compra é recomendado para os agentes que precisam adquirir um ativo no futuro. Observe o caso de um frigorífico, que ao possuir receio de que os preços do boi gordo aumentem, buscará adquirir contratos futuros que permitam garantir o preço de sua matéria-prima. Ou seja, irá realizar um hedge de compra, ficando em uma posição comprada no mercado (long).

Neste sentido, os agentes de mercado, acima citados, possuem o objetivo de minimizar os riscos de preço, os quais são inerentes às suas atividades. Verifica-se que o hedge em mercados futuros elimina a possibilidade de perdas futuras, porém os ganhos futuros, provenientes de alterações favoráveis nos preços à vista, são anulados.

É necessário ainda ressaltar a importância dos especuladores neste mercado. O objetivo econômico do hedge é a transferência do risco de preços para os especuladores, os quais se dispõem a assumir tal risco, visando realizar ganhos com as oscilações do ativo em negociação. Além disso, este agente é o responsável pela garantia de liquidez no mercado, já que sua atividade aumenta significativamente o volume de transações. Dessa forma, permite que o hedger abra ou feche posições no mercado, quando for conveniente (Bessada, 1995).

\footnotetext{
${ }^{4}$ De acordo com Hull (1996), o contrato futuro é um compromisso de comprar ou vender um ativo por um determinado preço em uma data futura estipulada. No entanto, são poucos os casos em que ocorre a entrega física da mercadoria. Isso se explica pelo fato do agente, em geral, preferir encerrar sua posição, tomando uma posição inversa daquela adotada inicialmente.
} 
Contudo, podem existir casos em que o ativo hedgeado não possua as mesmas características do objeto de contrato da Bolsa. A operação de hedge deste ativo é conhecida como cross hedge. Dahlgran (2000) menciona alguns exemplos destas operações: i) hedge de óleo de algodão sobre contratos futuros de óleo de soja; ii) hedge de venda de carne por atacado e produtos a base de carne de porco sobre contratos futuros de animais vivos e; iii) hedge de compra de diesel carburante com contratos futuros de óleo carburante. É necessário observar que a prática destas operações é realizada constantemente por agentes nacionais, que buscam travar o preço do produto de interesse em Bolsas internacionais, cujos contratos futuros apresentam produtos com características diferentes daquelas apresentadas pelo ativo hedgeado ${ }^{5}$.

\subsection{A Base}

Conforme Sharpe et al. (1995), a diferença entre o preço do ativo no mercado spot e seu correspondente preço no mercado de futuros é conhecida como base. É possível verificar que o preço à vista pode ser superior (inferior) ao seu correspondente preço futuro, dessa forma, a base será positiva (negativa).

De acordo com Pacheco (2000), a análise da base deve ser diferenciada entre as commodities estocáveis e as não estocáveis. A base para commodities estocáveis é formada pelos custos de carregamento, os quais refletem, basicamente, os custos ligados: a) ao transporte e; b) aos custos de armazenagem - gastos com aluguel do armazém, carga e descarga, juro e seguro -, os quais se elevam com o aumento do estoque. Tais custos variam de acordo com as condições de oferta e demanda do produto em questão. Se o espaço de tempo para o vencimento do contrato for longo, maiores serão os custos de carregamento. Com o passar do tempo, estes custos diminuem,

5 Vários estudos foram realizados a fim de comparar a efetividade entre o cross-hedge em Bolsas internacionais específicas e o hedge em Bolsas locais para determinados produtos. Dois exemplos podem ser citados. Rochelle (2000) realiza tal estudo no mercado de algodão, comparando a eficiência do hedge feito na BM\&F e na New York Cotton Exchange (NYCE). Lazzarini et al. (2000) realizam esta mesma análise no mercado futuro de café da BM\&F e da Coffee, Sugar \& Cocoa Exchange (CSCE). 
chegando ao ponto em que a diferença entre o preço à vista e o futuro reflete apenas os custos de transportes entre as diferentes localizações da negociação e os pontos de entrega da Bolsa (Schouchana, 1995; Marques \& Mello, 1999).

É necessário observar que no caso de commodities estocáveis, se o preço futuro exceder o preço à vista em um montante maior que o custo de carregamento, será aberto espaço para a arbitragem. $\mathrm{O}$ arbitrador compra o produto no mercado físico, faz um hedge de venda e liquida seu contrato pela entrega. Consequentemente, haverá elevação do preço à vista e redução do preço futuro, garantindo a convergência de preços. $\mathrm{O}$ processo oposto, quando o preço à vista é maior que o futuro, também pode ocorrer.

Quanto ao grupo das commodities não estocáveis (caso do boi gordo), Rich $(1990)^{6}$, citado por Rochelle (1997), aponta que a teoria sobre a base para estes produtos ainda não está bem desenvolvida. No caso do boi gordo, isso se deve ao fato de sua oferta não ser fixa e a formação de estoques ser difícil de ocorrer, o que acaba produzindo uma relação entre os preços à vista e futuro bastante instável.

Não bastasse o problema acima mencionado, as operações de arbitragem nestes mercados são bem mais difíceis de ocorrer. Isso acontece por causa de uma série de dificuldades relacionadas: i) à padronização dos lotes; ii) aos custos associados à transmissão de doenças, mortalidade, diferenças de qualidade, peso, sexo, raça, transporte e manuseio e mudanças fisiológicas que ocorrem com a maturidade do animal; iii) aos custos associados à emissão de aviso de entrega, inspeção e certificação da commodity e registro de transferência e; iv) aos custos associados à entrega da mercadoria para liquidar o contrato.

6 RICH, D.R. Feeder cattle cash settlement: impacts on basis variability and behavior in select U.S. markets. Urbana, 1990. 118p. Thesis (M.S.) - University of Illinois. 
Portanto, para que as operações de arbitragem sejam estimuladas, a diferença entre os preços à vista e futuro precisa exceder um montante que compense as despesas relativas à entrega da mercadoria. Neste sentido, torna-se possível a não convergência dos preços à vista e futuro durante o mês de vencimento do contrato. Porém, a probabilidade deste fato ocorrer é mínima. O comportamento padrão é a ocorrência da convergência dos preços no mês de vencimento, sendo que nos momentos que antecedem este mês, os preços à vista e futuro podem não apresentar relação.

\subsection{O Risco de Base}

Caso o preço à vista do ativo tenha um aumento maior que o preço futuro (ou o preço futuro apresente uma queda maior que o preço à vista), ocorre um fortalecimento da base (aumento da base), beneficiando os agentes que estão vendidos em contratos futuros (short). Por outro lado, quando o preço futuro obtiver um crescimento superior ao apresentado pelo preço à vista (ou o preço à vista apresente uma queda maior que o preço futuro), a base diminui. Ou seja, a base sofre enfraquecimento, situação positiva para aqueles que estão comprados em contratos futuros (long) (Sharpe et al., 1995).

Em geral, observa-se que os preços à vista e futuro se movem na mesma direção. Porém, este movimento, além de não ser simultâneo, não ocorre com a mesma intensidade. Portanto, é possível a existência de movimentos imprevisíveis relativos à base, os quais são definidos como risco de base. Dessa forma, fica claro o motivo pelo qual o mercado futuro não elimina totalmente o risco relativo aos preços, e sim o reduz. A operação de hedge no mercado de futuros não oferece uma proteção perfeita justamente pela existência do risco de base.

Para enfatizar ainda mais o conceito de risco de base, serão utilizados os passos desenvolvidos por Hull (1996). Suponha que o hedge seja iniciado em $t_{l}$ e encerrado em $t_{2}$. Dessa forma, é possível estabelecer que: 


$$
\begin{aligned}
& b_{1}=p_{1}-f_{1} \\
& b_{2}=p_{2}-f_{2}
\end{aligned}
$$

Sendo, $b_{1}$ e $b_{2}$ são definidas como base, $p_{1}$ e $p_{2}$ são os preços à vista e $f_{1}$ e $f_{2}$ são os preços futuros nos instantes $t_{1}$ e $t_{2}$ respectivamente.

O lucro ou prejuízo da posição futura é determinado pela diferença entre $f_{1}$ e $f_{2}$. Além disso, o agente receberá ou pagará $p_{2}$ pelo ativo no instante $t_{2}$. Portanto, o preço efetivo que o agente pagará ou receberá pelo ativo $(P)$ será:

$$
P=p_{2}+f_{1}-f_{2}
$$

Substituindo a equação (2) em (3), é possível chegar:

$$
P=f_{1}+b_{2}
$$

No instante $t_{1}, f_{1}$ é conhecido, porém $b_{2}$ geralmente não é possível de ser determinada. Caso a estimativa, feita em $t_{1}$, em relação à $b_{2}$ fosse confirmada em $t_{2}$, seria possível ocorrer um hedge perfeito. O risco associado a $b_{2}$ é chamado de risco de base.

No caso do cross hedge, o risco de base é ainda maior, pois a base associada a esta operação possui dois componentes. O agente pagará ou receberá o preço, já indicado na equação (4), ao realizar a operação de cross hedge. Porém, ao considerar $p_{2}{ }^{*}$ como o preço do ativo especificado no contrato no instante $t_{2}$ e $p_{2}$ como o preço do ativo hedgeado em $t_{2}$, a base no instante $t_{2}, b_{2}$, será igual a:

$$
b_{2}=\left(p_{2}{ }^{*}-f_{2}\right)+\left(p_{2}-p_{2}{ }^{*}\right)
$$


A diferença entre $p_{2}{ }^{*}$ e $f_{2}$ é o primeiro componente da base. Caso o ativo hedgeado fosse o mesmo daquele estabelecido no contrato, esta expressão seria considerada a base. O segundo componente da base no cross hedge surge da diferença de preço entre ativo hedgeado e aquele estabelecido no contrato, a qual é expressa por $\left(p_{2}-p_{2}^{*}\right)$.

Dessa forma, ao substituir a expressão (5) em (4), chega-se ao preço que o agente pagará ou receberá pelo ativo ao realizar a operação de cross hedge:

$$
P=f_{1}+\left(p_{2}{ }^{*}-f_{2}\right)+\left(p_{2}-p_{2}{ }^{*}\right)
$$

Verifica-se, portanto, que o risco do cross hedge pode estar associado: i) aos movimentos imprevisíveis que ocorrem na diferença entre os preços à vista e futuro do produto mencionado no contrato e; ii) aos movimentos imprevisíveis na diferença entre o preço à vista do ativo hedgeado e o preço à vista do ativo especificado no contrato.

\subsection{Razão de hedge de mínima variância}

O desconhecimento da base, em um determinado momento futuro, é a principal fonte de risco nas operações de hedge. Dessa forma, torna-se necessário que os agentes escolham uma proporção da posição à vista, que se deve assumir em mercados futuros, a fim de minimizar o risco associado às mudanças no valor de seu portfólio. Esta proporção é conhecida como razão de hedge de mínima variância.

Myers \& Thompson (1989) destacam que a escolha desta razão consiste em um grande problema para os agentes de mercado. Para se chegar à equação da razão de hedge ótima ${ }^{7}$, freqüentemente adotada, supõe-se que um agente tenha a expectativa de

7 As etapas utilizadas para se chegar à razão de hedge ótima tiveram como base Hull (1996) e Geppert(1995). 
negociar $N_{A}$ unidades de um ativo no período $t_{2}$. Para fixar o preço de venda ou de compra de seu ativo, irá transacionar contratos futuros de $N_{F}$ unidades deste ativo. A razão de hedge escolhida será:

$$
h=\frac{N_{F}}{N_{A}}
$$

O lucro ou a perda nesta operação, durante o período t, será igual a:

$$
Y_{t}=p_{2} N_{A}-\left(f_{2}-f_{1}\right) N_{F}
$$

Onde,

$p_{2}$ é o preço à vista em $t_{2} ; f_{1}$ e $f_{2}$ são os preços futuros nos instantes $t_{1}$ e $t_{2}$ respectivamente.

A equação (8) pode também ser escrita da seguinte forma:

$$
Y_{t}=p_{2} N_{A}+p_{1} N_{A}-p_{1} N_{A}-\left(f_{2}-f_{1}\right) N_{F}
$$

Substituindo a equação (7) em (8’) e realizando algumas transformações, obtémse:

$$
Y_{t}=p_{1} N_{A}+\left(p_{2}-p_{1}\right) N_{A}-\left(f_{2}-f_{1}\right) h N_{A}
$$

Dessa forma, pode-se chegar a:

$$
Y_{t}=p_{1} N_{A}+N_{A}\left[\left(p_{2}-p_{1}\right)-h\left(f_{2}-f_{1}\right)\right]
$$

Considerando,

$$
p_{\mathrm{t}}=p_{2}-p_{1}
$$




$$
f_{\mathrm{t}}=f_{2}-f_{1}
$$

Chega-se a:

$$
Y_{t}=p_{1} N_{A}+N_{A}\left(p_{t}-h f_{t}\right)
$$

$p_{1}$ e $N_{A}$ são conhecidas no instante $t_{1}$. Assim, a variância de $Y$ será minimizada quando a variância de $\left(\begin{array}{lll}p_{\mathrm{t}}-h & f_{\mathrm{t}}\end{array}\right)$ for minimizada. A variância desta expressão pode ser escrita como:

$$
\operatorname{Var}\left(Y_{\mathrm{t}}\right)=\operatorname{Var}\left(\begin{array}{ll}
p-h & f_{\mathrm{t}}
\end{array}\right)
$$

$$
\operatorname{Var}\left(Y_{\mathrm{t}}\right)=\operatorname{Var}\left(p_{\mathrm{t}}\right)+\operatorname{Var}\left(h f_{\mathrm{t}}\right)-2 \operatorname{Cov}\left(p_{\mathrm{t}}, h f_{\mathrm{t}}\right)
$$

$$
\operatorname{Var}(Y)=\operatorname{Var}\left(p_{\mathrm{t}}\right)+h^{2} \operatorname{Var}\left(f_{\mathrm{t}}\right)-2 h \operatorname{Cov}\left(p_{\mathrm{t}}, f_{\mathrm{t}}\right)
$$

O problema da minimização da variância será descrito como:

$$
\frac{\partial \operatorname{Var}\left(\Delta Y_{\mathrm{t}}\right)}{\partial h}=\frac{\partial\left[\operatorname{Var}\left(\Delta p_{t}\right)+\mathrm{h}^{2} \operatorname{Var}\left(\Delta f_{t}\right)-2 h \operatorname{Cov}\left(\Delta p_{t}, \Delta f_{t}\right)\right]}{\partial h}
$$

Aplicando a derivação,

$$
2 h^{*} \operatorname{Var}\left(f_{\mathrm{t}}\right)=2 \operatorname{Cov}\left(p_{\mathrm{t}}, f_{\mathrm{t}}\right)
$$

Consequentemente, a razão de hedge que minimiza a variância do lucro ou da perda na operação de hedge será:

$$
h^{*}=\frac{\operatorname{Cov}\left(\Delta p_{t}, \Delta f_{t}\right)}{\operatorname{Var}\left(\Delta f_{t}\right)}
$$


Mediante algumas transformações algébricas, aplicadas ao longo da exposição, é possível provar que a razão de hedge ótima também pode ser definida da seguinte maneira:

$$
h^{*}=\rho_{\Delta s, \Delta f} \frac{\sqrt{\operatorname{Var}\left(\Delta p_{t}\right)}}{\sqrt{\operatorname{Var}\left(\Delta f_{t}\right)}}
$$

Onde,

$\tilde{n} p, f$ é o coeficiente de correlação entre $p$ e $f$.

Vários métodos têm sido desenvolvidos para a estimação da razão de hedge ótima. Segundo Geppert (1995), o procedimento mais comum se baseia na estimação de uma regressão simples da variação dos preços à vista $(p)$ sobre a variação dos preços futuros ( $f$ ), pelo método dos Mínimos Quadrados Ordinários, com correções para a autocorrelação, onde a estimativa do coeficiente angular, desta regressão, corresponde à razão de hedge ótima ${ }^{8}$. Porém, este método possui algumas limitações, as quais serão abordadas nos próximos capítulos.

A partir da definição de razão de hedge ótima, é possível abordar o conceito de grau de efetividade do hedge. Segundo Carter \& Loyns (1985), a efetividade $\left(E^{*}\right)$ é definida como a redução percentual da variância, relativa à mudança dos preços à vista, causada pela realização do hedge, levando em conta a razão ótima. Ou seja, a efetividade da operação corresponde à proporção da variância das mudanças na receita que pode ser eliminada com a prática do hedge em sua razão ótima. Dessa forma, tal efetividade pode ser expressa da seguinte forma:

$E^{*}=\frac{\operatorname{Var}\left(\Delta p_{t}\right)-\operatorname{Var}\left(\Delta Y_{t}\right)}{\operatorname{Var}\left(\Delta p_{t}\right)}=1-\frac{\operatorname{Var}\left(\Delta Y_{t}\right)}{\operatorname{Var}\left(\Delta p_{t}\right)}=1-\frac{\operatorname{Var}\left(\Delta p-h^{*} \Delta f\right)}{\operatorname{Var}(\Delta p)}$

\footnotetext{
${ }^{8}$ No capítulo referente às considerações teóricas, serão desenvolvidos alguns dos métodos alternativos para a estimação da razão de hedge ótima.
} 
Sendo,

$\operatorname{Var}\left(p_{\mathrm{t}}-h^{*} f_{\mathrm{t}}\right)=$ variância da variação da receita em um portfolio com adoção do hedge na proporção ótima;

$\operatorname{Var}\left(p_{\mathrm{t}}\right)=$ variância da variação da receita sem a realização do hedge.

Marshall (1989) menciona que, ao obter a estimação da regressão entre a variação do preços à vista sobre a variação dos preços futuros, a efetividade do hedge irá depender de quanto a variação do preço à vista é compensada pela variação do preço futuro. Neste sentido, o grau de efetividade do hedge é obtido mediante o coeficiente de determinação da regressão, $R^{2}$, o qual é igual ao coeficiente de correlação entre preços à vista e futuro ao quadrado. Assim, quanto maior o valor deste coeficiente, mais eficiente será a operação de hedge, já que as variações dos preços à vista serão bem explicadas pelas variações nos preços futuros, o que demonstra um menor risco de base. 


\section{REVISÃO DE LITERATURA}

A revisão de literatura deste estudo foi centrada em trabalhos que visaram analisar a razão de hedge ótima e a efetividade de operações de cross hedge, utilizando contratos futuros de commodities que possuam características semelhantes àquelas apresentadas pelo ativo hedgeado ${ }^{9}$.

Conley (1994), com o objetivo de avaliar o uso do hedge como um método de gerenciar o risco de preço da gasolina e do diesel, analisou as razões de hedge e a efetividade desta operação na região das Planícies Norte dos Estados Unidos. Nos últimos vinte anos, vários choques de preços têm sido verificados neste mercado. Além disso, os preços destes produtos são influenciados por uma série de fatores, tais como as respectivas demandas e ofertas, ações dos países produtores visando a elevação dos preços e eventos geo-políticos, como guerras e disputas regionais.

\footnotetext{
${ }^{9}$ Para Black (1986), a existência de um cross hedge eficiente para o ativo de interesse determinará a fraca demanda pelo contrato futuro deste ativo. Neste sentido, a autora desenvolveu uma nova metodologia, unindo duas abordagens anteriores, uma que ressalta as características que um contrato futuro de um produto específico deve contemplar para que seja amplamente utilizado pelos agentes de mercado, e outra baseada na idéia de que o desenho do contrato é essencial para o seu uso em larga escala. De acordo com Black (1986), os agentes irão optar pelo cross hedge com base no trade-off entre custo de liquidez e efetividade do hedge em cada mercado.
} 
A escolha das Planícies Norte se deve ao fato desta região ter como atividade principal a agricultura, com extensas fazendas, e assim depender em alta medida de combustível refinado para suas operações. Como esta região possui quatro estados, foram escolhidas, em cada um, uma cidade representante: Scott City, Kansas; Lincoln, Nebraska; Bismark, North Dakota e Rapid City, South Dakota. Os preços da gasolina e do diesel foram pesquisados nestas quatro cidades, sendo considerado sua média semanal. Além disso, foram utilizados os preços futuros obtidos nos contratos futuros dos respectivos produtos e do óleo bruto, cotados na New York Mercantile Exchange (NYMEX). Utilizou-se o preço futuro praticado no momento do fechamento dos negócios na sexta-feira de cada semana. O período analisado teve início em janeiro de 1988 a dezembro de 1992.

O estudo levou em consideração a possibilidade da realização do cross hedge tanto da gasolina, como do óleo diesel, utilizando contratos futuros de óleo bruto. Explica-se, portanto, a inclusão deste contrato na análise. O autor considera razoável tal operação devido ao fato do ponto de distribuição de óleo bruto, negociado na $N Y M E X$, ser bem mais próximo das quatros cidades, anteriormente citadas. Dessa forma, os preços à vista e a base observada na região das Planícies Norte são mais influenciadas pelas condições de demanda e oferta do óleo bruto. Neste sentido, a utilização dos contratos futuros de óleo bruto pode resultar em um menor risco de base e, consequentemente, uma maior efetividade do hedge.

Para obter a razão de hedge ótima, estimou-se, pelo método dos Mínimos Quadrados Ordinários (MQO) e com correções para a autocorrelação, a regressão da variação dos preços à vista ( $p$ ) sobre a variação os preços futuros $(f)$, apresentada pela equação (15). Dessa forma, a razão de hedge ótima é equivalente ao coeficiente $\hat{a}$. Já a efetividade do hedge foi mensurada mediante o coeficiente de determinação, $R^{2}$, obtida nesta estimação. 


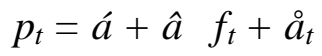

Onde,

$\stackrel{\circ}{a}_{t}$ é um termo de erro com média igual a zero e variância constante.

Os resultados obtidos mostraram que a efetividade das operações de hedge da gasolina e óleo diesel, utilizando os seus respectivos contratos futuros, foi bastante baixa para todas as cidades. Já a efetividade do cross hedge, em todas as cidades e para os dois produtos, utilizando os contratos futuros de óleo bruto, foi ainda mais baixa. Dessa forma, as operações de hedge e, principalmente, o cross hedge, como forma de proteção das variações dos preços, não foram considerados instrumentos eficientes.

Hayenga et al. (1996) analisaram as causas que vinham levando a uma baixa performance das operações de hedge, realizadas pelo setor de abate e processamento de carne bovina (no período entre janeiro de 1986 e junho de 1995) e de porco (entre janeiro de 1986 e dezembro de 1994) nos Estados Unidos. O procedimento das firmas consistia em estabelecer operações de cross hedge, cujos ativos hedgeados eram a carne de vaca e/ou carne de porco vendida no atacado e os ativos especificados nos contratos futuros eram porco e gado vivos, nos quais os contratos são negociados na Chicago Mercantile Exchange $(C M E)$. Estas operações ocorriam devido à não existência de um mercado de futuros para os ativos pelos quais estas firmas negociavam.

Neste sentido, os autores estimaram três modelos de regressão. O primeiro deles é baseado no trabalho de Ederington $(1979)^{10}$. Estimou-se a regressão do preço do produto à vista no atacado $\left(p_{t}\right)$, em nível, sobre o preço futuro do produto especificado no contrato $\left(f_{t}\right)$, em nível, conforme indicado na equação (16). É importante salientar que as firmas, em questão, utilizavam-se deste método para obterem a razão de hedge ótima.

\footnotetext{
${ }^{10}$ EDERINGTON, L.H. The hedging performance of the new futures markets. Journal of Finance, v.34,
} n.1, p.157-70, 1979 . 
$p_{t}=\ddot{a} f_{t}+\stackrel{\circ}{a}_{t}$

Sendo:

$\ddot{a}=$ coeficiente angular da regressão. A estimativa deste coeficiente é igual a razão de hedge ótima;

$\stackrel{\circ}{a}_{t}=$ termo de erro com média igual a zero e variância constante.

O segundo modelo, proposto por Hayenga et al. (1996), teve como base o trabalho de Hayenga \& DiPietre (1982) ${ }^{11}$. Observe, pela equação (17), que a diferença deste modelo em relação ao anterior é a inclusão do termo de intercepto, á.

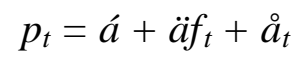

O terceiro modelo usado é baseado no estudo de Viswanath (1993) $)^{12}$. A regressão, utilizada neste modelo, encontra-se na equação (18). A principal vantagem do uso deste método consiste na inclusão de informações relativas à base em períodos anteriores ao hedge.

$$
p_{t}=a ́ a+\ddot{a} f_{t}+\hat{a} \sum_{t}^{t-n} B_{t}+\stackrel{\circ}{a}_{t}
$$

Onde,

$\sum_{t}^{t-n} B_{t}$ corresponde aos valores da base do período $t-n$ até o momento da realização do hedge, $t$. $p_{t}$ e $f_{t}$ correspondem ao preço à vista e futuro no período $t$, respectivamente; á, $\hat{a}$ e $\ddot{a}$ são os coeficientes da regressão, sendo que a estimativa $\ddot{a}$

11 HAYENGA, M.L.; DIPIETRE, D.D. Cross hedging wholesale pork products using live hog futures. American Journal of Agricultural Economics, v.64, p.747, 1982.

12 VISWANATH, P.V. Efficient use of information, convergence adjustment, and regression estimates of hedges ratios. Journal of Futures Markets, v.13, p.43, 1993. 
consistirá na razão ótima de hedge; $\stackrel{\circ}{t}_{t}$ corresponde ao termo de erro com média zero e variância constante.

Antes das estimações, os autores aplicaram o teste de raiz unitária para cada série de preços à vista e futuro. A hipótese de existência de uma raiz unitária foi rejeitada para as séries a um nível de $5 \%$ de significância. Dessa forma, concluiu-se que as séries eram estacionárias.

Seguindo o estudo, os três modelos foram estimados mediante o método dos Mínimos Quadrados Ordinários (MQO). Os preços à vista, usados na estimação, envolveram 5 tipos de carne de porco e 6 tipos de carne de vaca. Estas diferenciações advêm dos diferentes cortes realizados no animal. Além disso, as estimações ocorreram de maneira separada para cada mês do ano, visando capturar as variações sazonais do cross hedge.

Para o modelo 3, foram considerados os onze últimos valores da base anteriores à data do hedge. Dessa forma, foram desenvolvidas doze regressões para cada tipo de carne, para cada mês. Como exemplo, tem-se o lombo, um dos tipos de carne de porco analisada no estudo. Considerando que os agentes somente levam em conta o valor da base do período em que o hedge será feito, o procedimento adotado envolveu a estimação da equação (19) para cada mês do ano. Caso o agente use como informação, para estimar a razão de hedge, o valor da base do período atual e do mês anterior, serão aplicados os mesmos procedimentos, porém, agora, considerando dois valores da base. Este processo se verifica até o décimo primeiro valor da base defasado.

Duas importantes estatísticas foram utilizadas para comparar os modelos: o coeficiente de determinação da regressão $\left(R^{2}\right)$, que mensura a proporção da variável dependente que é explicada pelo modelo, e o desvio padrão da regressão ( $s$ ), que é usado para comparar a magnitude da variação no preço à vista que não é explicada pelos modelos em questão. 
Os resultados demonstraram que o modelo 1, usado pelas firmas que realizam o cross hedge, é o mais ineficiente para estas operações. Apenas dois dentre os cinco tipos de carne de vaca e dois dentre os seis tipos de carne de porco, apresentaram preços com um desvio padrão relativamente baixo. Adicionando o termo de intercepto, ou seja, considerando o modelo 2 , menores desvios padrões foram verificados, o que prova uma maior eficiência deste modelo em relação ao anterior. Já o terceiro modelo apresentou, em geral, os menores desvios padrões. Além disso, os resultados dos modelos 2 e 3 mostraram uma variação positiva significativa nas razões de hedge ótimas durante o ano, fato que não ocorreu com o primeiro modelo. Dessa forma, foi possível analisar os motivos pelos quais as operações de cross hedge utilizadas pelas firmas eram ineficientes.

Dahlgran (2000) realizou um trabalho, em que o objetivo foi achar a melhor maneira de realizar operações de cross hedge no mercado referente ao esmagamento do caroço de algodão. Verificou-se que quanto maior o período entre a comercialização do produto para esmagamento e a venda dos produtos advindos deste processo, a variância da margem por tonelada de caroço de algodão esmagada sofria um crescimento significativo. A alta variância, acima mencionada, poderia ser reduzida com a realização de operações de cross hedge do caroço de algodão e dos produtos obtidos com o esmagamento deste caroço (óleo vegetal, farinha com alto teor protéico, pequenas fibras de algodão e as cascas dos caroços), utilizando contratos futuros de commodities relacionadas.

A operação de cross hedge, analisada pelo autor, envolve a utilização de vários contratos futuros de ativos que possuem relações com os produtos acima mencionados, dentre os quais destacam-se os contratos futuros de: i) produtos do complexo da soja; ii) trigo, já que estes refletem, em geral, os preços dos grãos; iii) algodão, pois a oferta de caroço de algodão está intimamente associada à demanda desta commodity; iv) índice do dólar, devido ao fato do valor internacional desta moeda afetar a demanda pelas 
exportações de produtos com origem do caroço de algodão e; iv) moeda japonesa (yen), já que o Japão é um forte importador de óleo de algodão.

$\mathrm{O}$ autor considerou um horizonte de hedge de uma, quatro, treze e vinte e seis semanas. Além disso, foram utilizados dados de preço baseados na média semanal. Antes de iniciar os procedimentos, testou-se a estacionariedade das séries. Tal estacionariedade somente foi obtida com as séries nas primeiras diferenças. Dessa forma, trabalhou-se com os preços em suas variações. Prosseguindo a análise, foram realizadas as estimações, pelo método dos Mínimos Quadrados Ordinários, das variações dos preços do caroço de algodão e dos produtos obtidos no esmagamento sobre as variações dos preços futuros dos contratos futuros relacionados, de acordo com o modelo adotado no estudo realizado por Anderson \& Danthine (1980, 1981) e apresentado na equação (19) $)^{13}$.

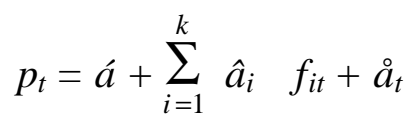

Onde,

$i$ representa cada uma das $k$ possibilidades de contratos futuros; $f_{i t}$ corresponde às variações do preço futuro de cada um dos contratos no período $t ; p_{t}$ representa o preço à vista na primeira diferença, no período $t$, do caroço do algodão e dos produtos obtidos com seu esmagamento; á, $\hat{a}_{i}$ são os coeficientes da regressão; å termo de erro com média zero e variância constante.

${ }^{13}$ ANDERSON, R.W.; DANTHINE, J. Hedging and joint production: theory and illustrations. Journal of Finance, v.35, p.487-501, 1980.

ANDERSON, R.W.; DANTHINE, J. Cross hedging. Journal of Political Economics, v.89, p.11821196, 1981. 
As razões de hedge foram obtidas mediante o coeficiente angular (âs). Além disso, a efetividade do hedge foi calculada através do coeficiente de determinação da regressão múltipla, $R^{2}$.

Os resultados das análises realizadas indicaram que com o aumento do número de variáveis explicativas no modelo, a efetividade do hedge, indicada pelo coeficiente $R^{2}$, sofria elevações. Como realizar operações de cross hedge, utilizando oito contratos futuros, é bastante difícil de se gerenciar, o autor estabeleceu um número máximo de quatro contratos futuros. Assim, foi possível obter as melhores estratégias para a realização do cross hedge. Ou seja, avaliou-se quais deveriam ser estes quatro contratos e qual o horizonte de hedge a ser praticado para a obtenção de uma maior efetividade da operação. 


\section{CONSIDERAÇÕES TEÓRICAS}

Como já comentado, vários procedimentos têm sido adotados para a estimação da razão de hedge ótima e para a obtenção da efetividade do hedge. Este capítulo visa apresentar e avaliar tais métodos.

Ederington (1979) foi responsável pelo início dos trabalhos relativos à estimação da razão de hedge de mínima variância. O autor realizou a estimação da regressão de preços à vista em nível, sobre os preços futuros em nível, pelo método dos Mínimos Quadrados Ordinários (MQO). O principal problema desta estimação está ligado ao uso destas variáveis em nível. Como a maior parte das séries econômicas possui autocorrelação serial e a regressão estimada pode ser de origem espúria, a estimativa da razão de hedge ótima pode não ser confiável (Brown, 1985).

Como já observado, o método mais utilizado consiste na estimação, por MQO, da regressão da variação dos preços à vista $(p)$ sobre a variação dos preços futuros $(f)$, com correções para a autocorrelação. O objetivo é achar a estimativa da razão de hedge que irá minimizar a soma do quadrado dos desvios da regressão, a qual é igual às variações do preço à vista que não são explicadas pela variação do preço futuro, ou seja, corresponde exatamente à porção aleatória da base. Conforme Rochelle (1997), esta é a parte do risco que não é eliminada pelo hedge de mínima variância. Dessa forma, quanto menor a variância da porção aleatória da base (risco de base), menor será o risco que envolve a operação de hedge em mercados futuros e, assim, maior a efetividade da operação (Netz, 1996). 
Um outro procedimento adotado tem base no trabalho de Brown (1985). A regressão é feita com os retornos no mercado à vista sobre os retornos no mercado futuro por MQO, cujo o retorno é definido como uma mudança percentual do preço em um dado intervalo de tempo.

No entanto, Myers \& Thompson (1989) apontam alguns problemas quanto à utilização do coeficiente angular da regressão simples do preço à vista sobre o preço futuro em nível, em variações ou em retornos. Segundo os autores, estes métodos somente são apropriados para estimar a razão de hedge ótima sob certas circunstâncias especiais. Isso se explica pelo fato desta razão, nestes procedimentos, ser igual à razão entre a covariância não condicional, entre a variável dependente e a explicativa, e a variância não condicional da variável explicativa. $\mathrm{Na}$ regra de hedge ótima, a covariância e variância, acima citadas, são momentos condicionais que dependem das informações disponíveis no momento da realização do hedge.

Neste sentido, visando superar este entrave, Myers \& Thompson (1989) desenvolveram um método generalizado de estimação, levando em consideração as informações disponíveis no período $t$ - 1 . O procedimento envolve a estimação da equação (20) pelo método de MQO.

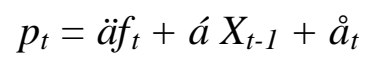

Onde,

$p_{t}$ e $f_{t}$ correspondem ao preço à vista e fut uro no período $t$, respectivamente; $X_{t-1}$ é uma matriz, na qual estão contidas as variáveis importantes para a formação dos preços à vista e futuro; $\ddot{a}$ e $a ́$ são os coeficientes da regressão não conhecidos, sendo que a estimativa $\ddot{a}$ consistirá na razão ótima de hedge; $\stackrel{\circ}{t}_{t}$ corresponde a um termo de zero com média igual a zero e variância constante. 
Uma simplificação, que pode ser feita neste modelo, é considerar que a matriz $X_{t-}$ 1 seja formada pelo termo constante e pelos preços à vista e futuros defasados, como pode ser observada na equação (21).

$$
p_{t}=\hat{a}_{0}+\ddot{a} f_{t}+\sum_{i=1}^{q} \hat{a}_{i} p_{t-i}+\sum_{j=1}^{q} \hat{a}_{q+j} f_{t-j}+\stackrel{\circ}{a}_{t}
$$

Sendo:

$q=$ número de defasagens do modelo.

Viswanath (1993) extendeu o modelo de Myers \& Thompson (1989), ao considerar que os valores da base mais recentes são as informações mais usadas e levadas em consideração no momento da elaboração da estimação da razão de hedge. $\mathrm{O}$ modelo proposto corresponde à equação (22).

$$
p_{t}=\dot{a}+\ddot{a} f_{t}+\hat{a} \sum_{t}^{t-n} B_{t}+\stackrel{\circ}{a}_{t}
$$

Onde,

$\sum_{t}^{t-n} B_{t}$ corresponde aos valores da base do período $t-n$ até o momento da realização do hedge, $t$. $p_{t}$ e $f_{t}$ correspondem ao preço à vista e futuro no período $t$, respectivamente; á, $\hat{a}$ e $\ddot{a}$ são os coeficientes da regressão, sendo que a estimativa $\ddot{a}$ consistirá na razão ótima de hedge; $\stackrel{\circ}{t}_{t}$ corresponde a um termo de erro com média igual a zero e variância constante ${ }^{14}$.

Como estes modelos envolvem a estimação de uma regressão múltipla, não é correto obter o grau de efetividade do hedge pelo coeficiente de determinação da

\footnotetext{
${ }^{14}$ Considerações mais específicas sobre o método de Myers \& Thompson (1989) serão desenvolvidas no próximo capítulo.
} 
regressão $\left(R^{2}\right)$. Dessa forma, para obter tal parâmetro, é preciso que sejam realizados cálculos das variâncias dos portfólios hedgeados e não hedgeados, seguindo a equação (14). 


\section{METODOLOGIA}

\subsection{Cálculo do Risco de Base}

A análise do risco de base, neste estudo, é de extrema importância, já que representa o risco de se realizar o hedge dos preços do boi gordo e o cross hedge dos preços do bezerro no mercado futuro de boi gordo da BM\&F. Ao realizar tais procedimentos será possível observar a diferença entre estas operações.

Em primeiro lugar, serão calculadas as bases semanais dos preços do boi gordo e do bezerro, em cada região. A base semanal será obtida pela média das bases diárias observadas durante a semana de vencimento do contrato, sendo estas calculadas pela diferença entre os preços à vista e os preços futuros. Como mencionado na seção 5.3, a base para as operações de cross hedge possui um componente adicional associado à diferença entre o ativo hedgeado e o ativo especificado no contrato.

É importante observar que os preços à vista e futuro do boi gordo estão mensurados em US\$ por arroba, tendo, portanto, uma mensuração diferente daquela apresentada pelos preços do bezerro (US\$/cabeça). Com o objetivo de uniformizar a mensuração de tais preços, as cotações do boi gordo à vista e futuro serão multiplicados por 16,5, já que o peso padrão de um boi gordo com idade superior a 36 meses é de 16.5 arrobas. Dessa forma, será possível obter valores referentes às bases por unidade de animal. 
Neste sentido, o cálculo da base para o bezerro segue a equação (23):

$B_{B E Z}=\left(16,5 * p_{B O I}-16,5 * f_{B O I}\right)+\left(p_{B E Z}-16,5 * p_{B O I}\right)$

Onde,

$B_{B E Z}=$ base diária por unidade de bezerro na semana de vencimento do contrato futuro do boi gordo da BM\&F;

$p_{B O I}=$ preços à vista do boi na semana de vencimento do contrato;

$f_{B O I}=$ preços futuros do boi no período considerado;

$p_{B E Z}=$ preços à vista do bezerro.

Já o cálculo da base para o boi gordo, por unidade do animal, pode ser obtido pela equação (24), que corresponde ao primeiro componente da base dos preços do bezerro.

$B_{B O I}=\left(16,5 * p_{B O I}-16,5 * f_{B O I}\right)$

Como a base a ser considerada somente leva em questão a semana que inclui a data de vencimento, admite-se que os preços à vista e futuro já tenham convergido para uma base histórica. Assim, é possível captar o risco de base calculando a variância desta série $^{15}$.

Além disso, para verificar como o risco de base difere entre o boi gordo e o bezerro e entre as regiões consideradas no estudo, será estimado um modelo de regressão pelo Método dos Mínimos Quadrados Ordinários, em que o desvio padrão da

\footnotetext{
$15 \mathrm{O}$ trabalho assume como hipótese o fato dos preços à vista e futuro estarem formalmente relacionados na semana de vencimento do contrato futuro de boi gordo da BM\&F. Neste sentido, as variações da base são explicadas exclusivamente pelo componente aleatório, que corresponde ao risco de base.
} 
base $^{16}$ na semana de vencimento do contrato será expresso em função de variáveis binárias, como mostra a equação (25):

$\ln \left(s_{\text {BASE } i j}\right)=\mathrm{OLTipo}_{i}+\sum_{j=1}^{8} \beta_{j} L_{j}+u_{i j}$

Sendo,

$\ln \left(s_{B A S E}\right)=$ logaritmo neperiano do desvio padrão da base na semana de vencimento do contrato;

Tipo $_{i}=$ variável binária para representar se o animal em questão se trata de boi gordo ou bezerro. Assumirá valor 0 , quando $i$ se refere ao desvio padrão da base para bezerro e valor 1, quando $i$ tiver relação com o desvio padrão da base para boi;

$L_{j}=$ variável binária que indica a localização. O valor será 1 para uma determinada região $j$ em que se refere o desvio padrão da base e 0 para as outras regiões;

$u_{i j}=$ termo de erro.

\subsection{Operações de hedge: razão ótima e efetividade}

Como já observado, o trabalho de Myers \& Thompson (1989) desenvolve um procedimento geral para a estimação da razão de hedge ótima. Para tanto, determinou-se um consistente modelo de determinação dos preços à vista e futuro.

A regra de hedge ótima é definida como a razão entre a covariância do preço à vista e futuro $\left(\sigma_{p, f}\right)$ e a variância do preço futuro $\left(\sigma_{f}^{2}\right)$. Estes parâmetros são considerados como momentos condicionais dos preços de mercado. Para estimar $\sigma_{f}^{2}$ e

\footnotetext{
16 Para obter uma maior estabilidade dos dados, o desvio padrão da base foi utilizado na forma de logaritmos neperianos.
} 
$\sigma_{p, f}$, é necessário que se tenha um modelo de equilíbrio de mercado, em que os comportamentos dos agentes sejam levados em consideração.

Para desenvolver o método, os autores supõem um modelo de equilíbrio linear para os preços à vista e futuro:

$$
\begin{aligned}
& p_{t}=\hat{a} X_{t-1}+u_{t} \\
& f_{t}=\hat{a} X_{t-1}+v_{t}
\end{aligned}
$$

Onde, $p_{t}$ e $f_{t}$ são os preços à vista e futuro no momento $t$, respectivamente; $X_{t-l}$ é um vetor de variáveis conhecidas em $t-1^{17}$, que ajudam a prever $p_{t}$ e $f_{t}$; $\hat{a}$ e $a ́$ são vetores de parâmetros não conhecidos; $v_{t}$ e $u_{t}$ correspondem aos termos de erro com média igual a zero e sem correlação serial.

A razão de hedge ótima será igual a estimativa $\ddot{a}$, que será obtida mediante a estimação da equação (28) pelo método de MQO:

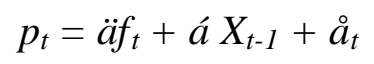

Sendo que $\stackrel{\circ}{a}_{t}$ corresponde a um termo de erro com média igual a zero e variância constante.

A partir de tais questões, é possível analisar em quais circunstâncias especiais os três métodos tradicionais, em que se utiliza o coeficiente angular da regressão simples como razão de hedge ótima, podem ser aplicados de maneira consistente.

No modelo em que ocorre a estimação da regressão simples dos preços à vista, em nível, sobre os preços futuros, em nível, Myers \& Thompson (1989) demonstram que

\footnotetext{
17 Alguns exemplos destas variáveis são: preços à vista e futuros, estoques, produção, exportação e consumo, que ocorreram em $t$ - 1 ou em períodos anteriores.
} 
a razão de hedge será consistente somente no caso em que os preços futuros e à vista sejam iguais a uma constante adicionada por seus respectivos termos erráticos, ou seja, a matriz $X_{t-1}$ será formada somente pelo termo constante. Conclui-se que o modelo de equilíbrio é bastante restrito.

Considerando o modelo que leva em conta as variações dos preços futuros e à vista, os autores argumentam que a razão de hedge ótima será igual à razão do método generalizado quando o equilíbrio dos preços à vista e futuro seguir um caminho aleatório com drift. Apesar de existirem confirmações empíricas, há algumas razões para se acreditar que o equilíbrio dos preços de uma commodity não segue, em todos os casos, um caminho aleatório.

As mesmas conclusões são obtidas no caso em que a razão de hedge ótima é estimada mediante a regressão dos retornos no mercado à vista sobre os retornos no mercado futuro. Entretanto, além dos retornos seguirem um caminho aleatório, é necessário que o preço à vista em um dado momento seja igual ao preço futuro. Tal fato deve ocorrer para garantir que a razão de hedge ótima não se altere ao longo do tempo. A segunda restrição torna o modelo inconsistente, pois não é lógico esperar que o preço à vista se iguale ao futuro em um instante de tempo futuro.

Como já mencionado, é possível realizar uma simplificação do modelo ao considerar que a matriz $X_{t-1}$ seja formada pelos seguintes elementos: termo constante, preços à vista defasados e preços futuros defasados. Duas pressuposições são realizadas em relação a estas duas últimas variáveis: i) correspondem a um processo autoregressivo (AR); ii) refletem as demais variáveis explicativas que poderiam estar presentes.

Além disso, os autores impõem uma importante restrição ao modelo de determinação dos preços relacionada à eficiência dos mercados futuros. Assim, as equações do modelo de equilíbrio seguem as equações a seguir: 


$$
\begin{aligned}
& p_{t}=a^{\prime} X_{t-1}+u_{t} \\
& f_{t}=f_{t-1}+v_{t}
\end{aligned}
$$

Observa-se que as duas equações possuem diferentes variáveis explicativas. Assim, não é apropriado utilizar o método de MQO para obtenção da razão de hedge ótima. Uma alternativa é aplicar o método das Equações Aparentemente Não Correlacionadas (SUR). No entanto, os autores argumentam que a estimação da equação abaixo por MQO resultará em uma estimativa da razão de hedge ótima equivalente daquela encontrada pelo método SUR:

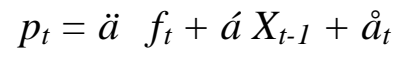

Na equação (31), $p_{t}$ é igual ao preço à vista no momento, $f_{t}$ corresponde à variação do preço futuro entre os períodos $t$ e $t-1, X_{t-1}$ é a matriz, cujo seus componentes são o termo intercepto e os preços à vista defasados, $\ddot{a}$ é a razão de hedge ótima e $\stackrel{\circ}{t}_{t}$ se refere a um ruído branco.

Vale observar, novamente, que o procedimento em questão envolve a estimação de uma regressão múltipla. Dessa forma, para se obter a efetividade do hedge, faz-se necessário que se calcule as variâncias dos portfólios hedgeados e não hedgeados, não sendo, portanto, correto utilizar o coeficiente de determinação da equação, $R^{2}$.

É de fundamental importância que se verifique a estacionariedade das séries de preço à vista e futuro. Para que a equação (31) possa ser estimada por MQO é necessário que: i) a série preços futuros seja estacionária em sua primeira diferença (fator determinante da eficiência dos mercados futuros); ii) caso a série de preços à vista seja estacionária em sua primeira diferença, a equação deve ser especificada novamente, de forma a apresentar o preço à vista na primeira diferença. Neste sentido, serão realizados testes de raiz unitária para verificar a estacionariedade das séries. 
Para se determinar o número de defasagens da variável preço à vista que estará contida em $X_{t-l}$, será utilizado o Critério de Informação de Akaike (AIC) e o Critério de Informação de Schwarz (SC), representadas pelas equações (32) e (33).

$$
\begin{aligned}
& A I C=\ln s^{2}+\left(\frac{2}{T}\right)\left(n^{o} \text { de parâmetros }\right) \\
& S C=\ln s^{2}+\left(\frac{\ln T}{T}\right)\left(n^{o} \text { de parâmetros }\right)
\end{aligned}
$$

Sendo $s^{2}$ igual à soma de quadrados dos resíduos da equação autorregressiva e $T$ corresponde ao número de observações.

A preferência será baseada nos modelos que possuírem os menores valores dos critérios acima mencionados. Ou seja, serão escolhidos os modelos que apresentarem as menores variâncias dos resíduos e uma menor quantidade de parâmetros.

Cabe ainda enfatizar que o estudo não leva em consideração os custos envolvidos nas operações de hedge, os custos de oportunidade presentes neste processo e os custos de se obter informações nos mercados.

\subsubsection{Teste de Raiz Unitária}

Os testes de raiz unitária possuem a finalidade de verificar se uma série temporal é estacionária em nível ou se torna estacionária nas diferenças.

Diversos testes são encontrados na literatura para analisar a existência de raiz unitária nas séries temporais. No presente estudo, optou-se pelo uso dos testes de Dickey \& Fuller (DF) e Dickey \& Fuller Aumentado (ADF). 
O teste de Dickey \& Fuller (DF) possui a pressuposição de que as séries são geradas por um processo auto-regressivo de ordem um e os termos aleatórios seguem um ruído branco. Neste sentido, parte-se de um modelo geral, com a presença dos componentes deterministas tendência e constante, como mostra a equação (34), conforme os procedimentos seqüenciais apresentado por Enders (1995) - Anexo A. É importante colocar que para cada modelo considerado, com base na presença dos termos constante e/ou tendência determinista, tem-se uma estatística para testar a presença de raiz unitária (Dickey \& Fuller, 1981). Utiliza-se o valor $t$ calculado relativo à hipótese nula, que indica a presença de raiz unitária na série, para comparar com o valor crítico da estatística específico ao modelo considerado, ao nível de probabilidade escolhido e ao número de observações da amostra em questão.

O teste envolve a estimação da equação abaixo pelo Método dos Mínimos Quadrados Ordinários e posteriormente testar a hipótese da presença de raiz unitária.

$$
\Delta Y_{t}=\alpha+(\rho-1) Y_{t-1}+\gamma T+u_{t}
$$

Sendo:

$a ́=$ termo constante;

$\ddot{A} Y_{t}=$ série $Y_{t}$ na primeira diferença;

$Y_{t-l}=$ série $Y_{t}$ defasada em um período;

$u_{t}=$ ruído branco;

$T=$ tendência determinista.

Teste de Hipótese: $\quad H_{0}: \tilde{n}-1=0$

$$
H_{a}: \tilde{n}-1<0 \quad[\tilde{n}-1] \quad(-2,0)
$$

Caso o processo gerador da série temporal seja um processo auto-regressivo de ordem superior a um $[\operatorname{Ar}(\mathrm{p})$, onde $\mathrm{p}>1)]$, o teste a ser utilizado corresponde ao Dickey \& 
Fuller Aumentado (ADF). O teste consiste em estimar a equação (36) pelo Método dos Mínimos Quadrados Ordinários e testar a hipótese (37):

$$
\begin{aligned}
& \Delta Y_{t}=\alpha+\theta Y_{t-1}+\sum_{i=1}^{p-1} \omega_{t} \Delta Y_{t-i}+\gamma T+u_{t} \\
& \text { Sendo: } \begin{aligned}
\theta & =\sum_{i=1}^{p} \rho_{i}-1 \\
\omega_{i} & =-\sum_{j=i+1}^{p} \rho_{j}
\end{aligned}
\end{aligned}
$$

$$
\text { Teste de Hipótese: } \quad \begin{aligned}
& H_{0}: \grave{e}=0 \\
& H_{a}: \grave{e}<0
\end{aligned}
$$

Os procedimentos seqüenciais utilizados no teste $\mathrm{DF}$, também serão utilizados no presente teste a fim de se verificar a existência de raiz unitária. De forma geral, compara-se o valor de $t$ calculado, relativo à hipótese nula, com o valor crítico da estatística que corresponde ao modelo especificado ${ }^{18}$, levando-se em conta um determinado nível de probabilidade e o número de observações da amostra.

Nota-se que a diferença básica do teste ADF com o DF envolve a inclusão de um determinado número de defasagens da variável dependente na primeira diferença. $\mathrm{O}$ objetivo é anular a eventual autocorrelação que os resíduos possam vir a apresentar. Neste sentido, é de fundamental importância a correta determinação do número de defasagens a ser incluído no modelo. De acordo com Enders (1995), no caso de se

\footnotetext{
18 De acordo com Dickey \& Fuller (1981), as estatísticas $\hat{o}_{\hat{o}}$, ồ $\hat{\mathrm{I}}_{\mathbf{~}}$ e ô correspondem ao teste $t$ para a estimativa do coeficiente de $Y_{t-1}$ da equação (36) para os respectivos modelos que: i) inclui constante e tendência (o modelo ainda possui uma estatística ô âo que testa se o coeficiente da tendência é estatisticamente significativa); ii) contém somente constante (utiliza-se a estatística ó ái para testar se a constante é significativa); iii) não inclui tanto a constante, quanto a tendência.
} 
incluir poucas defasagens, pode-se rejeitar a hipótese nula, quando ela é verdadeira. Já a inclusão de muitas defasagens, pode levar a uma redução no poder do teste.

Neste trabalho, a determinação do número de defasagens a ser usado no modelo será realizada pelos Critérios de Informação de Akaike e de Schwarz, descritos anteriormente, pelas equações (32) e (33).

\subsubsection{Metodologia para análise da eficiência do mercado futuro do boi gordo na BM\&F}

Como uma das hipóteses utilizadas pela metodologia para estimar a razão de hedge ótima, definida por Myers \& Thompson (1989), consiste na eficiência dos preços futuros, faz-se necessário verificar se este fato ocorre com os preços dos contratos futuros de boi gordo da BM\&F. Isso será realizado mediante o procedimento desenvolvido por Saboya \& Bacchi (1999).

Um mercado futuro é considerado eficiente quando não existe uma relação entre as variações de preços de um contrato de um determinado dia com as variações ocorridas em dias anteriores. Assim, os preços acabam refletindo todas as informações disponíveis até aquele instante. Para tanto, o processo formador da série deve ter um comportamento aleatório e ao transformá-la para sua primeira diferença deve-se obter estacionariedade. Para verificar tal fato, realiza-se o teste de raiz unitária, sendo que a eficiência do mercado requer que os elementos constante e tendência não sejam significativos (Saboya \& Bacchi, 1999).

Além disso, é necessário enfatizar que antes de se proceder ao teste de raiz unitária, torna-se fundamental que se identifique a ordem do processo auto-regressivo [AR(p)] gerador da série mediante os critérios de informação, citados anteriormente. Para a existência de um mercado eficiente, este processo deve se constituir em um 
AR(1). Assim, torna-se possível estimar a equação (38) e analisar se a hipótese de existência de raiz unitária $(\hat{a}=\hat{a}=\grave{e}=0)$ se verifica.

$\Delta f_{t}=\alpha+\beta t+\theta f_{t-1}+e_{t}$

Sendo, $\Delta f_{t}=f_{t}-f_{t-1}$ e $\boldsymbol{\theta}=\boldsymbol{\rho}-1$.

\subsection{Dados Utilizados}

O presente estudo utilizou os preços à vista do boi gordo e bezerro do Centro de Estudos Avançados em Economia Aplicada/ Fundação de Estudos Agrários "Luiz de Queiroz" (CEPEA/FEALQ). As regiões de interesse foram: Araçatuba (SP), Bauru/Marília (SP), São José do Ro Preto (SP), Presidente Prudente (SP), Três Lagoas (MG), Triângulo Mineiro (MG), Campo Grande (MS) e Noroeste do Paraná. Os preços do bezerro se referem aos machos da raça nelore e anelorados da fase pós desmama, com idade variando entre oito e doze meses. Os preços à vista do bezerro estão cotados em valores nominais por cabeça, já os preços à vista do boi gordo estão em valores nominais por arroba. Estes valores foram convertidos em dólares nominais pela taxa de câmbio das operações de venda.

Já os preços futuros, foram obtidos junto à Bolsa de Mercadorias \& Futuros e correspondem às cotações do primeiro vencimento do contrato futuro cambial de boi gordo.

O período da amostra foi de setembro de 1995 a fevereiro de 2001. O início em setembro de 1995 se explica pelo fato de marcar o início da possibilidade de liquidação financeira nos contratos futuros de boi gordo. O término das séries em fevereiro de 2001 se justifica devido à modificação que o preço futuro do boi gordo sofreu em março deste mesmo ano. A primeira posição, no mês de março, foi realizada em reais por arroba 
líquida. Anteriormente, a cotação era feita em pontos por arroba líquida, sendo que cada ponto correspondia à taxa de câmbio de reais por dólar.

É necessário colocar que as séries de preço à vista e futuro referem-se às cotações diárias. No entanto, para a estimação da razão de hedge ótima, foram calculadas médias semanais, devido ao problema de autocorrelação serial, sendo obtidas por meio de médias aritméticas dos preços de cada período em questão. A fim de obter uma maior estabilidade da variância das séries, estas foram transformadas em logaritmos. As Figuras 4 e 5 mostram a evolução das médias semanais dos preços do bezerro e do boi, utilizadas neste estudo.

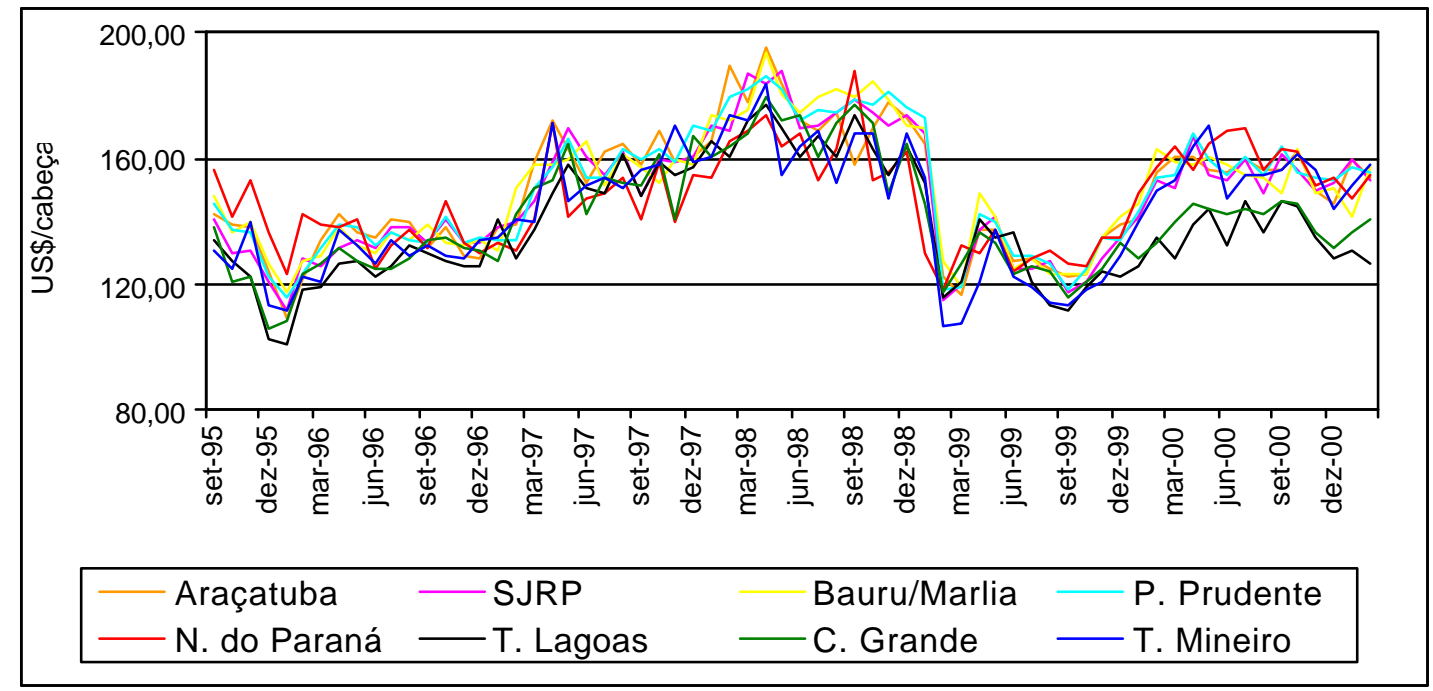

Figura 4 - Médias semanais dos preços à vista do bezerro (em US\$) nas regiões de Araçatuba, Noroeste do Paraná, São José do Rio Preto, Três Lagoas, Bauru/Marília, Campo Grande, Presidente Prudente e Triângulo Mineiro. Fonte: CEPEA/FEALQ/USP (2001) 


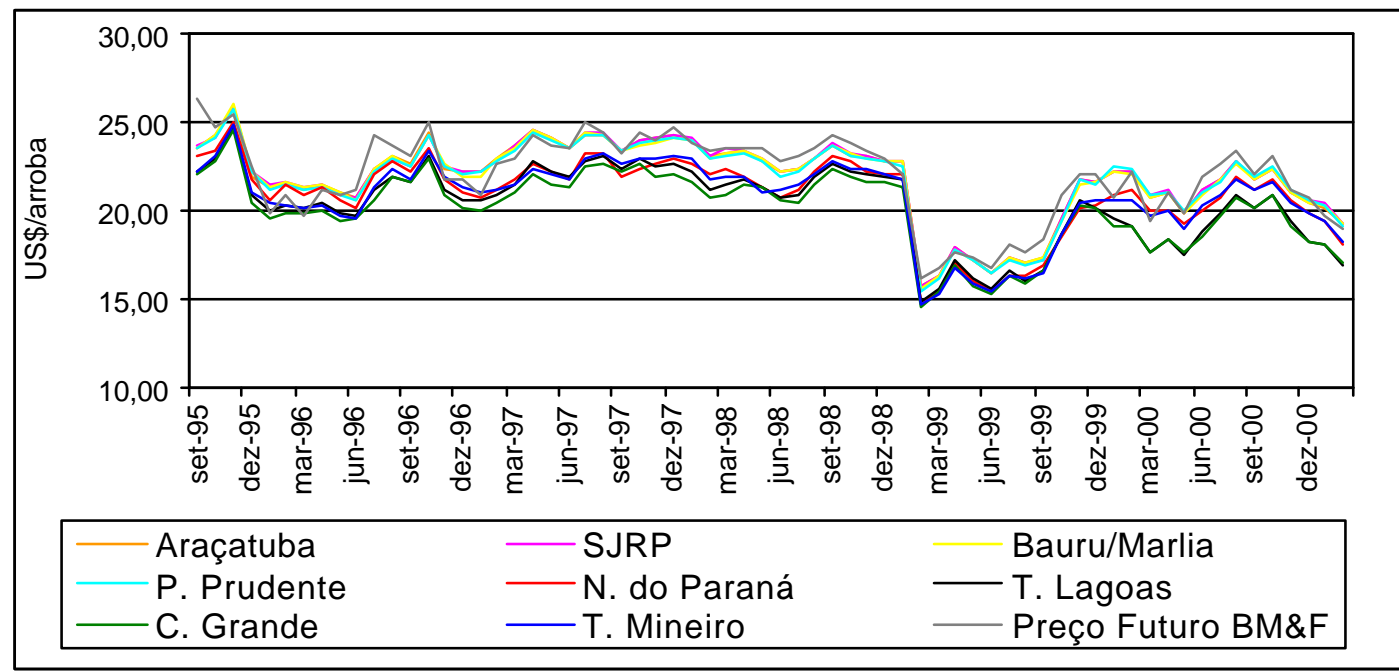

Figura 5 - Médias semanais dos preços futuros do boi gordo na BM\&F ( $1^{\circ}$ vencimento) e dos preços à vista (em US\$) nas regiões de Araçatuba, Noroeste do Paraná, São José do Rio Preto, Três Lagoas, Bauru/Marília, Campo Grande, Presidente Prudente e Triângulo Mineiro.

Fonte: CEPEA/FEALQ/USP (2001) e BM\&F (2001) 


\section{RESULTADOS E DISCUSSÃO}

\subsection{Análise do risco de base}

No período de análise, setembro de 1995 a fevereiro de 2001, totalizaram-se 58 contratos futuros de boi gordo na BM\&F. Nas semanas de vencimento de cada contrato, foram calculadas as bases dos preços do boi gordo e do bezerro e obtidas as variâncias e as médias das bases para cada região, somando oito pares dos respectivos cálculos.

A Tabela 6 traz os resultados do valor médio da base por unidade do animal e do risco de base associados às operações de hedge do boi gordo e de cross hedge do bezerro. $\mathrm{O}$ valor médio da base do bezerro foi bastante superior em todas as regiões de análise. Além disso, o risco de base nas operações de cross hedge é significativamente maior que o risco associado ao hedge do boi gordo.

Nas semanas de vencimento do contrato futuro de boi gordo, o maior valor médio da base do bezerro ocorreu em Três Lagoas (-US\$ 222,12), enquanto o menor valor se deu em Presidente Prudente (-US\$ 209,54). Com relação à base associada ao boi gordo, a maior e a menor média se verificaram em Campo Grande (-US\$ 32,74) e São José do Rio Preto (-US\$ 2,67), respectivamente. A evolução das bases, nas semanas de vencimento do contrato de boi gordo da BM\&F, pode ser visualizada nos Anexos B, C, D e E. 
Tabela 6. Valor médio e variância da base (risco de base) na semana de vencimento do contrato para boi gordo e bezerro no período entre setembro de 1995 e fevereiro de 2001 .

\begin{tabular}{lrrrr}
\hline \multirow{2}{*}{ Região } & \multicolumn{2}{c}{$\begin{array}{c}\text { Valor Médio da Base } \\
\text { (US\$) }\end{array}$} & \multicolumn{2}{c}{$\begin{array}{c}\text { Risco de Base } \\
\left(\text { US\$ }^{2}\right)\end{array}$} \\
\cline { 2 - 5 } & \multicolumn{1}{c}{ Bezerro } & \multicolumn{1}{c}{ Boi Gordo } & \multicolumn{1}{c}{ Bezerro } & Boi Gordo \\
\hline Araçatuba & $-211,19$ & $-2,98$ & 947,01 & 20,60 \\
Bauru & $-210,52$ & $-3,93$ & $1.094,35$ & 23,60 \\
S.J. do Rio Preto & $-212,02$ & $-2,67$ & 934,50 & 23,63 \\
Presidente Prudente & $-209,54$ & $-4,51$ & 896,33 & 25,45 \\
Triângulo Mineiro & $-216,46$ & $-21,03$ & 902,69 & 42,09 \\
Campo Grande & $-220,16$ & $-32,74$ & 998,09 & 76,42 \\
Noroeste do Paraná & $-215,93$ & $-20,32$ & $1.182,85$ & 63,44 \\
Três Lagoas & $-222,12$ & $-27,47$ & 964,82 & 79,64 \\
\hline Fonte: resultados da pesquisa & & & &
\end{tabular}

Para se realizar uma análise comparativa do risco de base entre o boi gordo e bezerro e entre as diferentes localidades, foi realizada a estimação do modelo apresentado pela equação (25).

A Tabela 7 mostra os resultados deste procedimento. A regressão se apresentou significativa a $1 \%$, com o valor da estatística $F$ igual a 35,65. Além disso, o modelo considerado explicou boa parte da variação do desvio padrão da base, já que o coeficiente de determinação da regressão se apresentou bastante elevado $\left(R^{2}=0,9760\right)$.

Tabela 7. Resultados da regressão do logaritmo neperiano do desvio padrão da base na semana de vencimento do contrato em função de variáveis binárias para tipo do animal e localização.

\begin{tabular}{lcc}
\hline \multicolumn{1}{c}{ Variáveis } & Estimativa dos Parâmetros & Valores de t \\
\hline Tipo & $-1,6224$ & $-16,63^{*}$ \\
L1 (Araçatuba) & 3,2808 & $22,42^{*}$ \\
L2 (Bauru/Marília) & 3,3510 & $22,90^{*}$ \\
L3 (São José do Rio Preto) & 3,3119 & $22,64^{*}$ \\
L4 (Presidente Prudente) & 3,3199 & $22,69^{*}$ \\
L5 (Triângulo Mineiro) & 3,4475 & $23,56^{*}$ \\
L6 (Campo Grande) & 3,6217 & $24,75^{*}$ \\
L7 (Noroeste do Paraná) & 3,6177 & $24,73^{*}$ \\
L8 (Três Lagoas) & 3,6236 & $24,77^{*}$ \\
\hline
\end{tabular}

Fonte: resultados da pesquisa

Notas: *significativo a $1 \% ; * *$ significativo a $2 \%$ 
Para obter o efeito das variáveis binárias referentes ao tipo do animal e localização (Tipo e $\mathrm{Lj}$ ) sobre a variável dependente (desvio padrão da base), realizou-se a transformação descrita pela equação (39). Isso se deve ao fato de se utilizar a variável dependente em logaritmo.

$$
\text { Efeito }=\exp (\text { coeficiente })-1
$$

Verifica-se pela variável binária Tipo que o risco de base difere, de forma significativa, entre o boi e o bezerro. Sendo o coeficiente desta variável negativo, após aplicar as transformações acima citadas, constatou-se que o desvio padrão da base do boi gordo foi $80,25 \%$ inferior ao desvio padrão da base do bezerro.

Outro importante resultado se refere aos valores dos coeficientes das variáveis binárias para localização. Tais valores se apresentaram positivos e estatisticamente significativos. Além disso, ao comparar os coeficientes relativos às regiões do IBG (Araçatuba, São José do Rio Preto, Presidente Prudente e Bauru/Marília) com as demais, conclui-se que o risco de base foi inferior para este primeiro grupo, o que está de acordo com os resultados obtidos por Rochelle (1997).

De forma a analisar se o risco de base difere estatisticamente entre as regiões, foram realizados testes de hipóteses sobre a variância da base do boi gordo e do bezerro nas semanas de vencimento do contrato do boi gordo na BM\&F. Considerou-se como hipótese nula a igualdade da variância da base entre duas regiões, contra a hipótese alternativa de que estas variâncias seriam diferentes. Pela estatística " $F$ ", testou-se 28 combinações de valores correspondentes ao risco de base.

O risco de base para as operações com boi gordo nas regiões do IBG se mostrou estatisticamente inferior às demais (Tabela 8). Além disso, constatou-se que entre as regiões que compõem este índice, o risco de base não difere estatisticamente. Este 
último resultado se explica pelo fato do índice ser calculado com base nas cotações dos principais centros de comercialização de boi gordo do Estado de São Paulo.

Cabe ainda destacar que não se observaram diferenças estatisticamente significativas entre as regiões que apresentaram os maiores riscos de base (Campo Grande, Três Lagoas e Noroeste do Paraná).

Já em relação aos resultados para o bezerro, não foi obtida nenhuma diferença estatisticamente significativa entre os riscos de base das regiões em análise. 
Tabela 8. Resultados dos testes "F" sobre a igualdade da variância da base do boi e do bezerro nas semanas de vencimento do contrato futuro de boi gordo da BM\&F no período entre setembro de 1995 e fevereiro de 2001.

\begin{tabular}{|c|c|c|c|}
\hline \multirow{2}{*}{ Hipóteses Nulas } & \multicolumn{2}{|l|}{ Boi } & \multirow{2}{*}{$\begin{array}{l}\text { Bezerro } \\
\text { Teste F }\end{array}$} \\
\hline & Teste F & & \\
\hline $\mathrm{H}_{0}:$ Araçatuba $=$ Bauru/Marília & 1,1457 & & 1,1556 \\
\hline $\mathrm{H}_{0}$ : Araçatuba $=$ Campo Grande & 3,7101 & $*$ & 1,0539 \\
\hline $\mathrm{H}_{0}:$ Araçatuba $=$ Três Lagoas & 3,8663 & $*$ & 1,0188 \\
\hline $\mathrm{H}_{0}:$ Araçatuba $=$ Triângulo Mineiro & 2,0435 & $*$ & 1,0491 \\
\hline $\mathrm{H}_{0}$ : Araçatuba $=$ Presidente Prudente & 1,2355 & & 1,0565 \\
\hline $\mathrm{H}_{0}:$ Araçatuba $=$ Noroeste do Paraná & 3,0798 & $*$ & 1,2490 \\
\hline $\mathrm{H}_{0}$ : Araçatuba = São José do Rio Preto & 1,1473 & & 1,0134 \\
\hline $\mathrm{H}_{0}$ : Bauru/Marília = Campo Grande & 3,2383 & $*$ & 1,0964 \\
\hline $\mathrm{H}_{0}$ : Bauru/Marília = Três Lagoas & 3,3746 & $*$ & 1,1342 \\
\hline $\mathrm{H}_{0}$ : Bauru/Marília = Triângulo Mineiro & 1,7836 & $* *$ & 1,2123 \\
\hline $\mathrm{H}_{0}$ : Bauru/Marília = Presidente Prudente & 1,0783 & & 1,2209 \\
\hline $\mathrm{H}_{0}$ : Bauru/Marília = Noroeste do Paraná & 2,6882 & $*$ & 1,0809 \\
\hline $\mathrm{H}_{0}:$ Bauru/Marília = São José do Rio Preto & 1,0014 & & 1,1710 \\
\hline $\mathrm{H}_{0}$ : Campo Grande $=$ Três Lagoas & 1,0420 & & 1,0345 \\
\hline $\mathrm{H}_{0}$ : Campo Grande $=$ Triângulo Mineiro & 1,8156 & $* *$ & 1,1057 \\
\hline $\mathrm{H}_{0}$ : Campo Grande $=$ Presidente Prudente & 3,0030 & $*$ & 1,1135 \\
\hline $\mathrm{H}_{0}$ : Campo Grande $=$ Noroeste do Paraná & 1,2046 & & 1,1851 \\
\hline $\mathrm{H}_{0}$ : Campo Grande =São José do Rio Preto & 3,2336 & $*$ & 1,0681 \\
\hline $\mathrm{H}_{0}$ : Três Lagoas $=$ Triângulo Mineiro & 1,8919 & $* *$ & 1,0325 \\
\hline $\mathrm{H}_{0}$ : Três Lagoas $=$ Presidente Prudente & 3,1294 & $*$ & 1,0764 \\
\hline $\mathrm{H}_{0}$ : Três Lagoas $=$ Noroeste do Paraná & 1,2553 & & 1,4512 \\
\hline $\mathrm{H}_{0}$ : Três Lagoas $=$ São José do Rio Preto & 3,3698 & $*$ & 1,0688 \\
\hline $\mathrm{H}_{0}$ : Triângulo Mineiro = Presidente Prudente & 1,7811 & $* *$ & 1,0071 \\
\hline $\mathrm{H}_{0}$ : Triângulo Mineiro = Noroeste do Paraná & 1,5071 & & 1,3104 \\
\hline $\mathrm{H}_{0}$ : Triângulo Mineiro = São José do Rio Preto & 1,7811 & $* *$ & 1,0352 \\
\hline $\mathrm{H}_{0}$ : Presidente Prudente $=$ Noroeste do Paraná & 2,4929 & $*$ & 1,3197 \\
\hline $\mathrm{H}_{0}$ : Presidente Prudente =São José do Rio Preto & 1,0767 & & 1,0426 \\
\hline $\mathrm{H}_{0}$ : Noroeste do Paraná =São José do Rio Preto & 2,6843 & $*$ & 1,2658 \\
\hline
\end{tabular}

Fonte: resultados da pesquisa

Notas: * valor de F significativo a 1\%; ** valor de F significativo a 5\% 


\subsection{Estimação das razões ótimas das operações de hedge e sua efetividade}

\subsubsection{Identificação dos processos auto-regressivos}

O primeiro passo para a realização da estimação da razão de hedge ótima e assim obter a efetividade da operação consiste na identificação dos processos auto-regressivos geradores das séries.

Observa-se pela Tabela 9, a ordem dos processos auto-regressivos das séries semanais dos preços à vista do bezerro e do boi gordo, de acordo com sua região, e do preço futuro do boi gordo na $\mathrm{BM} \& \mathrm{~F}$. Tais resultados foram obtidos mediante os Critérios de Informação de Akaike (AIC) e Schwarz (SC) (Anexos F, G, H e I). Em alguns casos, os menores valores encontrados do AIC e SC para estas séries diferem conforme o critério utilizado. Neste sentido, foi utilizada a menor defasagem indicada por um dos critérios. No entanto, ao realizar os testes de raiz unitária, foram analisados os resíduos, no que diz respeito à existência de autocorrelação. Ao apresentar autocorrelação nos resíduos, o modelo foi reespecificado, levando em conta a defasagem indicada pelo outro critério.

Tabela 9. Ordem dos processos auto-regressivos das séries de preços à vista de bezerro e boi gordo e do preço futuro de boi gordo da BM\&F indicada pelo AIC e SC.

\begin{tabular}{|c|c|c|c|c|}
\hline \multirow[b]{3}{*}{ Preços do boi gordo } & \multirow{2}{*}{\multicolumn{2}{|c|}{$\begin{array}{c}\text { Série de Preços de Boi Gordo } \\
\text { AR }(p) \text { indicada pelo: }\end{array}$}} & \multirow{2}{*}{\multicolumn{2}{|c|}{$\begin{array}{c}\text { Série de Preços de Bezerro } \\
\mathrm{AR}(\mathrm{p}) \text { indicada pelo: }\end{array}$}} \\
\hline & & & & \\
\hline & AIC & $\mathrm{SC}$ & AIC & $\mathrm{SC}$ \\
\hline \multicolumn{5}{|l|}{ A vista } \\
\hline Araçatuba & $\mathrm{p}=8$ & $\mathrm{p}=2$ & $\mathrm{p}=3$ & $\mathrm{p}=2$ \\
\hline Bauru/Marília & $\mathrm{p}=8$ & $\mathrm{p}=2$ & $\mathrm{p}=3$ & $\mathrm{p}=2$ \\
\hline São José do Rio Preto & $p=7$ & $p=2$ & $p=2$ & $p=1$ \\
\hline Presidente Prudente & $p=7$ & $\mathrm{p}=2$ & $\mathrm{p}=8$ & $\mathrm{p}=1$ \\
\hline Triângulo Mineiro & $p=7$ & $\mathrm{p}=2$ & $\mathrm{p}=3$ & $\mathrm{p}=3$ \\
\hline Campo Grande & $\mathrm{p}=11$ & $\mathrm{p}=2$ & $\mathrm{p}=3$ & $\mathrm{p}=3$ \\
\hline Noroeste do Paraná & $p=2$ & $p=2$ & $\mathrm{p}=4$ & $p=2$ \\
\hline Três Lagoas & $\mathrm{p}=7$ & $p=2$ & $\mathrm{p}=11$ & $\mathrm{p}=4$ \\
\hline Futuro (BM\&F) & $\mathrm{p}=2$ & $\mathrm{p}=2$ & - & - \\
\hline
\end{tabular}

Fonte: resultados da pesquisa 


\subsubsection{Teste de raiz unitária}

Definidas a ordem do processo auto-regressivo, foram realizados testes de raiz unitária, mediante os testes de Dikey e Fuller (DF) e Dickey \& Fuller Aumentado (DFA). Os passos para tal análise seguem o procedimento descrito por Enders (1985), mencionado no Anexo A.

Como os teses de raiz unitária não são válidos na presença de autocorrelação dos resíduos, foram analisadas as estatísticas Q de Ljung Box dos modelos em questão. Para os modelos que apresentaram autocorrelação nos resíduos, utilizou-se a defasagem indicada pelo critério alternativo, como já descrito anteriormente. Ao realizar tal alteração para estes casos, observou-se, mediante a estatística Q de Ljung Box, que os resíduos dos modelos estimados para se proceder ao teste de raiz unitária se apresentaram não correlacionados, validando, assim, os testes realizados.

Os resultados do teste de raiz unitária para as séries de preço à vista do bezerro e do boi gordo, em nível, e para a série de preço futuro de boi gordo, em nível, são apresentados na Tabela 10 e 11. Verifica-se que os elementos deterministas tendência e constante não devem ser incluídos em nenhum dos modelos, já que as estatísticas calculadas $\hat{o}_{\hat{o}}$, ôâ̂o, ồi e ốá não são significativas. Dessa forma, ao comparar o valor obtido da estatística ô com seu valor crítico, conclui -se que as séries, em nível, apresentaram raiz unitária. Além disso, foram realizados testes de raiz unitária com as séries nas primeiras diferenças. Os resultados podem ser vistos na Tabela 12 e 13 . Mediante os valores obtidos, a hipótese de raiz unitária é rejeitada em todas as séries, com um nível de significância de $1 \%$. Ou seja, as séries de preços de bezerro e boi gordo são estacionárias nas primeiras diferenças. 
Tabela 10. Resultados da identificação dos elementos deterministas e teste de raiz unitária para as séries de preços semanais à vista e futuro de boi gordo no período entre setembro de 1995 e fevereiro de 2001.

\begin{tabular}{lcccccc}
\hline $\begin{array}{l}\text { Série de Preços do Boi } \\
\text { Gordo em Nível }\end{array}$ & Defasagens & $\hat{\mathrm{o}}_{\hat{o}}$ & $\hat{\mathrm{o}}_{\hat{a} \hat{o}}$ & $\hat{\mathrm{o}}_{\grave{i}}$ & $\hat{\mathrm{o}}_{\mathfrak{a} \mathbf{i}}$ & $\hat{\mathrm{o}}$ \\
\hline À Vista & 7 & $-2,47$ & $-0,82$ & $-2,35$ & 2,33 & $-0,66$ \\
$\quad$ Araçatuba & 7 & $-2,46$ & $-0,84$ & $-2,33$ & 2,31 & $-0,65$ \\
$\quad$ Bauru/Maŕlia & 6 & $-2,59$ & $-1,00$ & $-2,39$ & 2,37 & $-0,56$ \\
$\quad$ São José do Rio Preto & 6 & $-2,62$ & $-0,97$ & $-2,43$ & 2,42 & $-0,55$ \\
$\quad$ Presidente Prudente & 6 & $-2,59$ & $-0,86$ & $-2,45$ & 2,44 & $-0,57$ \\
$\quad$ Triângulo Mineiro & 10 & $-2,57$ & $-1,29$ & $-2,22$ & 2,20 & $-0,59$ \\
$\quad$ Campo Grande & 1 & $-2,76$ & $-1,19$ & $-2,49$ & 2,48 & $-0,50$ \\
$\quad$ Noroeste do Paraná & 6 & $-2,84$ & $-1,45$ & $-2,44$ & $-2,41$ & $-0,62$ \\
$\quad$ Três Lagoas & 1 & $-2,93$ & $-0,89$ & $-2,79$ & 2,78 & $-0,58$ \\
Futuro (BM\&F) & & $-3,99$ & 3,49 & $-3,45$ & 3,19 & $-2,58$ \\
\hline Valor Crítico* & & & & & & \\
\hline
\end{tabular}

Fonte: resultados da pesquisa

Nota: * valor crítico a $1 \%$ de significância

Tabela 11. Resultados da identificação dos elementos deterministas e teste de raiz unitária para as séries semanais de preços à vista de bezerro no período entre setembro de 1995 e fevereiro de 2001.

\begin{tabular}{lcccccc}
\hline $\begin{array}{l}\text { Série de Preços do Bezerro } \\
\text { em Nível }\end{array}$ & Defasagens & $\hat{\mathrm{o}}_{\hat{\mathrm{o}}}$ & $\hat{\mathrm{o}}_{\hat{\mathrm{a}} \mathrm{o}}$ & $\hat{\mathrm{o}}_{\grave{i}}$ & $\hat{\mathrm{o}}_{\text {á̀ }}$ & $\hat{\mathrm{o}}$ \\
\hline Araçatuba & 2 & $-2,18$ & 0,48 & $-2,13$ & 2,14 & 0,15 \\
Bauru/Marília & 2 & $-2,27$ & 2,27 & $-2,18$ & 0,03 & 0,19 \\
São José do Rio Preto & 1 & $-2,44$ & 0,67 & $-2,35$ & 2,35 & 0,07 \\
Presidente Prudente & 7 & $-2,13$ & 0,48 & $-2,08$ & 2,08 & 0,13 \\
Triângulo Mineiro & 2 & $-2,49$ & 0,68 & $-2,40$ & 2,41 & 0,26 \\
Campo Grande & 2 & $-2,39$ & 0,17 & $-2,40$ & 2,40 & $-0,02$ \\
$\quad$ Noroeste do Paraná & 3 & $-3,23$ & 1,03 & $-3,05$ & 3,05 & 0,03 \\
$\quad$ Três Lagoas & 3 & $-2,43$ & $-0,12$ & $-2,46$ & 2,47 & 0,13 \\
Valor Crítico* & & $-3,99$ & 3,49 & $-3,45$ & 3,19 & $-2,58$ \\
\hline
\end{tabular}

Fonte: resultados da pesquisa

Nota: * valor crítico a $1 \%$ de significância 
Tabela 12. Resultados da identificação dos elementos deterministas e teste de raiz unitária para as séries de preços semanais à vista e futuro de boi gordo na primeira diferença no período entre setembro de 1995 e fevereiro de 2001.

\begin{tabular}{lc}
\hline Série de Preços do Boi Gordo $\left(1^{\circ}\right.$ Diferença) & $\hat{\mathrm{o}}$ \\
\hline À Vista & \\
Araçatuba & $-6,83$ \\
Bauru/Marília & $-6,81$ \\
São José do Rio Preto & $-7,01$ \\
Presidente Prudente & $-6,88$ \\
Triângulo Mineiro & $-6,98$ \\
Campo Grande & $-6,14$ \\
Noroeste do Paraná & $-11,08$ \\
Três Lagoas & $-6,91$ \\
Futuro Boi (BM\&F) & $-11,33$ \\
Valor Crítico* & $-2,58$ \\
\hline
\end{tabular}

Fonte: resultados da pesquisa

Nota: * valor crítico a $1 \%$ de significância

Tabela 13. Resultados da identificação dos elementos deterministas e teste de raiz unitária para as séries de preços à vista semanais de bezerro na primeira diferença no período entre setembro de 1995 e fevereiro de 2001.

\begin{tabular}{lc}
\hline Série de Preços do Bezerro $\left(1^{\circ}\right.$ Diferença $)$ & $\hat{o}$ \\
\hline Araçatuba & $-10,53$ \\
Bauru/Marília & $-9,39$ \\
São José do Rio Preto & $-12,01$ \\
Presidente Prudente & $-6,45$ \\
Triângulo Mineiro & $-11,44$ \\
Campo Grande & $-10,51$ \\
Noroeste do Paraná & $-10,56$ \\
Três Lagoas & $-10,91$ \\
Valor Crítico* & $-2,58$ \\
\hline
\end{tabular}

Fonte: resultados da pesquisa

Nota: * valor crítico a $1 \%$ de significância

\subsubsection{Hipótese de mercado futuro eficiente}

Após a identificação da ordem dos processos auto-regressivos e os testes de raiz unitária, a hipótese de mercado futuro eficiente para a série de preço futuro da $B M \& F$ foi analisada. Para tanto, como colocado anteriormente, o procedimento realizado por Saboya \& Bacchi (1999) foi adotado. 
Constatou-se na seção 8.2.1 que o processo auto-regressivo da série de preços futuros do boi gordo da BM\&F possui ordem dois [AR(2)], ou seja, o preço médio observado em uma semana possui relação com o preço das duas semanas anteriores. Este resultado indica que a formação destes preços deve possuir tendenciosidade. No entanto, não se pode concluir de forma definitiva que o mercado, em questão, é ineficiente, pois a ordem do processo auto-regressivo é baixa. Cabe ressaltar que Saboya \& Bacchi (1999), utilizando dados diários dos preços futuros de boi gordo na BM\&F no período entre outubro de 1994 a fevereiro de 1999 e excluindo os contratos de boi gordo que apresentaram baixa liquidez, concluíram que em todos os 39 contratos analisados, o processo auto-regressivo da série de preços foi um $[\mathrm{AR}(1)]$, mostrando haver eficiência neste mercado futuro.

Como não é possível chegar a uma conclusão exata a respeito da eficiência do mercado futuro de boi gordo da $\mathrm{BM} \& \mathrm{~F}$, os cálculos das razões de hedge ótima serão realizados de acordo com a metodologia proposta por Myers \& Thompson (1989), reconhecendo as limitações dos procedimentos, já que uma das hipóteses básicas deste procedimento consiste na eficiência dos preços futuros.

\subsubsection{As razões ótimas de hedge}

Para se obter as estimativas das razões de hedge (cross hedge), os preços à vista do boi gordo (bezerro) estarão em suas primeiras diferenças, sendo suas variáveis explicativas: i) os preços futuros de boi gordo da BM\&F em sua primeira diferença; ii) os preços à vista de boi gordo (bezerro) defasados nas primeiras diferenças e; iii) o preço futuro de boi gordo defasado na primeira diferença. O número de períodos destas defasagens será obtido conforme a ordem dos processos auto-regressivos geradores das séries na primeira diferença (Anexos J. K, L e M).

Dessa forma, o modelo a ser estimado corresponde à equação (40): 
$\Delta P_{t}=\alpha+\delta \Delta F_{t}+\sum_{i=1}^{p} \beta_{i} \Delta P_{t-i}+\gamma \Delta F_{t-1}+u_{t}$

Sendo:

$\ddot{A} P_{t}=$ preço à vista do boi gordo (bezerro) na primeira diferença no momento $t$;

$\ddot{a}=$ razão ótima de hedge;

$\ddot{A} F_{t}=$ preço futuro do boi gordo na BM\&F na primeira diferença;

$\ddot{A} P_{t-i}=$ preço à vista do boi gordo (bezerro) na primeira diferença no momento $t-i$;

$\ddot{A} F_{t-1}=$ preço futuro do boi gordo na BM\&F no momento $t-1$;

$u_{t}=$ termo de erro

As Tabelas 14 e 15 mostram os resultados obtidos nas operações de hedge relativos ao mercado do boi gordo. Já nas Tabelas 16 e 17, estão as estimativas referentes às operações de cross hedge dos preços de bezerro no mercado futuro de boi gordo da BM\&F. Verificou-se, mediante o teste $F$, que todas as regressões são significativas tanto para o boi gordo quanto para o bezerro. Além disso, a razão ótima de hedge, indicada pelo coeficiente $\ddot{a}$, apresentou-se significativa em todos os casos.

Com relação ao hedge dos preços do boi gordo, constatou-se que as razões de hedge foram muito próximas entre as regiões, variando entre 55\% a 63\% (Tabela 15). O maior valor ocorreu com o modelo relativo a Três Lagoas - a proporção da posição à vista a ser compensada com os contratos futuros de boi gordo, com o objetivo de minimizar o risco das posições à vista, foi de 62,22\%. Já a menor razão de hedge foi verificada no Triângulo Mineiro (55,84\%).

Já quanto às operações de cross hedge dos preços de bezerro, as proporções da posição à vista a ser compensada com os contratos futuros de boi gordo também se mostraram muito próximas - entre 37\% a 49\%. A maior razão de hedge também ocorreu 
com o modelo relativo a Três Lagoas $(48,27 \%)$. As razões dos modelos do Triângulo Mineiro e Presidente Prudente também se apresentaram elevadas, $47,84 \%$ e $43,81 \%$ respectivamente. Os resultados mais baixos ocorreram com os modelos de Campo Grande e Noroeste do Paraná - 37,41\% e 38,69\% respectivamente. 
Tabela 14. Resultados das estimativas das razões de hedge dos preços semanais do boi gordo em Três Lagoas, Araçatuba, Bauru/Marília e Campo Grande no mercado futuro de boi gordo da BM\&F no período entre setembro de 1995 e fevereiro de 2001.

\begin{tabular}{|c|c|c|c|c|}
\hline & Três Lagoas & Araçatuba & Bauru/Marília & Campo Grande \\
\hline Análise de Regressão & $\mathrm{F}=119,19 *$ & $\mathrm{~F}=120,51^{*}$ & $\mathrm{~F}=111,56^{*}$ & $\mathrm{~F}=91,50^{*}$ \\
\hline Variáveis & \multicolumn{4}{|c|}{ Coeficientes } \\
\hline Constante & $-7,8600(-0,08)$ & $-19,7000(-0,02)$ & $3,2100(0,03)$ & $-0,0001(-0,09)$ \\
\hline$\ddot{a}$ & $0,6222^{*}(16,73)$ & $0,5835^{*}(16,62)$ & $0,5836^{*}(16,80)$ & $0,6019 *(14,41)$ \\
\hline$P_{t-1}$ & $0,0303(0,50)$ & $0,0665(1,09)$ & $0,0030(0,05)$ & $0,0220(0,37)$ \\
\hline$F_{t-1}$ & $0,1189 * *(2,29)$ & $0,0840 * *(1,71)$ & $0,1508 *(3,05)$ & $0,0542 *(3,04)$ \\
\hline
\end{tabular}

Fonte: resultados da pesquisa

Notas: os valores da estatística t se encontram entre parênteses; *significativo a $1 \%$; **significativo a 5\%; ***significativo a $10 \%$

Tabela 15. Resultados das estimativas das razões de hedge dos preços semanais do boi gordo no Noroeste do Paraná, Presidente Prudente, São José do Rio Preto e Triângulo Mineiro no mercado futuro de boi gordo da BM\&F no período entre setembro de 1995 e fevereiro de 2001.

\begin{tabular}{|c|c|c|c|c|}
\hline & Noroeste do Paraná & Presidente Prudente & São José do Rio Preto & Triângulo Mineiro \\
\hline Análise de Regressão & $\mathrm{F}=90,39 *$ & $\mathrm{~F}=107,94 *$ & $\mathrm{~F}=115,42 *$ & $\mathrm{~F}=105,38^{*}$ \\
\hline Variáveis & \multicolumn{4}{|c|}{ Coeficientes } \\
\hline Constante & $-4,9700(-0,04)$ & $1,4500(0,01)$ & $3,7800(0,03)$ & $7,0500(0,07)$ \\
\hline$\ddot{a}$ & $0,6147 *(15,00)$ & $0,5951 *(16,08)$ & $0,5997 *(16,58)$ & $0,5584 *(15,31)$ \\
\hline$P_{t-1}$ & $-0,0912(-1,54)$ & $0,0371(0,61)$ & $0,0306(0,51)$ & $0,0975(0,10)$ \\
\hline$F_{t-1}$ & $0,2079 *(3,84)$ & $0,0946 * * *(1,86)$ & $0,1145 *(2,27)$ & $0,0888 * * *(1,81)$ \\
\hline
\end{tabular}

Fonte: resultados da pesquisa

Notas: os valores da estatística t se encontram entre parênteses; *significativo a $1 \%$; **significativo a $5 \%$; ***significativo a $10 \%$ 
Tabela 16. Resultados das estimativas das razões de cross hedge dos preços semanais do bezerro em Três Lagoas, Araçatuba, Bauru/Marília e Campo Grande no mercado futuro de boi gordo da BM\&F no período entre setembro de 1995 e fevereiro de 2001.

\begin{tabular}{ccccc}
\hline & Três Lagoas & Araçatuba & Bauru/Marília & Campo Grande \\
\hline Análise de Regressão & $\mathrm{F}=11,64^{*}$ & $\mathrm{~F}=16,08$ & $\mathrm{~F}=12,23^{*}$ & $\mathrm{~F}=12,15^{*}$ \\
\hline Variáveis & & Coeficientes & & $0,0007(0,29)$ \\
\hline Constante & $0,0014(0,42)$ & $0,0012(0,56)$ & $0,0012(0,51)$ & $0,3741^{*}(4,27)$ \\
$\ddot{a}$ & $0,4827^{*}(3,91)$ & $0,4055^{*}(5,01)$ & $0,4112^{*}(4,55)$ & $-0,1792^{*}(-3,11)$ \\
$P_{t-1}$ & $-0,3847^{*}(-6,52)$ & $-0,2924^{*}(-5,05)$ & $-0,3096^{*}(-5,26)$ & $-0,2540^{*}(-4,53)$ \\
$P_{t-2}$ & $-0,2378^{*}(-3,94)$ & $-0,1538^{*}(-2,77)$ & $-0,1571^{*}(-2,74)$ & - \\
$P_{t-3}$ & $-0,1432^{* *}(-2,47)$ & - & $0,1974^{* *}(2,11)$ & $0,2461^{*}(2,73)-$ \\
$F_{t-1}$ & $0,2841^{* *}(2,23)$ & $0,3292^{*}(3,88)$ &
\end{tabular}

Fonte: resultados da pesquisa

Notas: os valores da estatística t se encontram entre parênteses; *significativo a $1 \% ; * *$ significativo a $5 \%$; ***significativo a $10 \%$ 
Tabela 17. Resultados das estimativas das razões de cross hedge dos preços semanais do bezerro no Noroeste do Paraná, Presidente Prudente, São José do Rio Preto e Triângulo Mineiro no mercado futuro de boi gordo da BM\&F no período entre setembro de 1995 e fevereiro de 2001.

\begin{tabular}{|c|c|c|c|c|}
\hline & Noroeste do Paraná & Presidente Prudente & São José do Rio Preto & Triângulo Mineiro \\
\hline Análise de & $\mathrm{F}=10,44^{*}$ & $\mathrm{~F}=8,88^{*}$ & $\mathrm{~F}=14,14^{*}$ & $\mathrm{~F}=18,20^{*}$ \\
\hline Variáveis & \multicolumn{4}{|c|}{ Coeficientes } \\
\hline Constante & $0,0008(0,27)$ & $0,0009(0,49)$ & $0,0010(0,44)$ & $0,0019(0,58)$ \\
\hline$\ddot{a}$ & $0,3869 *(3,45)$ & $0,4381 *(6,43)$ & $0,4123 *(4,89)$ & $0,4784 *(3,84)$ \\
\hline$P_{t-1}$ & $-0,3403 *(-5,72)$ & $-0,1458 * *(-2,42)$ & $-0,2223 *(-3,81)$ & $-0,4489 *(-7,71)$ \\
\hline$P_{t-2}$ & $-0,0967(-1,58)$ & $-0,0387(0,68)$ & - & $-0,2374 *(-4,13)$ \\
\hline$P_{t-3}$ & $-0,1467 *(-2,52)$ & $-0,0445(-0,82)$ & - & - \\
\hline$P_{t-4}$ & - & $-0,0127(-0,23)$ & - & - \\
\hline$P_{t-5}$ & - & $0,1972 *(3,65)$ & - & - \\
\hline$P_{t-6}$ & - & $0,0131(0,23)$ & - & - \\
\hline$P_{t-7}$ & - & $-0,1962 *(-3,51)$ & - & - \\
\hline$F_{t-1}$ & $0,1926 * * *(1,68)$ & $0,0955(1,29)$ & $0,2457 *(2,84)$ & $0,2884 * *(2,26)$ \\
\hline
\end{tabular}

Fonte: resultados da pesquisa

Notas: os valores da estatística t se encontram entre parênteses; *significativo a $1 \%$; **significativo a $5 \%$; ***significativo a $10 \%$ 
Para verificar o efeito da sazonalidade nas razões de hedge, foi inserida uma variável dummy nos modelos, como mostra a equação (40’). Ou seja, buscou-se captar as diferenças que os coeficientes de inclinação, que correspondem à razão de hedge, podem apresentar nos períodos de safra e entressafra. Para os modelos referentes às operações de hedge dos preços do boi gordo, levou-se em consideração uma variável dummy com valor um no período da safra $\left(1^{\circ}\right.$ semestre) e valor zero na entressafra ( $2^{\circ}$ semestre). Já no caso dos modelos de cross hedge dos preços do bezerro, a dummy teve valor um nos meses de abril a julho (período da safra) e valor zero para os demais meses. Os resultados podem ser observados pelas Tabelas 18, 19, 20 e 21.

$\Delta P_{t}=\alpha+\delta \Delta F_{t}+\sum_{i=1}^{p} \beta_{i} \Delta P_{t-i}+\gamma \Delta F_{t-1}+\gamma D_{i} \Delta F_{t}+u_{t}$

Nas operações de hedge do boi gordo, a variável dummy se mostrou significativa nos modelos referentes à Araçatuba, Bauru, Presidente Prudente, São José do Rio Preto e Triângulo Mineiro, indicando que a razão de hedge ótima no período da safra é superior à da entressafra. Percebe-se, portanto, que, em todas as regiões do IBG, as razões ótimas de hedge foram distintas de forma significativa. Cabe ainda observar que a região do Triângulo Mineiro apresentou a diferença mais acentuada, tendo uma razão de hedge de $45,52 \%$ na entressafra e $61,99 \%$ na safra.

Já no cross hedge do bezerro, a variável dummy foi significativa somente em três modelos, Araçatuba, Presidente Prudente e Triângulo Mineiro. Observa-se pelas Tabelas 20 e 21, que ao contrário dos resultados observados no hedge com boi gordo, a razão do cross hedge se mostrou bastante inferior no período da safra. Novamente, o modelo relativo ao Triângulo Mineiro obteve as maiores diferenças, enquanto a razão na safra foi de $6,71 \%$, na entressafra este valor foi de $61,25 \%$. 
Tabela 18. Resultados das estimativas das razões de hedge dos preços semanais do boi gordo em Três Lagoas, Araçatuba, Bauru/Marília e Campo Grande com a inclusão da variável dummy no período entre setembro de 1995 e fevereiro de 2001.

\begin{tabular}{|c|c|c|c|c|}
\hline & Três Lagoas & Araçatuba & Bauru/Marília & Campo Grande \\
\hline Análise de Regressão & $\mathrm{F}=89,98^{*}$ & $\mathrm{~F}=91,79 *$ & $\mathrm{~F}=86,05^{*}$ & $\mathrm{~F}=68,75^{*}$ \\
\hline Variáveis & \multicolumn{4}{|c|}{ Coeficientes } \\
\hline Constante & $-0,0002(-0,20)$ & $-0,0002(-0,16)$ & $0,0002(-0,17)$ & $-0,0002(-0,17)$ \\
\hline$\ddot{a}$ & $0,5647 *(9,59)$ & $0,5094 *(9,23)$ & $0,4854 *(8,52)$ & $0,5568^{*}(8,32)$ \\
\hline$P_{t-1}$ & $0,0286(0,48)$ & $0,0631(1,04)$ & $-0,0003(-0,01)$ & $0,0225(0,38)$ \\
\hline$F_{t-1}$ & $0,1207 * *(2,33)$ & $0,0870 * * *(1,78)$ & $0,1541 *(3,14)$ & $0,1654^{*}(3,05)$ \\
\hline$\tilde{a}$ & $0,0919(1,25)$ & $0,1188 * * *(1,73)$ & $0,1571 * *(2,21)$ & $0,0717(0,86)$ \\
\hline
\end{tabular}

Fonte: resultados da pesquisa

Notas: os valores da estatística t se encontram entre parênteses; *significativo a $1 \%$; **significativo a $5 \%$; ***significativo a $10 \%$

Tabela 19. Resultados das estimativas das razões de hedge dos preços semanais do boi gordo no Noroeste do Paraná, Presidente Prudente, São José do Rio Preto e Triângulo Mineiro com inclusão da variável dummy no período entre setembro de 1995 e fevereiro de 2001.

\begin{tabular}{|c|c|c|c|c|}
\hline & Noroeste do Paraná & Presidente Prudente & São José do Rio Preto & Triângulo Mineiro \\
\hline Análise de Regressão & $\mathrm{F}=68,75^{*}$ & $\mathrm{~F}=82,81^{*}$ & $\mathrm{~F}=90,57^{*}$ & $\mathrm{~F}=81,57^{*}$ \\
\hline Variáveis & \multicolumn{4}{|c|}{ Coeficientes } \\
\hline Constante & $-0,0002(-0,19)$ & $-0,0002(-0,17)$ & $-0,0001(-0,12)$ & $-0,0001(-0,14)$ \\
\hline$\ddot{a}$ & $0,5348^{*}(8,17)$ & $0,5049 *(8,64)$ & $0,5247 *(9,14)$ & $0,4552 *(7,89)$ \\
\hline$P_{t-1}$ & $-0,0992 * * *(-1,68)$ & $0,0331(0,55)$ & $0,0282(0,47)$ & $0,0961 * * *(1,63)$ \\
\hline$F_{t-1}$ & $0,2139 *(3,96)$ & $0,0982 * * *(1,94)$ & $0,1169 * *(2,33)$ & $0,0909 * * *(1,86)$ \\
\hline$\tilde{a}$ & $0,1288(1,56)$ & $0,1446 * *(1,99)$ & $0,1201 * * *(1,68)$ & $0,1647 * *(2,29)$ \\
\hline
\end{tabular}

Fonte: resultados da pesquisa

Notas: os valores da estatística t se encontram entre parênteses; *significativo a $1 \%$; **significativo a $5 \%$; ***significativo a $10 \%$ 
Tabela 20. Resultados das estimativas das razões de cross hedge dos preços semanais do bezerro em Três Lagoas, Araçatuba, Bauru/Marília e Campo Grande com a inclusão da variável dummy no período entre setembro de 1995 e fevereiro de 2001.

\begin{tabular}{|c|c|c|c|c|}
\hline & \multicolumn{4}{|c|}{ Preços à vista } \\
\hline & Três Lagoas & Araçatuba & Bauru/Marília & Campo Grande \\
\hline Análise de Regressão & $\mathrm{F}=9,94 *$ & $\mathrm{~F}=13,93^{*}$ & $\mathrm{~F}=9,79 *$ & $\mathrm{~F}=10,27^{*}$ \\
\hline Variáveis & \multicolumn{4}{|c|}{ Coeficientes } \\
\hline Constante & $0,0019(0,55)$ & $0,0018(0,80)$ & $0,0014(0,56)$ & $0,0011(0,46)$ \\
\hline$\ddot{a}$ & $0,5656 *(3,96)$ & $0,5032 *(5,43)$ & $0,4346^{*}(4,15)$ & $0,4538^{*}(4,50)$ \\
\hline$P_{t-1}$ & $-0,3877 *(-6,57)$ & $-0,2966^{*}(-5,15)$ & $-0,3105^{*}(-5,27)$ & $-0,1879 *(-3,26)$ \\
\hline$P_{t-2}$ & $-0,2478^{*}(-4,07)$ & $-0,1595 *(-2,89)$ & $-0,1602 *(-2,77)$ & $-0,2569 *(-4,59)$ \\
\hline$P_{t-3}$ & $-0,1508^{*}(-2,59)$ & - & - & - \\
\hline$F_{t-1}$ & $0,2838 * *(2,24)$ & $0,3225^{*}(3,85)$ & $0,1967 * *(2,10)$ & $0,2447 *(2,72)$ \\
\hline$\tilde{a}$ & $-0,3263(-1,15)$ & $-0,3925^{*}(-2,12)$ & $-0,0928(-0,44)$ & $-0,3178(-1,58)$ \\
\hline
\end{tabular}

Fonte: resultados da pesquisa

Notas: os valores da estatística t se encontram entre parênteses; *significativo a 1\%; **significativo a $5 \%$; ***significativo a $10 \%$ 
Tabela 21. Resultados das estimativas das razões de cross hedge dos preços semanais do bezerro no Noroeste do Paraná, Presidente Prudente, São José do Rio Preto e Triângulo Mineiro com a inclusão da variável dummy no período entre setembro de 1995 e fevereiro de 2001.

\begin{tabular}{|c|c|c|c|c|}
\hline & \multicolumn{4}{|c|}{ Preços à vista } \\
\hline & Noroeste do Paraná & Presidente Prudente & São José do Rio Preto & Triângulo Mineiro \\
\hline Análise de Regressão & $\mathrm{F}=8,68^{*}$ & $\mathrm{~F}=8,86^{*}$ & $\mathrm{~F}=10,92^{*}$ & $\mathrm{~F}=15,44^{*}$ \\
\hline Variáveis & \multicolumn{4}{|c|}{ Coeficientes } \\
\hline Constante & $0,0008(0,25)$ & $-0,0015(0,80)$ & $0,0013(0,56)$ & $0,0027(0,79)$ \\
\hline$\ddot{a}$ & $0,3739 *(2,88)$ & $0,5393 *(6,95)$ & $0,4663 *(4,78)$ & $0,6125 *(4,31)$ \\
\hline$P_{t-1}$ & $-0,3386 *(-5,62)$ & $-0,1608 *(-2,09)$ & $-0,2297 *(-3,91)$ & $-0,4431 *(-7,64)$ \\
\hline$P_{t-2}$ & $-0,0956(-1,56)$ & $0,0328(0,59)$ & - & $-0,2383 *(-4,16)$ \\
\hline$P_{t-3}$ & $-0,1448 * *(-2,45)$ & $-0,0550(-1,02)$ & - & - \\
\hline$P_{t-4}$ & - & $-0,0073(-0,14)$ & - & - \\
\hline$P_{t-5}$ & - & $0,1801 *(3,47)$ & - & - \\
\hline$P_{t-6}$ & - & $-0,0058(-0,10)$ & - & - \\
\hline$P_{t-7}$ & - & $-0,1958 *(-3,54)$ & - & - \\
\hline$F_{t-1}$ & $0,1924 * * *(1,68)$ & $0,0977(1,34)$ & $0,2452 *(2,84)$ & $0,2781 * *(2,19)$ \\
\hline$\tilde{a}$ & $-0,0517(0,19)$ & $-0,4088 *(-2,63)$ & $-0,2129(-1,09)$ & $-0,5454 * * *(1,92)$ \\
\hline
\end{tabular}

Fonte: resultados da pesquisa

Notas: os valores da estatística t se encontram entre parênteses; *significativo a $1 \%$; **significativo a 5\%; ***significativo a $10 \%$ 


\subsubsection{Efetividade das operações de hedge e cross hedge}

A efetividade do hedge foi calculada de acordo com a equação (14), a partir das variâncias dos portfólios hedgeados e não hedgeados. Os resultados podem ser observados nas Tabelas 22 e 23.

Para as operações de hedge do boi gordo, nota-se, pela Tabela 22, que as diferenças de efetividade nas regiões consideradas no estudo foram próximas. Os maiores valores ocorreram em Araçatuba e Três Lagoas, indicando que a tomada de posição em contratos futuros de boi gordo na BM\&F na proporção de hedge ótima $(58,35 \%$ e $62,22 \%$ respectivamente) reduziria o risco em $51,50 \%$ e $50,15 \%$ respectivamente. Já os menores valores de efetividade foram verificados nos modelos relativos à Campo Grande (41,83\%) e Noroeste do Paraná (42,86\%). Além disso, observou-se que, em todas as regiões, as operações tiveram uma maior efetividade no período da safra. Isso pode ser explicado pelo maior número de informações que o mercado possui neste período, o que contribui para a existência de um menor risco de base em relação ao período da entressafra. Este fato ocorreu com uma maior intensidade nos modelos do Triângulo Mineiro e de Bauru/Marília.

Tabela 22. Efetividade e razão de hedge dos preços do boi gordo no período entre setembro de 1995 e fevereiro de 2001.

\begin{tabular}{lcccccc}
\hline & \multicolumn{3}{c}{ Razão de hedge do boi gordo (\%) } & \multicolumn{3}{c}{ Efetividade do hedge do boi gordo (\%) } \\
\hline \multicolumn{1}{c}{ Regiões } & Geral & Safra & Entressafra & Geral & Safra & Entressafra \\
\hline Araçatuba & 58,35 & 62,82 & 56,47 & 51,50 & 55,42 & 49,09 \\
S. J. Rio Preto & 59,97 & 64,48 & 52,47 & 48,55 & 50,98 & 47,53 \\
Bauru/Marília & 58,36 & 64,24 & 48,54 & 48,87 & 53,41 & 45,05 \\
P. Prudente & 59,51 & 64,95 & 50,49 & 49,55 & 53,72 & 46,40 \\
Noroeste PR & 61,47 & 66,36 & 53,48 & 42,86 & 46,06 & 41,14 \\
Três Lagoas & 62,22 & 65,66 & 56,47 & 50,15 & 51,80 & 49,82 \\
Campo Grande & 60,19 & 62,85 & 55,68 & 41,83 & 43,27 & 41,77 \\
T. Mineiro & 55,84 & 61,99 & 45,52 & 47,12 & 52,69 & 42,18 \\
\hline
\end{tabular}

Fonte: resultados da pesquisa 
Apesar de se constatar altas razões de hedge, a efetividade das operações de cross hedge dos preços do bezerro no mercado futuro de boi gordo da BM\&F se mostrou bastante baixa - em torno de 1,5\%. O principal motivo para tal fato consiste no alto risco de base que envolve estas operações quando comparadas com o risco de base do hedge de boi gordo. Além disso, a efetividade do cross hedge não diferiu significativamente entre os períodos de safra e entressafra (Tabela 23).

Tabela 23. Efetividade e razão do cross hedge dos preços do bezerro no período entre setembro de 1995 e fevereiro de 2001.

\begin{tabular}{lcccccc}
\hline & \multicolumn{2}{c}{ Razão de cross hedge do bezerro (\%) } & \multicolumn{3}{c}{ Efetividade do cross hedge do bezerro (\%) } \\
\hline \multicolumn{1}{c}{ Regiões } & Geral & Safra & Entressafra & Geral & Safra & Entressafra \\
\hline Araçatuba & 40,55 & 11,07 & 50,32 & 1,89 & 0,77 & 2,52 \\
S. J. Rio Preto & 41,23 & 25,34 & 46,63 & 2,05 & 1,28 & 2,49 \\
Bauru/Marília & 41,12 & 34,18 & 43,46 & 1,33 & 0,53 & 2,00 \\
P. Prudente & 43,81 & 13,05 & 53,93 & 3,13 & 0,94 & 4,52 \\
Noroeste PR & 38,69 & 32,22 & 37,39 & 1,00 & 1,08 & 0,89 \\
Três Lagoas & 48,27 & 23,93 & 56,56 & 1,13 & 0,87 & 1,29 \\
Campo Grande & 37,41 & 13,60 & 45,38 & 1,47 & 0,46 & 2,72 \\
T. Mineiro & 47,84 & 6,71 & 61,25 & 0,66 & $-0,30$ & 1,84 \\
\hline
\end{tabular}

Fonte: resultados da pesquisa 


\section{CONCLUSÕES}

O risco de preço na pecuária bovina de corte é bastante elevado, especialmente para os produtores especializados em uma ou duas etapas do processo produtivo (sistema de produção horizontal). Neste contexto, o preço do bezerro é uma das variáveis chaves da atividade, especialmente para os pecuaristas especializados na cria dos animais e para aqueles produtores especializados na cria/engorda, recria/engorda e engorda, que utilizam a relação de troca entre boi gordo e bezerro para gerenciamento de seu negócio.

Dada a não existência dos contratos futuros de bezerro, os pecuaristas brasileiros possuem como alternativa a realização de operações conhecidas como cross hedge no mercado futuro de boi gordo da $\mathrm{BM} \& \mathrm{~F}$, com o objetivo de se protegerem de variações adversas nos preços do bezerro. No entanto, tais operações são caracterizadas por estarem associadas a um alto risco. Aém dos movimentos imprevisíveis que ocorrem na diferença entre os preços à vista e futuro do produto mencionado no contrato (boi gordo), é preciso levar em consideração os movimentos imprevisíveis na diferença entre os preços à vista do ativo hedgeado (bezerro) e do ativo especificado no contrato (boi gordo). Ou seja, existe um risco adicional de preço associado às diferenças na qualidade do produto.

Neste sentido, o risco de se realizar esta operação foi avaliado e comparado ao risco do hedge do boi gordo. Verificou-se que o cross hedge possui um risco de base, nas semanas de vencimentos dos 58 contratos futuros do boi gordo da BM\&F observados entre setembro de 1995 e fevereiro de 2001, aproximadamente $80 \%$ superior 
àquele visto no own hedge. Cabe observar que, nas operações de hedge dos preços do boi gordo, o risco de base se mostrou estatisticamente inferior nas regiões relativas ao Indicador do Preço Disponível do Boi Gordo ESALQ/BM\&F, calculado pelo CEPEA/FEALQ. No entanto, no cross hedge, o risco de base não teve diferenças estatisticamente significativas entre as regiões de análise.

As razões ótimas de hedge e a efetividade destas duas operações foram calculadas para cada região de forma a obter resultados que levassem a uma maior caracterização das operações no mercado de futuros do boi gordo na BM\&F. Tanto no cross hedge, como também no own hedge, as razões se mostraram elevadas - no primeiro caso esteve entre $37 \%$ e $49 \%$, já no segundo variou entre $58 \%$ a $63 \%$.Com relação à efetividade, constatou-se que, no caso do own hedge, o risco pode ser reduzido em cerca de $50 \%$ com a tomada de posição em contratos futuros de boi gordo na proporção de hedge ótima. Para o cross hedge, a efetividade foi bastante baixa para todas as regiões (em torno de 1,5\%). Ou seja, tal operação não pode ser considerada eficiente para a proteção dos riscos de preço do bezerro. A explicação desta questão consiste no alto risco de base que envolve este tipo de hedge. Adicionalmente, foi visto que a efetividade do own hedge no mercado futuro de boi gordo se mostrou superior no período da safra em relação à entressafra. Este mesmo aspecto foi analisado no cross hedge, porém não se apresentaram diferenças significativas.

Dessa forma, o presente trabalho procurou demonstrar que os pecuaristas, que utilizam o preço do bezerro para gerenciamento de sua atividade, não possuem um instrumento eficiente de proteção dos riscos de preço de sua atividade, considerando operações em mercados futuros. A criação dos contratos futuros de bezerro seria uma alternativa para a solução deste problema, pois os produtores especializados na cria teriam condições de realizar operações com um menor risco e maior efetividade, e aqueles especializados na cria/engorda, recria/engorda e engorda iriam se garantir das variações adversas dos preços do bezerro, possuindo, portanto, instrumentos eficientes 
para proteção contra os movimentos não favoráveis apresentados pela relação de troca entre boi gordo e bezerro.

Neste sentido, tornam-se de fundamental importância estudos que visem analisar a viabilidade de tais contratos no mercado de derivativos brasileiro, pois não só poderiam servir como instrumento eficiente de proteção contra movimentos adversos nos preços do bezerro e na relação de troca (em conjunto com os contratos de boi gordo), como também permitiriam um planejamento mais eficaz da atividade ao fornecer uma sinalização futura da relação de preços entre boi gordo e bezerro, antecipando as decisões de produção e de troca. No entanto, deve-se considerar os aspectos relacionados à liquidez deste possível mercado e o impacto, que poderia trazer, no número de negociações no mercado futuro de boi gordo. 
ANEXOS 
ANEXO A - Procedimento seqüencial para testar a presença de raiz unitária em séries temporais.

Estimar Modelo Geral: $\Delta Y_{t}=\alpha+\theta Y_{t-1}+\sum_{i=1}^{p-1} \omega_{t} \Delta Y_{t-i}+\gamma T+u_{t}$

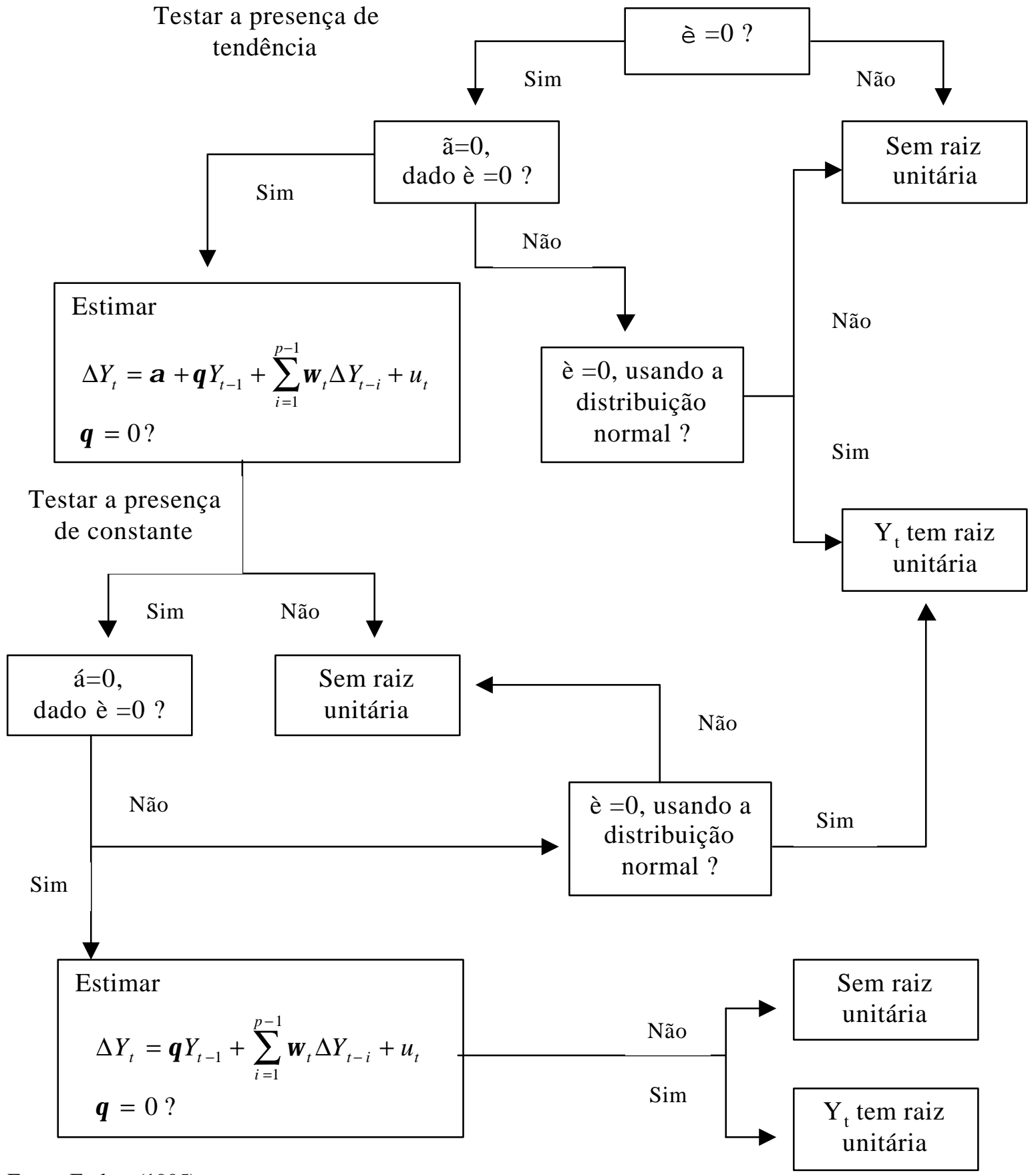

Fonte: Enders (1995) 
ANEXO B - Evolução das bases semanais do boi gordo nas regiões que compõem o IBG (São José do Rio Preto, Araçatuba, Presidente Prudente e Bauru/Marília) nas semanas de vencimento do contrato futuro do boi gordo da BM\&F entre setembro de 1995 e fevereiro de 2001.

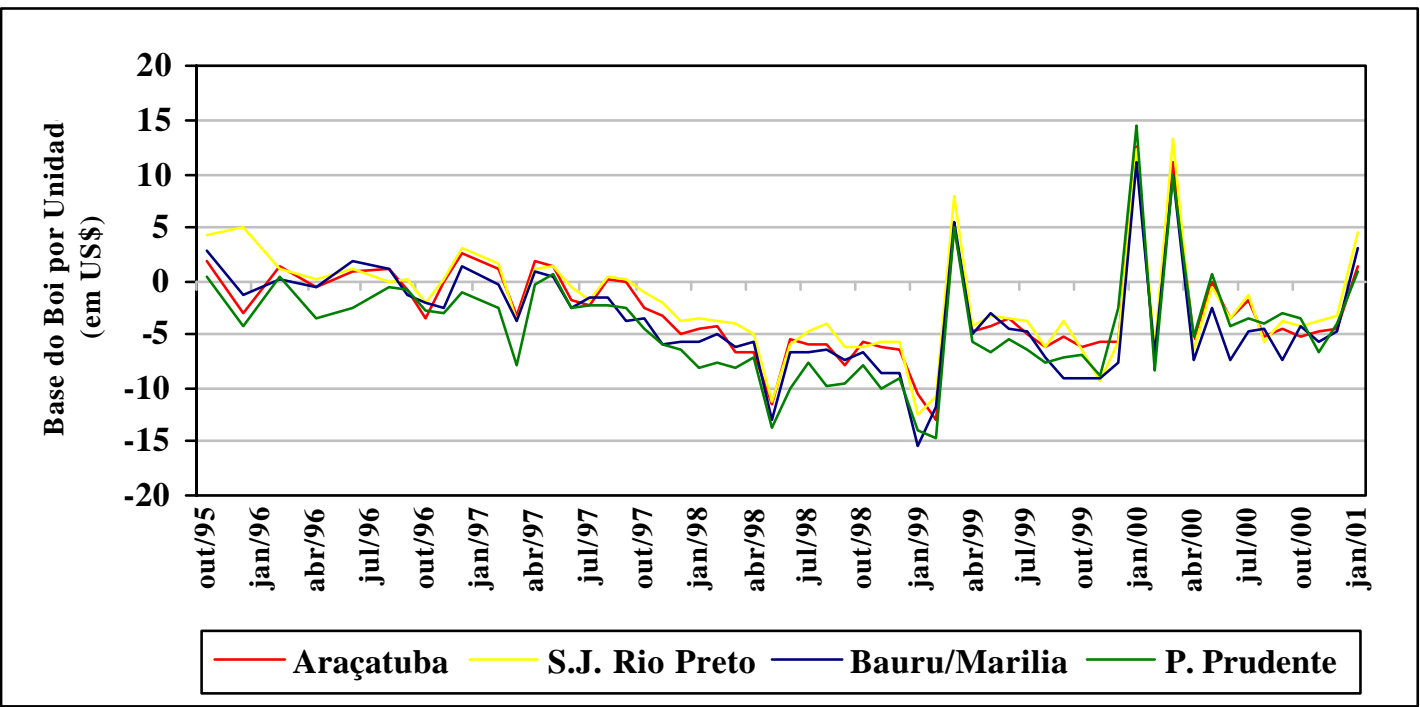

Fonte: CEPEA/FEALQ/USP (2001) e BM\&F (2001)

ANEXO C - Evolução das bases semanais do boi gordo no Triângulo Mineiro, Noroeste do Paraná, Campo Grande e Três Lagoas nas semanas de vencimento do contrato futuro do boi gordo da BM\&F entre setembro de 1995 e fevereiro de 2001 .

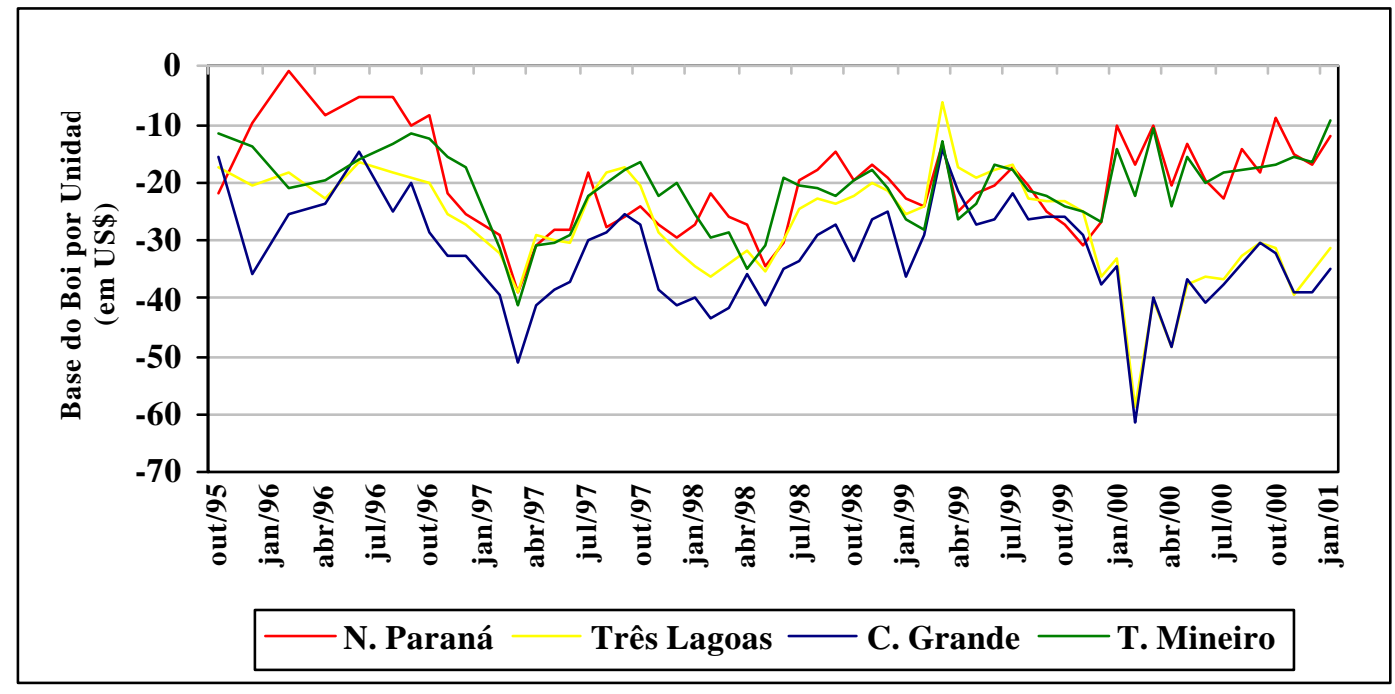

Fonte: CEPEA/FEALQ/USP (2001) e BM\&F (2001) 
ANEXO D - Evolução das bases semanais do bezerro nas regiões que compõem o IBG (São José do Rio Preto, Araçatuba, Presidente Prudente e Bauru/Marília) nas semanas de vencimento do contrato futuro do boi gordo da BM\&F entre setembro de 1995 e fevereiro de 2001.

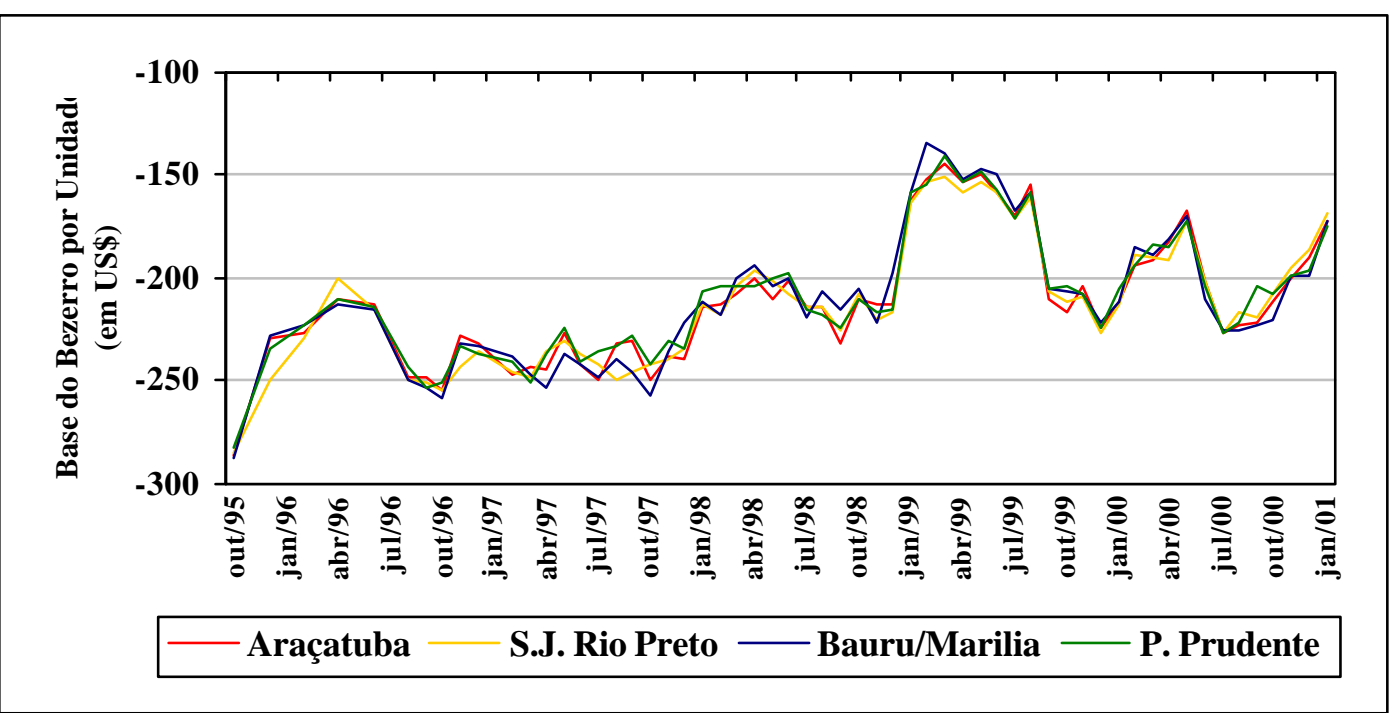

Fonte: CEPEA/FEALQ/USP (2001) e BM\&F (2001)

ANEXO E - Evolução das bases semanais do bezerro no Triângulo Mineiro, Noroeste do Paraná, Campo Grande e Três Lagoas nas semanas de vencimento do contrato futuro do boi gordo da BM\&F entre setembro de 1995 e fevereiro de 2001.

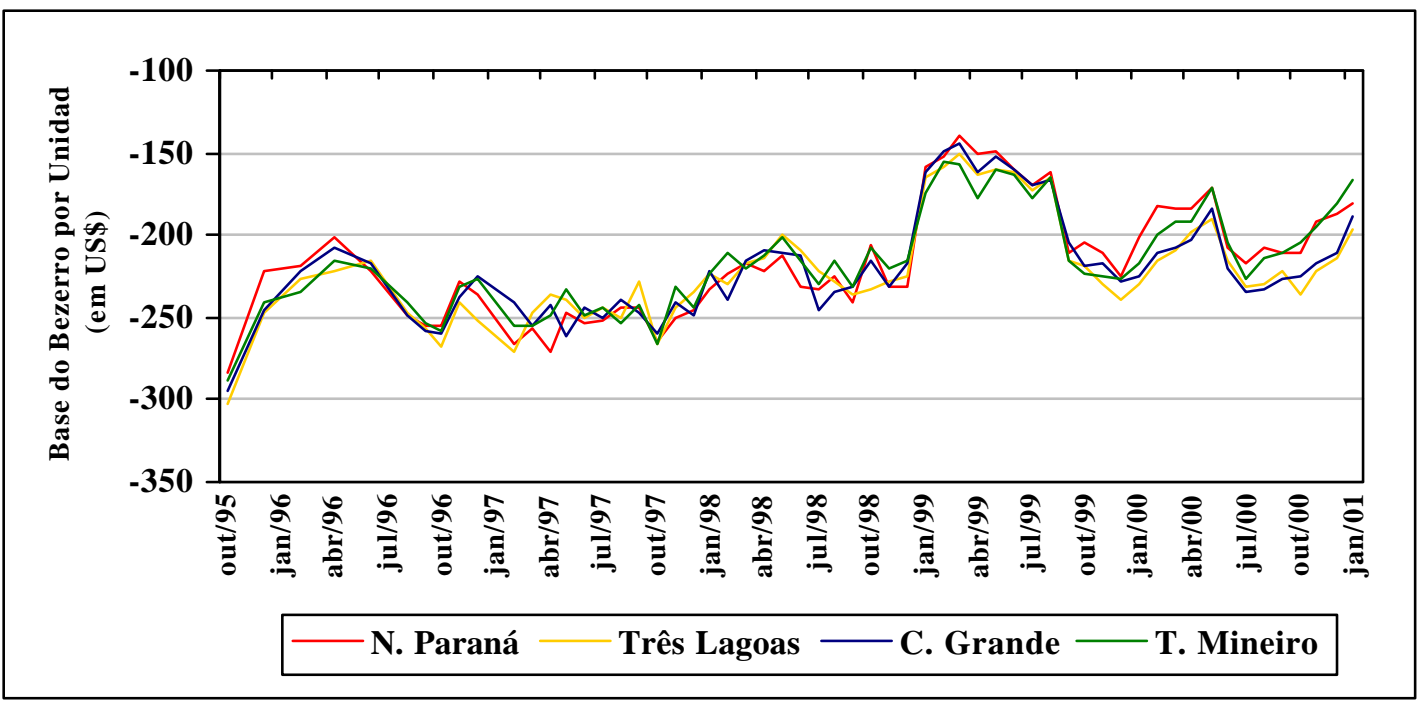

Fonte: CEPEA/FEALQ/USP (2001) e BM\&F (2001) 
ANEXO F - Resultados dos critérios de informação das séries semanais de preços à vista de boi gordo em Três Lagoas, Araçatuba, Campo Grande e Noroeste do Paraná.

\begin{tabular}{|c|c|c|c|c|c|c|c|c|c|c|}
\hline & \multicolumn{10}{|c|}{ Série semanal de preços à vista de boi gordo (em nível) } \\
\hline & \multicolumn{2}{|c|}{ Três Lagoas } & \multicolumn{2}{|c|}{ Araçatuba } & \multicolumn{2}{|c|}{ Bauru/Marília } & \multicolumn{2}{|c|}{ Campo Grande } & \multicolumn{2}{|c|}{ Noroeste do Paraná } \\
\hline $\begin{array}{c}\mathrm{N}^{\circ} \text { de } \\
\text { Defasagens }\end{array}$ & $\mathrm{AIC}$ & $\mathrm{SC}$ & AIC & $\mathrm{SC}$ & AIC & $\mathrm{SC}$ & $\mathrm{AIC}$ & $\mathrm{SC}$ & $\mathrm{AIC}$ & $\mathrm{SC}$ \\
\hline 1 & $-4,5414$ & $-4,5285$ & $-4,6619$ & $-4,6491$ & $-4,6249$ & $-4,6122$ & $-4,4273$ & $-4,4195$ & $-4,4565$ & $-4,4437$ \\
\hline 2 & $-4,6604$ & $-4,6347$ & $-4,7939$ & $-4,7682$ & $-4,7207$ & $-4,6950$ & $-4,5331$ & $-4,5074$ & $-4,4995$ & $-4,4738$ \\
\hline 3 & $-4,6545$ & $-4,6159$ & $-4,7936$ & $-4,7549$ & $-4,7149$ & $-4,6763$ & $-4,5344$ & $-4,4958$ & $-4,4931$ & $-4,4545$ \\
\hline 4 & $-4,6511$ & $-4,5994$ & $-4,7904$ & $-4,7387$ & $-4,7136$ & $-4,6619$ & $-4,5382$ & $-4,4866$ & $-4,4912$ & $-4,4396$ \\
\hline 5 & $-4,6507$ & $-4,5859$ & $-4,7888$ & $-4,7240$ & $-4,7180$ & $-4,6533$ & $-4,5410$ & $-4,4763$ & $-4,4828$ & $-4,4181$ \\
\hline 6 & $-4,6484$ & $-4,5705$ & $-4,7967$ & $-4,7188$ & $-4,7406$ & $-4,6627$ & $-4,5451$ & $-4,4673$ & $-4,4776$ & $-4,3998$ \\
\hline 7 & $-4,6714$ & $-4,5803$ & $-4,8177$ & $-4,7266$ & $-4,7724$ & $-4,6813$ & $-4,5653$ & $-4,4742$ & $-4,4770$ & $-4,3859$ \\
\hline 8 & $-4,6705$ & $-4,5661$ & $-4,8193$ & $-4,7149$ & $-4,7739$ & $-4,6695$ & $-4,5629$ & $-4,4585$ & $-4,4761$ & $-4,3717$ \\
\hline 9 & $-4,6642$ & $-4,5464$ & $-4,8128$ & $-4,6951$ & $-4,7681$ & $-4,6504$ & $-4,5678$ & $-4,4500$ & $-4,4719$ & $-4,3541$ \\
\hline 10 & $-4,6587$ & $-4,5276$ & $-4,8057$ & $-4,6746$ & $-4,7588$ & $-4,6276$ & $-4,5647$ & $-4,4335$ & $-4,4611$ & $-4,3299$ \\
\hline 11 & $-4,6639$ & $-4,5193$ & $-4,8139$ & $-4,6692$ & $-4,7709$ & $-4,6263$ & $-4,5812$ & $-4,4365$ & $-4,4710$ & $-4,3264$ \\
\hline 12 & $-4,6613$ & $-4,5031$ & $-4,8069$ & $-4,6486$ & $-4,7644$ & $-4,6062$ & $-4,5811$ & $-4,4229$ & $-4,4801$ & $-4,3219$ \\
\hline
\end{tabular}

Fonte: resultados da pesquisa 
ANEXO G - Resultados dos critérios de informação das séries semanais de preços à vista de boi gordo em Presidente Prudente, São José do Rio Preto e Triângulo Mineiro e da série de preços futuros do contrato de boi gordo da BM\&F.

\begin{tabular}{|c|c|c|c|c|c|c|c|c|}
\hline \multirow[b]{3}{*}{$\begin{array}{c}\mathrm{N}^{\mathrm{o}} \text { de } \\
\text { Defasagens }\end{array}$} & \multicolumn{6}{|c|}{ Série semanal de preços à vista de boi gordo (em nível) } & \multirow{2}{*}{\multicolumn{2}{|c|}{$\begin{array}{c}\text { Série semanal de preços } \\
\text { futuros } \\
\text { Boi Gordo - BM\&F }\end{array}$}} \\
\hline & \multicolumn{2}{|c|}{ Presidente Prudente } & \multicolumn{2}{|c|}{ São José do Rio Preto } & \multicolumn{2}{|c|}{ Triângulo Mineiro } & & \\
\hline & AIC & $\mathrm{SC}$ & AIC & $\mathrm{SC}$ & $\mathrm{AIC}$ & $\mathrm{SC}$ & AIC & $\mathrm{SC}$ \\
\hline 1 & $-4,6013$ & $-4,5885$ & $-4,6038$ & $-4,5909$ & $-4,6376$ & $-4,6247$ & $-4,3124$ & $-4,2995$ \\
\hline 2 & $-4,7039$ & $-4,6783$ & $-4,7093$ & $-4,6836$ & $-4,7709$ & $-4,7453$ & $-4,3379$ & $-4,3122$ \\
\hline 3 & $-4,6978$ & $-4,6592$ & $-4,7081$ & $-4,6694$ & $-4,7671$ & $-4,7284$ & $-4,3312$ & $-4,2926$ \\
\hline 4 & $-4,6922$ & $-4,6405$ & $-4,7037$ & $-4,6521$ & $-4,7689$ & $-4,7173$ & $-4,3217$ & $-4,2700$ \\
\hline 5 & $-4,6931$ & $-4,6284$ & $-4,7066$ & $-4,6418$ & $-4,7685$ & $-4,7038$ & $-4,3128$ & $-4,2481$ \\
\hline 6 & $-4,7149$ & $-4,6371$ & $-4,7227$ & $-4,6448$ & $-4,7865$ & $-4,7086$ & $-4,3038$ & $-4,2259$ \\
\hline 7 & $-4,7534$ & $-4,6623$ & $-4,7536$ & $-4,6625$ & $-4,8265$ & $-4,7354$ & $-4,3279$ & $-4,2369$ \\
\hline 8 & $-4,7484$ & $-4,6440$ & $-4,7516$ & $-4,6472$ & $-4,8256$ & $-4,7212$ & $-4,3174$ & $-4,2130$ \\
\hline 9 & $-4,7454$ & $-4,6276$ & $-4,7495$ & $-4,6317$ & $-4,8171$ & $-4,6994$ & $-4,3232$ & $-4,2055$ \\
\hline 10 & $-4,7368$ & $-4,6056$ & $-4,7457$ & $-4,6145$ & $-4,8129$ & $-4,6818$ & $-4,3201$ & $-4,1889$ \\
\hline 11 & $-4,7468$ & $-4,6021$ & $-4,7472$ & $-4,6025$ & $-4,8144$ & $-4,6697$ & $-4,3143$ & $-4,1696$ \\
\hline 12 & $-4,7391$ & $-4,5808$ & $-4,7399$ & $-4,5817$ & $-4,8069$ & $-4,6486$ & $-4,3058$ & $-4,1476$ \\
\hline
\end{tabular}

Fonte: resultados da pesquisa 
ANEXO H - Resultados dos critérios de informação das séries semanais de preços à vista de bezerro em Três Lagoas, Araçatuba, Campo Grande e Noroeste do Paraná.

\begin{tabular}{|c|c|c|c|c|c|c|c|c|c|c|}
\hline & \multicolumn{10}{|c|}{ Série semanal de preços à vista de bezerro (em nível) } \\
\hline & \multicolumn{2}{|c|}{ Três Lagoas } & \multicolumn{2}{|c|}{ Araçatuba } & \multicolumn{2}{|c|}{ Bauru/Marília } & \multicolumn{2}{|c|}{ Campo Grande } & \multicolumn{2}{|c|}{ Noroeste do Paraná } \\
\hline $\begin{array}{c}\mathrm{N}^{\mathrm{o}} \mathrm{de} \\
\text { Defasagens }\end{array}$ & $\mathrm{AIC}$ & $\mathrm{SC}$ & AIC & $\mathrm{SC}$ & $\mathrm{AIC}$ & $\mathrm{SC}$ & AIC & $\mathrm{SC}$ & AIC & $\mathrm{SC}$ \\
\hline 1 & $-2,7227$ & $-2,7098$ & $-3,5459$ & $-3,5330$ & $-3,3702$ & $-3,3573$ & $-3,4370$ & $-3,4242$ & $-2,9376$ & $-2,9248$ \\
\hline 2 & $-2,7835$ & $-2,7578$ & $-3,5705$ & $-3,5448$ & $-3,4099$ & $-3,3842$ & $-3,4352$ & $-3,4095$ & $-3,0220$ & $-2,9963$ \\
\hline 3 & $-2,8006$ & $-2,7620$ & $-3,5724$ & $-3,5338$ & $-3,4184$ & $-3,3797$ & $-3,4744$ & $-3,4358$ & $-3,0237$ & $-2,9850$ \\
\hline 4 & $-2,8184$ & $-2,7667$ & $-3,5647$ & $-3,5131$ & $-3,4094$ & $-3,3578$ & $-3,4726$ & $-3,4209$ & $-3,0279$ & $-2,9762$ \\
\hline 5 & $-2,8135$ & $-2,7488$ & $-3,5627$ & $-3,4979$ & $-3,3989$ & $-3,3342$ & $-3,4729$ & $-3,4082$ & $-3,0240$ & $-2,9592$ \\
\hline 6 & $-2,8144$ & $-2,7365$ & $-3,5543$ & $-3,4764$ & $-3,3885$ & $-3,3106$ & $-3,4691$ & $-3,3912$ & $-3,0133$ & $-2,9354$ \\
\hline 7 & $-2,8078$ & $-2,7167$ & $-3,5447$ & $-3,4536$ & $-3,3777$ & $-3,2866$ & $-3,4688$ & $-3,3776$ & $-3,0063$ & $-2,9152$ \\
\hline 8 & $-2,8098$ & $-2,7055$ & $-3,5392$ & $-3,4348$ & $-3,3677$ & $-3,2633$ & $-3,4683$ & $-3,3639$ & $-2,9963$ & 2,8919 \\
\hline 9 & $-2,8179$ & $-2,7002$ & $-3,5349$ & $-3,4171$ & $-3,3588$ & $-3,2411$ & $-3,4638$ & $-3,3461$ & $-2,9957$ & $-2,8779$ \\
\hline 10 & $-2,8069$ & $-2,6758$ & $-3,5476$ & $-3,4164$ & $-3,3520$ & $-3,2208$ & $-3,4584$ & $-3,3332$ & $-2,9964$ & $-2,8652$ \\
\hline 11 & $-2,8399$ & $-2,6953$ & $-3,5375$ & $-3,3929$ & $-3,3495$ & $-3,2048$ & $-3,4584$ & $-3,3137$ & $-2,9993$ & $-2,8546$ \\
\hline 12 & $-2,8337$ & $-2,6754$ & $-3,5340$ & $-3,3757$ & $-3,3495$ & $-3,1866$ & $-3,4473$ & $-3,2891$ & $-2,9891$ & $-2,8309$ \\
\hline
\end{tabular}

Fonte: resultados da pesquisa 
ANEXO I - Resultados dos critérios de informação das séries semanais de preços à vista de bezerro em Presidente Prudente, São José do Rio Preto e Triângulo Mineiro.

\begin{tabular}{|c|c|c|c|c|c|c|}
\hline & \multicolumn{6}{|c|}{ Série semanal de preços à vista de bezerro (em nível) } \\
\hline & \multicolumn{2}{|c|}{ Presidente Prudente } & \multicolumn{2}{|c|}{ São José do Rio Preto } & \multicolumn{2}{|c|}{ Triângulo Mineiro } \\
\hline $\begin{array}{c}\mathrm{N}^{\mathrm{o}} \mathrm{de} \\
\text { Defasagens }\end{array}$ & AIC & $\mathrm{SC}$ & AIC & $\mathrm{SC}$ & AIC & $\mathrm{SC}$ \\
\hline 1 & $-3,9082$ & $-3,8954$ & $-3,5369$ & $-3,5241$ & $-2,6649$ & $-2,6521$ \\
\hline 2 & $-3,9004$ & $-3,8747$ & $-3,5433$ & $-3,5176$ & $-2,7679$ & $-2,7423$ \\
\hline 3 & $-3,8911$ & $-3,8524$ & $-3,5349$ & $-3,4963$ & $-2,7960$ & $-2,7574$ \\
\hline 4 & $-3,8811$ & $-3,8294$ & $-3,5426$ & $-3,4910$ & $-2,7862$ & $-2,7346$ \\
\hline 5 & $-3,8721$ & $-3,8074$ & $-3,5322$ & $-3,4674$ & $-2,7889$ & $-2,7242$ \\
\hline 6 & $-3,8992$ & $-3,8213$ & $-3,5226$ & $-3,4447$ & $-2,7809$ & $-2,7030$ \\
\hline 7 & $-3,8898$ & $-3,7987$ & $-3,5208$ & $-3,4297$ & $-2,7747$ & $-2,6836$ \\
\hline 8 & $-3,9435$ & $-3,8391$ & $-3,5172$ & $-3,4128$ & $-2,7747$ & $-2,6703$ \\
\hline 9 & $-3,9332$ & $-3,8155$ & $-3,5146$ & $-3,3968$ & $-2,7674$ & $-2,6496$ \\
\hline 10 & $-3,9298$ & $-3,7986$ & $-3,5203$ & $-3,3891$ & $-2,7720$ & $-2,6408$ \\
\hline 11 & $-3,9318$ & $-3,7871$ & $-3,5094$ & $-3,3647$ & $-2,7634$ & $-2,6188$ \\
\hline 12 & $-3,9283$ & $-3,7700$ & $-3,5046$ & $-3,3464$ & $-2,7617$ & $-2,6035$ \\
\hline
\end{tabular}

Fonte: resultados da pesquisa 
ANEXO J - Resultados dos critérios de informação das séries semanais de preços à vista de boi gordo na primeira diferença em Três Lagoas, Araçatuba, Campo Grande e Noroeste do Paraná.

\begin{tabular}{|c|c|c|c|c|c|c|c|c|c|c|}
\hline & \multicolumn{10}{|c|}{ Série semanal de preços à vista de boi gordo ( $1^{\circ}$ diferença $)$} \\
\hline & \multicolumn{2}{|c|}{ Três Lagoas } & \multicolumn{2}{|c|}{ Araçatuba } & \multicolumn{2}{|c|}{ Bauru/Marília } & \multicolumn{2}{|c|}{ Campo Grande } & \multicolumn{2}{|c|}{ Noroeste do Paraná } \\
\hline $\begin{array}{c}\mathrm{N}^{\mathrm{o}} \mathrm{de} \\
\text { Defasagens }\end{array}$ & AIC & $\mathrm{SC}$ & AIC & $\mathrm{SC}$ & AIC & $\mathrm{SC}$ & AIC & $\mathrm{SC}$ & AIC & $\mathrm{SC}$ \\
\hline 1 & $-4,6665$ & $-4,6536$ & $-4,8002$ & $-4,7874$ & $-4,7270$ & $-4,7142$ & $-4,5391$ & $-4,5263$ & $-4,5056$ & $-4,4927$ \\
\hline 2 & $-4,6607$ & $-4,6349$ & $-4,7999$ & $-4,7742$ & $-4,7212$ & $-4,6954$ & $-4,5405$ & $-4,5147$ & $-4,4993$ & $-4,4735$ \\
\hline 3 & $-4,6572$ & $-4,6184$ & $-4,7966$ & $-4,7579$ & $-4,7198$ & $-4,6810$ & $-4,5442$ & $-4,5054$ & $-4,4973$ & $-4,4586$ \\
\hline 4 & $-4,6567$ & $-4,6049$ & $-4,7951$ & $-4,7433$ & $-4,7243$ & $-4,6725$ & $-4,5472$ & $-4,4954$ & $-4,4889$ & $-4,4371$ \\
\hline 5 & $-4,6545$ & $-4,5896$ & $-4,8029$ & $-4,7381$ & $-4,7469$ & $-4,6819$ & $-4,5512$ & $-4,4863$ & $-4,4838$ & $-4,4189$ \\
\hline 6 & $-4,6771$ & $-4,5990$ & $-4,8236$ & $-4,7456$ & $-4,7784$ & $-4,7003$ & $-4,5712$ & $-4,4931$ & $-4,4830$ & $-4,4049$ \\
\hline 7 & $-4,6757$ & $-4,5843$ & $-4,8248$ & $-4,7335$ & $-4,7795$ & $-4,6881$ & $-4,5682$ & $-4,4769$ & $-4,4819$ & $-4,3906$ \\
\hline 8 & $-4,6689$ & $-4,5643$ & $-4,8181$ & $-4,7134$ & $-4,7734$ & $-4,6687$ & $-4,5725$ & $-4,4678$ & $-4,4772$ & $-4,3726$ \\
\hline 9 & $-4,6639$ & $-4,5459$ & $-4,8114$ & $-4,6933$ & $-4,7642$ & $-4,6462$ & $-4,5701$ & $-4,4520$ & $-4,4666$ & $-4,3485$ \\
\hline 10 & $-4,6699$ & $-4,5383$ & $-4,8201$ & $-4,6886$ & $-4,7771$ & $-4,6456$ & $-4,5871$ & $-4,4556$ & $-4,4772$ & $-4,3457$ \\
\hline 11 & $-4,6669$ & $-4,5219$ & $-4,8129$ & $-4,6679$ & $-4,7704$ & $-4,6254$ & $-4,5866$ & $-4,4416$ & $-4,4859$ & $-4,3408$ \\
\hline 12 & $-4,7058$ & $-4,5471$ & $-4,8411$ & $-4,6825$ & $-4,7960$ & $-4,6329$ & $-4,6241$ & $-4,4655$ & $-4,5111$ & $-4,3524$ \\
\hline
\end{tabular}

Fonte: resultados da pesquisa 
ANEXO K - Resultados dos critérios de informação das séries semanais de preços à vista de boi gordo na primeira diferença em Presidente Prudente, São José do Rio Preto e Triângulo Mineiro e da série de preços futuros do contrato de boi gordo da BM\&F.

\begin{tabular}{|c|c|c|c|c|c|c|c|c|}
\hline & \multicolumn{6}{|c|}{ Série semanal de preços à vista de boi gordo ( $1^{\circ}$ diferença $)$} & \multirow{2}{*}{\multicolumn{2}{|c|}{$\begin{array}{l}\text { Série de preço futuro } \\
\text { Boi Gordo - BM\&F }\end{array}$}} \\
\hline & Presider & Prudente & São José & io Preto & Triângı & Mineiro & & \\
\hline $\begin{array}{c}\mathrm{N}^{\mathrm{o}} \text { de } \\
\text { Defasagens }\end{array}$ & AIC & $\mathrm{SC}$ & $\mathrm{AIC}$ & $\mathrm{SC}$ & $\mathrm{AIC}$ & $\mathrm{SC}$ & $\mathrm{AIC}$ & $\mathrm{SC}$ \\
\hline 1 & $-4,7102$ & $-4,8974$ & $-4,7156$ & $-4,7028$ & $-4,7775$ & $-4,7646$ & $-4,3438$ & $-4,3309$ \\
\hline 2 & $-4,7041$ & $-4,6783$ & $-4,7144$ & $-4,6886$ & $-4,7736$ & $-4,7478$ & $-4,3369$ & $-4,3112$ \\
\hline 3 & $-4,6984$ & $-4,6597$ & $-4,7101$ & $-4,6713$ & $-4,7753$ & $-4,7366$ & $-4,3276$ & $-4,2889$ \\
\hline 4 & $-4,6994$ & $-4,6476$ & $-4,7129$ & $-4,6611$ & $-4,7749$ & $-4,7231$ & $-4,3189$ & $-4,2672$ \\
\hline 5 & $-4,7213$ & $-4,6564$ & $-4,7291$ & $-4,6642$ & $-4,7928$ & $-4,7279$ & $-4,3101$ & $-4,2452$ \\
\hline 6 & $-4,7594$ & $-4,6813$ & $-4,7596$ & $-4,6815$ & $-4,8325$ & $-4,7544$ & $-4,3338$ & $-4,2557$ \\
\hline 7 & $-4,7542$ & $-4,6628$ & $-4,7572$ & $-4,6659$ & $-4,8312$ & $-4,7398$ & $-4,3231$ & $-4,2317$ \\
\hline 8 & $-4,7507$ & $-4,6461$ & $-4,7546$ & $-4,6499$ & $-4,8225$ & $-4,7178$ & $-4,3288$ & $-4,2241$ \\
\hline 9 & $-4,7424$ & $-4,6244$ & $-4,7514$ & $-4,6333$ & $-4,8187$ & $-4,7001$ & $-4,3261$ & $-4,2081$ \\
\hline 10 & $-4,7531$ & $-4,6216$ & $-4,7533$ & $-4,6218$ & $-4,8207$ & $-4,6892$ & $-4,3205$ & $-4,1891$ \\
\hline 11 & $-4,7452$ & $-4,6001$ & $-4,7460$ & $-4,6009$ & $-4,8131$ & $-4,6681$ & $-4,3127$ & $-4,1672$ \\
\hline 12 & $-4,7716$ & $-4,6129$ & $-4,7648$ & $-4,6061$ & $-4,8522$ & $-4,6936$ & $-4,3041$ & $-4,1454$ \\
\hline
\end{tabular}

Fonte: resultados da pesquisa 
ANEXO L - Resultados dos critérios de informação das séries semanais de preços à vista de bezerro na primeira diferença de Três Lagoas, Araçatuba, Campo Grande e Noroeste do Paraná.

\begin{tabular}{|c|c|c|c|c|c|c|c|c|c|c|}
\hline \multirow[b]{3}{*}{$\begin{array}{c}\mathrm{N}^{\mathrm{o}} \text { de } \\
\text { Defasagens }\end{array}$} & \multicolumn{10}{|c|}{ Série semanal de preços à vista bezerro ( $1^{\circ}$ diferença $)$} \\
\hline & \multicolumn{2}{|c|}{ Três Lagoas } & \multicolumn{2}{|c|}{ Araçatuba } & \multicolumn{2}{|c|}{ Bauru/Marília } & \multicolumn{2}{|c|}{ Campo Grande } & \multicolumn{2}{|c|}{ Noroeste do Paraná } \\
\hline & AIC & $\mathrm{SC}$ & $\mathrm{AIC}$ & $\mathrm{SC}$ & $\mathrm{AIC}$ & $\mathrm{SC}$ & AIC & $\mathrm{SC}$ & AIC & $\mathrm{SC}$ \\
\hline 1 & $-2,7906$ & $-2,7777$ & $-3,5775$ & $-3,5646$ & $-3,4169$ & $-3,4041$ & $-3,4423$ & $-3,4294$ & $-3,0290$ & $-3,0161$ \\
\hline 2 & $-2,8077$ & $-2,7819$ & $-3,5794$ & $-3,5537$ & $-3,4253$ & $-3,3996$ & $-3,4815$ & $-3,4557$ & $-3,0307$ & $-3,0073$ \\
\hline 3 & $-2,8255$ & $-2,7867$ & $-3,5717$ & $-3,5329$ & $-3,4163$ & $-3,3776$ & $-3,4796$ & $-3,4409$ & $-3,0350$ & $-2,9963$ \\
\hline 4 & $-2,8206$ & $-2,7688$ & $-3,5697$ & $-3,5179$ & $-3,4059$ & $-3,3541$ & $-3,4800$ & $-3,4282$ & $-3,0311$ & $-2,9793$ \\
\hline 5 & $-2,8215$ & $-2,7566$ & $-3,5614$ & $-3,4964$ & $-3,3955$ & $-3,3306$ & $-3,4762$ & $-3,4112$ & $-3,0204$ & $-2,9555$ \\
\hline 6 & $-2,8150$ & $-2,7369$ & $-3,5519$ & $-3,4738$ & $-3,3848$ & $-3,3067$ & $-3,4759$ & $-3,3978$ & $-3,0135$ & $-2,9354$ \\
\hline 7 & $-2,8171$ & $-2,7200$ & $-3,5464$ & $-3,4550$ & $-3,3747$ & $-3,2833$ & $-3,4755$ & $-3,3842$ & $-3,0034$ & $-2,9121$ \\
\hline 8 & $-2,8251$ & $-2,7204$ & $-3,5421$ & $-3,4374$ & $-3,3659$ & $-3,2612$ & $-3,4710$ & $-3,3664$ & $-3,0029$ & $-2,8922$ \\
\hline 9 & $-2,8142$ & $-2,6961$ & $-3,5547$ & $-3,4366$ & $-3,3591$ & $-3,2411$ & $-3,4715$ & $-3,3534$ & $-3,0036$ & $-2,8855$ \\
\hline 10 & $-2,8469$ & $-2,7154$ & $-3,5447$ & $-3,4132$ & $-3,3566$ & $-3,2251$ & $-3,4655$ & $-3,3340$ & $-3,0065$ & $-2,8750$ \\
\hline 11 & $-2,8404$ & $-2,6954$ & $-3,5410$ & $-3,3959$ & $-3,3518$ & $-3,2068$ & $-3,4545$ & $-3,3094$ & $-2,9964$ & $-2,8513$ \\
\hline 12 & $-2,8359$ & $-2,6773$ & $-3,5307$ & $-3,3721$ & $-3,3481$ & $-3,2895$ & $-3,4458$ & $-3,2872$ & $-2,9947$ & $-2,8360$ \\
\hline
\end{tabular}

Fonte: resultados da pesquisa 
ANEXO M - Resultados dos critérios de informação das séries semanais de preços à vista de bezerro na primeira diferença de Presidente Prudente, São José do Rio Preto e Triângulo Mineiro.

\begin{tabular}{|c|c|c|c|c|c|c|}
\hline \multirow[b]{3}{*}{$\begin{array}{c}\mathrm{N}^{\circ} \text { de } \\
\text { Defasagens }\end{array}$} & \multicolumn{6}{|c|}{ Série semanal de preços à vista de bezerro ( $1^{\circ}$ diferença) } \\
\hline & \multicolumn{2}{|c|}{ Presidente Prudente } & \multicolumn{2}{|c|}{ São José do Rio Preto } & \multicolumn{2}{|c|}{ Triângulo Mineiro } \\
\hline & AIC & $\mathrm{SC}$ & AIC & $\mathrm{SC}$ & $\mathrm{AIC}$ & $\mathrm{SC}$ \\
\hline 1 & $-3,9074$ & $-3,8946$ & $-3,5504$ & $-3,5375$ & $-2,7749$ & $-2,7620$ \\
\hline 2 & $-3,8981$ & $-3,8724$ & $-3,5420$ & $-3,5163$ & $-2,8028$ & $-2,7771$ \\
\hline 3 & $-3,8882$ & $-3,8494$ & $-3,5496$ & $-3,5109$ & $-2,7930$ & $-2,7543$ \\
\hline 4 & $-3,8792$ & $-3,8274$ & $-3,5392$ & $-3,4874$ & $-2,7956$ & $-2,7438$ \\
\hline 5 & $-3,9067$ & $-3,8413$ & $-3,5296$ & $-3,4647$ & $-2,7877$ & $-2,7228$ \\
\hline 6 & $-3,8969$ & $-3,8188$ & $-3,5278$ & $-3,4498$ & $-2,7816$ & $-2,7035$ \\
\hline 7 & $-3,9506$ & $-3,8593$ & $-3,5243$ & $-3,4329$ & $-2,7817$ & $-2,6904$ \\
\hline 8 & $-3,9404$ & $-3,8357$ & $-3,5217$ & $-3,4170$ & $-2,7743$ & $-2,6696$ \\
\hline 9 & $-3,9369$ & $-3,8188$ & $-3,5273$ & $-3,4092$ & $-2,7789$ & $-2,6609$ \\
\hline 10 & $-3,9389$ & $-3,8075$ & $-3,5164$ & $-2,3849$ & $-2,7705$ & $-2,6389$ \\
\hline 11 & $-3,9354$ & $-3,7904$ & $-3,5117$ & $-3,3667$ & $-2,7687$ & $-2,6237$ \\
\hline 12 & $-3,9389$ & $-3,7803$ & $-3,5079$ & $-3,3492$ & $-2,7608$ & $-2,6021$ \\
\hline
\end{tabular}

Fonte: resultados da pesquisa 


\section{REFERÊNCIAS BIBLIOGRÁFICAS}

ANDERSON, R.W.; DANTHINE, J. Hedging and joint production: theory and illustrations. Journal of Finance, v.35, p.487-501, 1980.

ANDERSON, R.W.; DANTHINE, J. Cross hedging. Journal of Political Economics, v.89, p.1182-1196, 1981.

FNP CONSULTORIA \& COMÉRCIO. Anualpec: Anuário da pecuária brasileira. São Paulo, 2001. p.113-158: Pecuária de corte - preços.

BARROS, G.S.C. (Coord.). Mercados futuros e política agrícola no Brasil. Piracicaba: ESALQ, Depto. de Economia, Administração e Sociologia, 2000. 17p. (Relatório final)

BESSADA, O. O mercado de futuros e de opções. 3.ed. Rio de Janeiro: Record, 1995. 297p.

BLACK, D. G. Success and failure of futures contracts: theory and empirical evidences. New York, 1986. 70p. Monograph (Graduate) - School of Business Administration, New York University. 
BLISKA, F.M.M.; GONÇALVES, J.R. Cadeia produtiva da carne bovina no Brasil: principais fatores limitantes e críticos. In: SIMPÓSIO GOIANO SOBRE PRODUÇÃO DE BOVINOS DE CORTE, Goiânia, 1999. Anais. Goiânia: CBNA, 1999. p.9-26.

BROWN, S.L. A Reformulation of portfolio model of hedging. American Journal of Agricultural Economics, v.67, n.3, p.508-512, 1985.

CARTER, C.A.; LOYNS, R.M.A. Hedging feedlot cattle: a canadian perspective. American Journal of Agricultural Economics, v.67, n.1, p.32-39, 1985.

CONLEY, D.M. Hedging ratios and effectiveness for diesel fuel and gasoline in the Nothern Plains. Agribusiness, v.10, n.4, p.305-317, 1994.

DAHLGRAN, R.A. Cross-hedging the cottonseed crush: a case study. Agribusiness, v.16, n.2, p.141-158, 2000.

DE ZEN, Sérgio. Alguns aspectos do processo de formação de preços da pecuária de corte. Preços Agrícolas, v.86, p.4-9, dez.1993.

DE ZEN, Sérgio. Integração entre mercados de boi gordo e carne bovina nas regiões Centro-Oeste e Sudeste do Brasil. Piracicaba, 1997. 81p. Dissertação (Mestrado) Escola Superior de Agricultura “Luiz de Queiroz”, Universidade de São Paulo.

DICKEY,W.; FULLER,W.A. Likelihood ratio statistics for autoregressive time series with a unit root. Econometrics, v.49, n.4, p.1057-72, 1981.

EDERINGTON, L.H. The hedging performance of the new futures markets. Journal of Finance, v.34, n.1, p.157-70, 1979. 
ENDERS,W. Applied ecometric time series. New York: John Willey, 1995. 433p.

FARIA, V.P. Medidas para o aumento da eficiência de produção de carne bovina. In: PEIXOTO, A.M.; MOURA, J.C.; FARIA, V.P. Bovinocultura de corte: fundamentos da exploração racional. 3.ed. Piracicaba: FEALQ, 1999. p.347-360. (Série Atualização em Zootecnia, 8)

FILENI, D.H. O risco de base, a efetividade do hedging e um modelo para estimativa da base: uma contribuição ao agronegócio do café em Minas Gerais. Lavras, 1999. 137p. Dissertação (Mestrado) - Universidade Federal de Lavras.

FRICK, Oscar. O mercado futuro de boi gordo em nova versão. Preços Agrícolas, v.107, p.8-9, nov.1995.

FUNDAÇÃO INSTITUTO BRASILEIRO DE GEOGRAFIA E ESTATÍSTICA. Censo Agropecuário. Rio de Janeiro: IBGE, 1980, 1985, 1996.

GEPPERT, J.M. A statistical model for the relationship beetween futures contract hedging effectiveness and investiment horizon length. Journal of Futures Markets, v.15, n.5, p.507-536, 1995.

HASEGAWA, M.M. O mercado de reposição da pecuária bovina de corte no Estado de São Paulo. Piracicaba, 1995. 142p. Dissertação (Mestrado) - Escola Superior de Agricultura 'Luiz de Queiroz’, Universidade de São Paulo.

HAYENGA, M.L.; DIPIETRE, D.D. Cross hedging wholesale pork products using live hog futures. American Journal of Agricultural Economics, v.64, n.4, p.747-751, 1982. 
HAYENGA, M.L.; JIANG, B.; LENCE, S.H. Improving wholesale beef and pork product cross hedging. Agribusiness, v.12, n.6, p.541-560, 1996.

HULL, J. Introdução aos mercados futuros e de opções. 2.ed. São Paulo: BM\&F; Cultura Editores Associados, 1996. 448p.

IGREJA, A.C.M. Evolução da pecuária bovina de corte no estado de São Paulo no período 1969-84. Piracicaba, 1987. 197p. Dissertação (Mestrado) - Escola Superior de Agricultura “Luiz de Queiroz”, Universidade de São Paulo.

KASSOUF, A.L. Previsão de preços na pecuária de corte do Estado de São Paulo. Piracicaba, 1988. 102p. Dissertação (Mestrado) - Escola Superior de Agricultura “Luiz de Queiroz", Universidade de São Paulo.

LAZZARINI, S.G.; SAES, M.S.M., NAKAZONE, D. Competição entre bolsas de futuros: o caso da BM\&F e da CSCE no mercado de café. Economia Aplicada, v.4, n.2, p.283-314, 2000.

LEUTHOLD, R.M.; JUNKUS, J.C.; CORDIER, J.E. The theory and practice of futures markets. Massachusetts: Lexington Books, 1989. 410p.

MARQUES, P. V.; MELLO, P. C. Mercados futuros de commodities agropecuárias: exemplos e aplicações para os mercados brasileiros. São Paulo: BM\&F, 1999. 208p.

MARSHALL, J.F. Futures and options contracting: theory and practice. Cincinnti: South-Western Publishing, 1989. 636p. 
MARTITS, L.A. Avaliação do uso de derivativos agrícolas no Brasil: os fatores que determinam o sucesso ou fracasso dos contratos negociados na BM\&F. São Paulo, 1998. 178 p. Dissertação (Mestrado) - Escola de Administração de Empresas de São Paulo, Fundação Getúlio Vargas.

MYERS, R.J.; THOMPSON, S.R. Generalized optimal hedge ratio estimation. American Journal of Agricultural Economics, v.71, n.4, p.858-867, nov.1989.

NETZ, J.S. An empirical test of the effect of basis risk on cash market positions. Journal of Futures Markets, v.16, n.3, p.289-311, 1996.

NEVES, M.E.; COUTO, M.T. Confinamento de bovinos de corte: condicionantes econômicos e instrumentos de apoio à tomada de decisão. In: PEIXOTO, A.M.; MOURA, J.C.; FARIA, V.P. Bovinocultura de corte: fundamentos da exploração racional. 3.ed. Piracicaba: FEALQ, 1999. p.1-18. (Série Atualização em Zootecnia, 8)

OLIVEIRA, J.A.F.G. Condicionantes do crescimento da pecuária bovina de corte nos anos 80. Rio de Janeiro: IPEA, 1991. 15p. (Texto para Discussão, 221)

PACHECO, F.B.P. Análise das operações de hedging em mercados futuros: o caso do café arábica no Brasil. Piracicaba, 2000. 79p. Dissertação (Mestrado) - Escola Superior de Agricultura “Luiz de Queiroz”, Universidade de São Paulo.

PEROBELLI, F.S. As commodities no ano de 2001. Resenha BM\&F, n.147, p.49-55, 2001.

PAROUSH, J. ; WOLF, A. Production and hedging decisions in the presence of basis risk. Journal of Futures Markets, v.9, n.6, p.547-563, 1989. 
PEIXOTO, A.M. Fatores que interferem no crescimento do gado de corte até a desmama. In: PEIXOTO, A.M.; MOURA, J.C.; FARIA, V.P. Bovinocultura de corte: fundamentos da exploração racional. 3.ed. Piracicaba: FEALQ, 1999. p.12958. (Série Atualização em Zootecnia, 8)

PENNINGS, J.M.E.; MEULENBERG, M.T.G. The hedging performance in new agricultural futures markets: a note. Agribusiness, v.13, n.3, p.295-300, 1997.

PURCELL, W.D. Agricultural futures and options: principles and strategies. New York : Macmillan, 1991. 363p.

RESENHA BM\&F. São Paulo: BM\&F, 1996-2002.

RICH, D.R. Feeder cattle cash settlement: impacts on basis variability and behavior in select U.S. markets. Urbana, 1990. 118p. Thesis (M.S.) - University of Illinois.

ROCHELLE, T.C.P. O contrato futuro de boi gordo: uma análise do impacto da introdução financeira sobre o risco de base. Piracicaba, 1997. 140p. Dissertação (Mestrado) - Escola Superior de Agricultura "Luiz de Queiroz", Universidade de São Paulo.

ROCHELLE, T.C.P. Relações de preço no mercado de algodão em pluma e desenvolvimento do mercado futuro de algodão no Brasil. Piracicaba, 2000. 163p. Dissertação (Doutorado) - Escola Superior de Agricultura "Luiz de Queiroz", Universidade de São Paulo.

SABOYA, L.V.; BACCHI, M.R.P. Uma proposta metodológica para análise da eficiência na formação de preços de contratos futuros (compacto disc). In: CONGRESSO BRASILEIRO DE ECONOMIA E SOCIOLOGIA RURAL, Foz do Iguaçú, 1999. Anais. Foz do Iguaçú: SOBER, 1999. 
SANTOS, J.B.U. Bovinocultura de corte na região Centro-Oeste. In: SIMPÓSIO GOIANO SOBRE PRODUÇÃO DE BOVINOS DE CORTE, Goiânia, 1999. Anais. Goiânia: CBNA, 1999. p.1-8.

SCHOUCHANA, F. Mercados futuros e de opções agropecuários: teoria e prática. São Paulo: BM\&F, 1995.

SCHOUCHANA, F.; CAFFAGNI, L.C. Fatores que determinam o preço do bezerro. Resenha BM\&F, n.143, p.67-75, 2001.

SCHOUCHANA, F.; PEROBELLI, F.S. O financiamento da agricultura e o mercado futuro. Resenha BM\&F, n.142, p.78-81, 2000.

SHARPE, W.F.; GORDON, J.A.; BAILEY, J.V. Investments. 5.ed. Princenton: Prentice Hall, 1995. 1058p.

SILVA NETO, L.A. Derivativos: definições, emprego e risco. 3.ed. São Paulo: Atlas, 1999. 298p.

SOUZA, A.C. As perspectivas da pecuária brasileira num contexto de integração: o papel da indústria de defensivos animais. Rio de Janeiro, 1996. 292p. Dissertação (Mestrado) - Universidade Federal Rural do Rio de Janeiro.

SOUZA, W.A. Determinantes da viabilidade de mercados futuros agropecuários no âmbito do Mercosul. Piracicaba, 1998. 136p. Dissertação (Mestrado) - Escola Superior de Agricultura “Luiz de Queiroz”, Universidade de São Paulo.

VISWANATH, P.V. Efficient use of information, convergenceadjustment, and regression estimates of hedges ratios. Journal of Futures Markets, v.13, p.43, 1993. 
WORKING, H. New concepts concerning futures markets and price. The American Economic Review, v.52, n.3, p.431-459, June 1962.

ZIMMER, A.H. Pastagens para bovinos de corte. In: PEIXOTO, A.M.; MOURA, J.C.; FARIA, V.P. Bovinocultura de corte: fundamentos da exploração racional. 3.ed. Piracicaba: FEALQ, 1999. p.231-67. (Série Atualização em Zootecnia, 8) 